\title{
Estudos Teóricos de Propriedades Estruturais e Eletrônicas da Molécula Emodina em Solução.
}

\author{
Antonio Rodrigues da Cunha
}

Orientadora: Prof. ${ }^{a}$ Kaline Rabelo Coutinho

\section{Banca Examinadora:}

Prof. Dr. Dr. Kaline Rabelo Coutinho (IF/USP)

Prof. Dr. Munir Salomão Skaf (IQ/UNICAMP)

Prof. Dr. Luiz Carlos Gomide Freitas (IQ/UFSCar) 


\section{FICHA CATALOGRÁFICA}

Preparada pelo Serviço de Biblioteca e Informação do Instituto de Física da Universidade de São Paulo

Antonio Rodrigues da Cunha

Estudos Teóricos de Propriedades Estruturais e

Eletrônicas da Molécula Emodina em Solução.

Dissertação (Mestrado) - Universidade de São Paulo.

Instituto de Física. Depto. de Física Geral.

Grupo de Biofísica

Orientadora: Prof. ${ }^{a}$ Kaline Rabelo Coutinho

Área de Concentração: Física

Unitermos: 1. Física Computacional;

2. Mecânica estatística;

3. Mecânica Quântica;

4. Propriedades da Solução. 
"Precisamos renunciar a todas as esperanças de encontrar qualquer coisa como a teoria correta simplesmente porque nunca teremos acesso à totalidade da experiência" H. Everett

"Sempre existirá oportunidades de abrirmos mão de nossas esperanças e com elas nossos preconceitos" C. Contrário 



\section{Agradecimentos}

Antes de mais nada, agradeço a minha orientadora, a Prof. ${ }^{a}$ Kaline Coutinho, por sua enorme dedicação no desenvolvimento deste trabalho, e por estar sempre presente com sua amizade, apoio e orientação, pelas oportunidades oferecidas, meu sincero agradecimento. Ao Prof. Sylvio Canuto e a Prof. ${ }^{a}$ Teresa Lamy pela colaboração a este trabalho.

Não tenho como expressar minha gratidão a Equipe do Laboratório de Biofísica, coordenada pela Prof. ${ }^{\text {a }}$ Teresa Lamy, pelo apoio, discussões e ajuda, em especial, T. Oliveira, C. Vequi-Suplicy e E. L. Duarte, pelo acompanhamento nas medidas espectrocópicas. Meus agradecimentos também ao Grupo de Física Molecular e Modelagem coordenado pelo Prof. Sylvio Canuto e Prof. ${ }^{a}$ Kaline Coutinho, pelo apoio, discussões e oportunidades de apresentação deste trabalho nos seus seminários. Quero agradeçer também ao Rafael Barreto pela sua contribuição com o programa Tinker.

Sem as horas de descontracão com meus amigos e colegas que juntos convivemos no DFGE do IFUSP, em especial aos amigos: M. Damasceno, T. Oliveira, C. VequiSuplicy, E. Duarte, R. Barroso, P. Jaramillo, H. Georg, T. Enoki, A. Barros, R. Gester, M. Hidalgo, L. Modesto, Y. Orozco, R. Barreto, C. Bistafa, F. da Silva e Evanildo, realizar este trabalho e cursar o mestrado em Física, no mínimo não teria sido tão divertido.

Minha eterna gratidão a minha família em especial, minha mãe, Irene Cunha e meu pai, Francisco Borges e aos meus irmãos que sempre estiveram ao meu lado. Ao casal Prof. Paulo Ramos e Prof ${ }^{\mathrm{a}}$. Sofia Almeida, por me incentivar nos primeiros passos em direcão ao conhecimento.

Ao $\mathrm{CNPq}$, pelo apoio financeiro concedido para realização deste trabalho. 



\section{Resumo}

Estudamos as propriedades estruturais e eletrônicas da molécula emodina (EM), em diferentes condições, do ponto de vista experimental e teórico. Numa primeira parte, realizamos medidas do espectro eletrônico de absorção da EM, em meio solvente (água, clorofórmio e metanol). Nessa parte, obtivemos que o solvente provoca pouco efeito nos deslocamentos das bandas. Numa segunda parte, estudamos a EM, isoladamente e nos três solventes, através de cálculos quânticos com funcional de densidade (B3LYP), conjunto de função base de Pople (6-31G*) e modelo contínuo polarizável (PCM). Como principais resultados obtivemos que a EM é rígida a menos da orientação relativa das 3 hidroxilas. A mudança orientacional nessas hidroxilas pode provocar formação de até 2 ligações de hidrogênio intramolecular (o que estabiliza sua geometria) e conseqüente uma diminuição no momento dipolo de 5.5 a 1.7D (o que desestabiliza sua interação com a água). Numa terceira parte, realizamos simulações com método Monte Carlo e Dinâmica Molecular em solução. Nessa parte, obtivemos que as ligações de hidrogênio intramoleculares são raramente quebradas devido as interações com o solvente e isso atribui a EM um caráter hidrofóbico. Adicionalmente, utilizando Teoria de Perturbação Termodinâmica nas simulações, calculamos a variação de energia livre de solvatação da EM em partição água/clorofórmio e água/metanol e obtivemos -2.6 e $-4.9 \mathrm{kcal} / \mathrm{mol}$, respectivamente. Esse resultado está em boa concordância com o resultado experimental de $-5.6 \mathrm{kcal} / \mathrm{mol}$ para partição de água/octanol. Por último, realizamos cálculos do espectro eletrônico de absorção da EM, isoladamente e nos três solventes, considerando as moléculas através do modelo, contínuo de solvente (SCRF) e explícito de solvente, com o método INDO/CIS. Nessa parte, obtivemos que o efeito do solvente é bem descrito teoricamente. 



\section{Abstract}

We study the structural and electronic properties of the emodin (EM) in different solvents of experimental and theoretical the point of view. We started performing measurements of the UV-Vis absorption spectrum of the EM in solution (water, chloroform and methanol). Our main result is that the solvent causes little effect on shifts the bands. In the second part of this work, we performing quantum calculations of isolated EM and in the three solutions using density functional (B3LYP), a set of Pople basis function (6-31G*) and the polarizable continuum model (PCM). In this part, our result is that EM presents a rigid conformation unless the orientation of its 3 hydroxyls. The change in these hydroxyls orientation can form up to 2 intramolecular H-bonds (which stabilizes its geometry) and causes a decrease in the dipole moment from 5.5 to $1.7 \mathrm{D}$ (which destabilizes its interaction with water). In the third part of this work, we performing Monte Carlo and Molecular Dynamics simulations in solution. Our main result is that the intramolecular H-bonds are rarely broken, even in aqueous solution, and these give to EM a hydrophobic character. Additionally, using Thermodynamics Perturbation Theory in the simulations, we calculate variations of free energy of solvation of EM in partition of water/chloroform and water/methanol and obtained -2.6 and $-4.9 \mathrm{kcal} / \mathrm{mol}$, respectively. This last result is in good agreement with the experimental result [3] of $-5.6 \mathrm{kcal} / \mathrm{mol}$ for partition of water/octanol. Finally, we performing calculations of UV-Vis absorption spectrum of isolated EM and in the three solutions. In this calculations, we considering the molecules through the continuum solvent (SCRF) and explicit solvent model with the method INDO/CIS. In this part, we obtaining that effect of solvent is well described theoretically. 
$\longrightarrow$ 


\section{Sumário}

Lista de Abreviaturas xii

Lista de Figuras $\quad$ xv

Lista de Tabelas $\quad$ xxi

1 Introdução 23

1.1 Levantamento bibliográfico da emodina . . . . . . . . . . . . . . . 24

1.2 Métodos de solventes . . . . . . . . . . . . . . . . 28

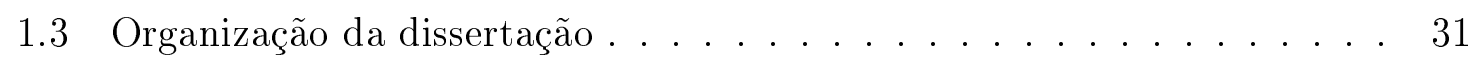

2 Métodos Teóricos 33

2.1 Introdução $\ldots \ldots \ldots \ldots . \ldots \ldots \ldots$

2.2 Química Quântica . . . . . . . . . . . . . . . . 33

2.2 .1 A aproximação de Born-Oppenheimer(BO) . . . . . . . . . . . 34

2.2 .2 Método de Hartree-Fock . . . . . . . . . . . . . . . . . 35

2.2 .3 Métodos semi-empíricos . . . . . . . . . . . . . . . 41

2.2 .4 Teoria do Funcional da Densidade (DFT) . . . . . . . . . . . . 43

2.2.4.1 Aproximação de Kohn-Sham. . . . . . . . . . . . 45

$2.2 .5 \quad$ Ajuste de cargas parciais-CHELPG . . . . . . . . . . . . 48

$2.3 \quad$ Simulação computacional . . . . . . . . . . . . . . . . . . . 49

2.3 .1 Dinâmica Molecular(MD) . . . . . . . . . . . . 51

2.3 .2 Método Monte Carlo . . . . . . . . . . . . . . . . 55

$2.3 .2 .1 \quad \mathrm{O}$ algoritmo . . . . . . . . . . . . . . 59

2.3 .3 Potencial de interação molecular . . . . . . . . . . . . 60 
2.3.3.1 Potencial intramolecular . . . . . . . . . . . . 60

2.3.3.2 Potencial intermolecular . . . . . . . . . . . 63

2.3 .4 Cálculo da energia livre . . . . . . . . . . . . . 65

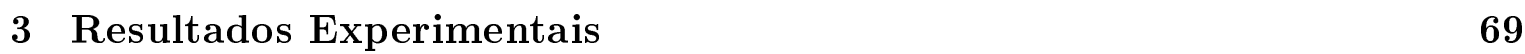

3.1 Introdução $\ldots \ldots \ldots \ldots \ldots \ldots$

3.2 Material utilizado . . . . . . . . . . . . . . . . 69

3.3 Preparação das soluções $\ldots \ldots \ldots \ldots$. . . . . . . . . . 70

3.4 Resultados e discussões $\ldots \ldots \ldots \ldots$. . . . . . . . . . . 70

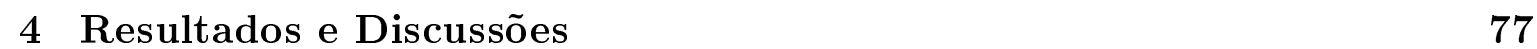

4.1 Introdução . . . . . . . . . . . . . . . . . 77

4.2 Análise conformacional _. . . . . . . . . . . . . . . 77

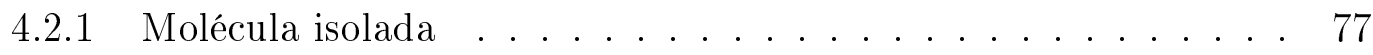

4.2 .2 Molécula com modelo contínuo de solvente . . . . . . . . . 81

4.2 .3 Molécula com modelo explícito de solvente . . . . . . . . . . . . 82

4.2.3.1 Simulação com moléculas flexíveis . . . . . . . . . . 89

4.2.3.2 Simulação com moléculas rígidas . . . . . . . . . 97

4.2.3.3 Comparação das simulações . . . . . . . . . . . . . . . 101

4.3 Solvatação diferencial $\ldots \ldots \ldots$. . . . . . . . . . . 106

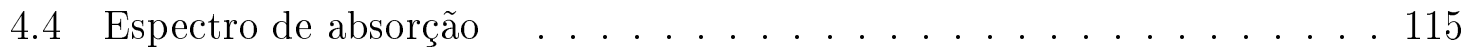

4.4 .1 Molécula isolada . . . . . . . . . . . . . . . 115

4.4 .2 Molécula em solução . . . . . . . . . . . . . . . . . . 119

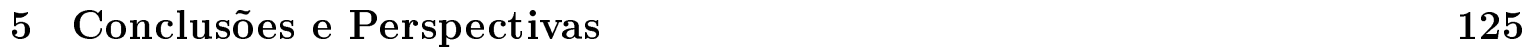

\begin{tabular}{lr}
\hline Referências Bibliográficas & 129
\end{tabular}

\begin{tabular}{|l|l|}
\hline A Aproximação de Born-Oppenheimer(BO) & 145
\end{tabular}

B Arquivos de Entrada da Dinâmica Molecular da Emodina 149 


\section{Lista de Abreviaturas}

$\begin{array}{ll}\text { SCRF } & \text { Self-consistent reaction field } \\ \text { DFT } & \text { Modelo contínuo polarizável } \\ \text { MC } & \text { Monte Carlo } \\ \text { MD } & \text { Dinâmica Molecular } \\ \text { QM } & \text { Química Quântica } \\ \text { MM } & \text { Mecânica Molecular } \\ \text { EM } & \text { Emodina } \\ \text { EMdp } & \text { Emodina na forma ionizada } \\ \text { AM1 } & \text { Austin Model 1 } \\ \text { ZINDO } & \text { Zerner's Intermediate Neglect of Differential Overlap } \\ \text { HF } & \text { Hartree-Fock } \\ \text { CIS } & \text { Configuration Interaction Singles } \\ \text { TD } & \text { Time-dependent } \\ \text { B3LYP } & \text { Funcional híbrido de exchange de (Becke, three-parameter, } \\ \text { Lee-Yang-Parr) } & \\ \text { PBE0 } & \text { Funcional de DFT de Perdew, Burke e Ernzerhof } \\ \text { DFT } & \text { Toria dosionais da Densidade } \\ & \end{array}$


BO Aproximação de Born-Oppenheimer

LCAO Linear Combination of Atomic Orbitals

CNDO Complete Neglect of Differential Overlap

NDDO Neglect of Diatomic Differential Overlap

INDO Intermediate Neglect of Differential Overlap

KS Kohn-Sham

LDA Local Density Approximation

LSDA Local Spin Density Approximation

GGA Generalized Gradient Approximation

B88 Gradiente de correção do funcional de exchange de Becke de 1988

LYP Funcional de correlação de Lee-Yang-Parr

VWN Funcional de correlação de Vosko-Wilk-Nusair

CHELPG Charges from Electrostatic Potential Grid Based

LJ Lennard-Jones

HB Hydrogen bond

TS Transition state

OPLS Optimized Potentials for Liquid Simulations

CLA Correção de Longo Alcance

PME Particle Mesh Ewald

SPC Simple Point Charge Model

RDF Função de Distribuição Radial

MDDF Função de Distribuição de Mínima Distântica

HOMO Highest Occupied Molecular Orbital

LUMO Lowest Unoccupied Molecular Orbital 


\section{Lista de Figuras}

$1.1 \quad$ Estrutura química da molécula emodina . . . . . . . . . . . . . . 24

1.2 Na figura a esquerda, está ilustrado o efeito do $p H$ no espectro de absorção da emodina $\left(2.5 \times 10^{-5} \mathrm{~mol} l^{-1}\right)$, em água-metanol(1:1). $p H: 1,2.23$; $2,5.25 ; 3,6.04 ; 4,6.80 ; 5,8.34 ; 6,9.67 ; 7,10.10 ; 8,10.80 ;$ e $9,11.36$. Na figura a direita, está ilustrado o efeito do $p H$ na absorbância da emodina para diferentes comprimentos de onda intensos, ou seja, para valores de $\lambda_{\max }$. A, 440; B, 496; e C, $526 \mathrm{~nm}$. Essas figuras foram retiradas da referência, $[22] . \ldots \ldots \ldots \ldots \ldots \ldots$

$1.3 \quad$ A direita, geometria da molécula emodina neutra (EM) e emodina desprotonada (EMdp) a esquerda o espectro eletrônico de absorção de (EM) e (EMdp). Essas figuras foram retiradas da referência [25].] . . . . . . 27

$2.1 \quad$ Ilustração do algoritmo da Dinâmica Molecular . . . . . . . . . . . . . 53

2.2 Ilustração dos termos do potencial de interação intramolecular mostrado na equaçâo 2.76 . . . . . . . . . . . . . . . . . 61

2.3 Ilustração do potencial de torção intramolecular para o ângulo diedro da molécula de n-butano. Figura retirada da referência, [109]. . . . . . . . 62 
2.4 Ilustração da interação entre duas moléculas com dois sítios cada. $\quad O$ potencial entre a e b é composto pelos quatro termos; $i_{1} j_{1}, i_{1} j_{2}, i_{2} j_{1} e$ $i_{2} j_{2}$. Figura retirada da referência, [49]] . . . . . . . . . . . . 64

3.1 Gráfico do espectro eletrônico de absorção da molécula emodina em solução metanol na forma ácida (EM), alcalina (EMdp) e neutra (EM+EMdp), na concentração de $0.1 m M$. . . . . . . . . . . . . . . 71

3.2 Gráfico do espectro eletrônico de absorção da molécula de emodina em solução aquosa na forma ácida (EM), alcalina (EMdp) e neutra (EM+EMdp),

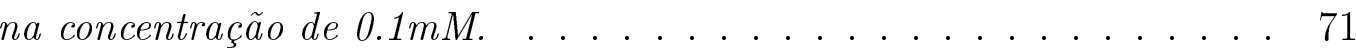

3.3 Gráfico do espectro eletrônico de absorção da $\mathbf{E M}$ em água, clorofórmio e metanol, na concentração de 0.1nM, normalizado pela intensidade da

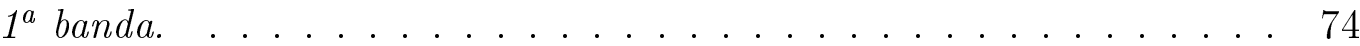

3.4 Gráfico do espectro eletrônico de absorção da EMdp em água e metanol, na concentração de $0.1 n M . . \ldots \ldots \ldots . \ldots . \ldots . \ldots 74$

$4.1 \quad$ Estrutura química da molécula emodina . . . . . . . . . . . . . 78

4.2 Os rotâmeros da $\boldsymbol{E} \boldsymbol{M}$ nas conformações estudadas. . . . . . . . . . . 80

$4.3 \quad$ Geometria da emodina, indicando os diedros Dh16, Dh19 e Dh21, que foram rotacionado para gerar as configurações dos rotâmeros. Nessa

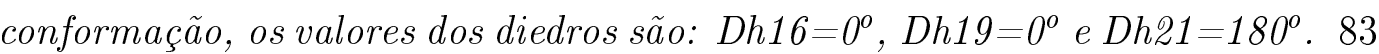

4.4 Variação das cargas nos oxigênios da emodina, referente a rotação do Dh16, mostradas nas tabelas $|4.4|$ e| 4.5 . . . . . . . . . . . . 86

4.5 Gráfico dos momentos os dipolo versus diedro para cada rotâmero estudado para os valores mostrados na tabela $\mid 4.6$. . . . . . . . . . . . . 88 
4.6 Gráfico da energia potencial versus diedro para cada rotâmero estudado, para oconjunto de carga OPLS. Para os demais conjuntos de cargas, os resultados são semelhantes. . . . . . . . . . . . . . . . . . . 89

4.7 Gráfico da energia cinética da Dinâmica Molecular da emodina no equilibrio para o caso com cargas OPLS. Para os demais conjuntos de cargas, os resultados são semelhantes. . . . . . . . . . . . . . . . . . . 92

4.8 Gráfico da energia potencial da MD da emodina no equilíbrio para o caso com cargas OPLS. Para os demais conjuntos de cargas, os resultados são semelhantes . . . . . . . . . . . . . . . . . 93

4.9 Gráfico da densidade da MD da emodina para o caso com cargas OPLS. Para os demais conjuntos de cargas, os resultados são semelhantes. . . 93

4.10 Gráfico do ângulo diedro Dh16 versus número de configurações para CONF esquerda e OPLS direita. Para os demais conjuntos de cargas, os resultados são semelhantes. . . . . . . . . . . . . . . . . . . . 94

4.11 Histograma referente ao diedro Dh16 para o conjunto cargas CONF e OPLS. Para os demais conjuntos de cargas, os resultados são semelhantes. 95

4.12 Gráfico do ângulo diedro Dh21 versus número de configurações para CONF esquerda e OPLS direita. Para os demais conjuntos de cargas, os resultados são semelhantes. . . . . . . . . . . . . . . . . . . 95

4.13 Histograma referente ao diedro Dh21 para o conjunto cargas CONF e OPLS. Para os demais conjuntos de cargas, os resultados são semelhantes. 96

4.14 Gráfico do ângulo diedro Dh26 versus número de configurações a esquerda e histograma referente a esse diedro a direita. Ambos os gráficos para o conjunto de cargas OPLS. Para os demais conjuntos de cargas, os resultados são semelhantes. . . . . . . . . . . . . . . . . . . . . . 96 
4.15 Geometria da molécula emodina na conformação com os três diedros, Dh16, Dh19 e Dh21 em $180^{\circ}$. . . . . . . . . . . . . . . . . . 97

4.16 Gráfico energia por molécula versus número de ciclos para simulação MC da $\boldsymbol{E M}$ no ensemble NPT no processo de termalização para o caso OPLS. Para os demais conjuntos de cargas, os resultados são semelhantes. 99

4.17 Gráfico energia por molécula versus número de ciclos para simulação MC da EM no ensemble NPT no equilibrio térmico para o caso OPLS. Para os demais conjuntos de cargas, os resultados são semelhantes. . . 100

4.18 Gráfico da densidade da simulação $M C$ da emodina para o caso com cargas OPLS. Para os demais conjuntos de cargas, os resultados são semelhantes. . . . . . . . . . . . . . . . 100

4.19 Gráfico da função de distribuição radial (RDF) de pares entre o oxigênio O20 da emdina e o oxigênio da água para os métodos $M D$ e $M C$, com o conjunto de cargas OPLS. Para os demais conjuntos de cargas, os resultados são semelhantes. . . . . . . . . . . . . . . . . . 105

4.20 : Gráfico da distribuição de mínima distância (MDDF), entre a emodina e a água para o modelo de distribuição de cargas atômicas OPLS, obtido da simulação com os métodos MD e MC. Para os demais conjuntos de cargas, os resultados são semelhantes. . . . . . . . . . . . . . . . . . 106

4.21 Ciclo Termodinâmico descrevendo o cálculo da diferença de energia livre em água e outro solvente para a molécula de emodina. . . . . . . . . . . 108

4.22 Representação do potencial dispersivo de Lennard-Jones, para o conjunto de parâmetros $\{\epsilon=100 \%, \sigma=100 \%\}$ e $\{\epsilon=0.1 \%, \sigma=100 \%\}$, para o par de átomos $C$-O. . . . . . . . . . . . . . . . . . . . 109

4.23 Geometria da molécula emodina otimizada com B3LYP/6-31G*. . . 115 4.24 Orbitais moleculares envolvidos na transição $n-\pi^{*}$ da emodina. . . . . 117 
4.25 Orbitais moleculares envolvidos nas transições $\pi-\pi^{*}$ intensas da emodina.117

4.26 Gráfico do espectro eletrônico de absorção da molécula emodina em clorofórmio na concentração de $0.1 \mathrm{mM}$ (linha sólida), com os valores dos máximos das bandas calculados com método INDO/CIS para essa molécula isolada (linha verticais tracejadas). As alturas das linhas verticais não representam a intensidade da transição calculada. . 


\section{Lista de Tabelas}

1.1 Sumário dos valores para os máximos da $1^{\mathrm{a}}$ banda do espectro eletrônico de absorção, encontrado na literatura para diferentes métodos, em $10^{3} \mathrm{~cm}^{-1}$. Em parênteses estão mostrados os valores em $\mathrm{nm}$. . . . . 27

3.1 Valores medidos para os máximos das bandas do espectro eletrônico de absorção da emodina em solução na forma ácida, alcalina (água e \begin{tabular}{|l|l|l|}
\hline metanol) e neutra (água, metanol e clorofórmio), em $10^{3} \mathrm{~cm}^{-1}$. Em \\
\hline
\end{tabular} parênteses os valores são apresentados em $n m$. . . . . . . . . . 72

4.1 Comparação das distâncias atômicas obtidas para a geometria otimizada da emodina, neste trabalho, com nível B3LYP/6-31G* com o tra-

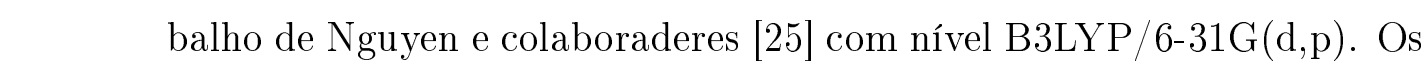
valores estão em $\AA$ e a numeração dos átomos está mostrada na figura

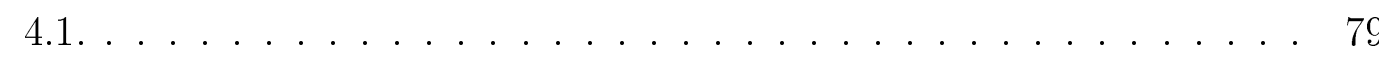

4.2 Energias relativas dos rotâmeros e seus respectivos momentos de dipolo, obtidos com a otimização de geometria com método B3LYP/6-31G*. Ver os rotâmeros estudados da figura 4.2 . . . . . . . . . . . . . . . 81

4.3 Energias relativas dos rotâmeros e seus respectivos momentos de dipolo, obtidos com método B3LYP/6-31G* e o solvente descrito com o modelo contínuo polarizável, PCM. Ver os rotâmeros estudados da figura 4.2 . 82 
4.4 As cargas nos oxigênios pertencentes às hidroxilas para cada cálculo QM com método B3LYP/6-31G*/CHELPG. Ver definição dos diedros na figura $4.3 \mid \ldots \ldots \ldots \ldots \ldots . \ldots \ldots$

4.5 As cargas nos oxigênios pertencentes aos carbonilas para cada cálculo QM com método B3LYP/6-31G*/CHELPG. Ver definição dos diedros na figura $4.3 . \ldots \ldots \ldots \ldots \ldots \ldots \ldots$

4.6 Momento de dipolo $(D)$ para cada rotâmero obtido da rotação dos diedros. Ver definição dos diedros na figura 4.3 . . . . . . . . . . . . . 85

4.7 Cargas atômicas obtidas do campo de força (OPLS), do ajuste do potencial eletrostático da geometria de mínima energia (CONF) e da média sobre os 21 rotâmeros(MÉDIA). . . . . . . . . . . . . . . . 87

4.8 Energia total $(\mathcal{E} / N)$, potencial $(\mathcal{U} / N)$ e cinética $(\mathcal{K} / N)$ por molécula em $k c a l / m o l$, das simulações para os conjuntos de cargas CONF, MÉDIA e OPLS. . . . . . . . . . . . . . . . . . . . 91

4.9 Temperatura $(K)$ e densidade $\left(\mathrm{g} / \mathrm{cm}^{3}\right)$, obtidas das simulações para os diferentes conjuntos de cargas: CONF, MÉDIA e OPLS. . . . . . . . . 91

4.10 Tempo total e percentual em que os ângulos diedros Dh16, Dh19 e Dh21 ficaram na orientação dentro do intervalo de $180^{\circ}$ a $150^{\circ}$, ou seja, H16 e H19 formam ligação de hidrogênio intramolecular com O17 e para a hidroxila O20H21 aponta no sentido do O22. . . . . . . . . . . . . . . 94

4.11 Parâmetros Lennard-Jones da molécula emodina do campo de força OPLS [110]. . . . . . . . . . . . . . . . . . . . . 98

4.12 Dipolo da emodina e suas energias de interação com a água obtidas das simulações MD e MC. . . . . . . . . . . . . . . . . . . . . . 101

4.13 Número médio e energia média por ligação de hidrogênio formadas pelas águas com as hidroxilas da emodina obtidas das simulações MC e MD. 103 
4.14 Estudo da camada de solvatação da emodina em água para os métodos de simulação MC e MD, onde LH refere a camada de água que forma ligações de hidrogênio. . . . . . . . . . . . . . . . . 105

4.15 Energia livre de aniquilação em $(\mathrm{kcal} / \mathrm{mol})$ para o conjunto de cargas $\left\{q_{i}\right\}$, e o conjunto de parâmetros do potencial atrativo de LennardJones, $\left\{\epsilon_{i}\right\}$, para a molécula de emodina em água, clorofórmio e metanol.110

4.16 Energia livre de aniquilação em (kcal/mol) para o conjunto de parâme\begin{tabular}{|c|}
\hline $\operatorname{tros}\left\{\sigma_{i}\right\}$ do potencial de Lennard-Jones, para a molécula de emodina \\
\hline
\end{tabular} em água, clorofórmio e metanol. . . . . . . . . . . . . . . . . . . 111

4.17 Sumário da energia livre de solvatação de uma molécula de emodina em água, metanol e clorofórmio nas condições normais de pressão e temperatura . . . . . . . . . . . . . . . . . . . 112

4.18 Valores da energia livre de solvatação de uma molécula de emodina em água, metanol e clorofórmio, com o solvente descrito com o modelo contínuo polarizável $(\mathrm{PCM})$.

4.19 Parâmetros dos solventes metanol, octanol, clorofórmio e água. Onde $E_{T}(30)$, corresponde um parâmetro de polaridade do solvente, segundo a molécula, 2,6-diphenyl-4-(2,4,6-triphenylpyridium-1-yl), $\epsilon$, corresponde a constante dielétrica, $n$, o índice de refração e $\rho$ a densidade em ${\mathrm{g} . \mathrm{cm}^{-3}}^{-1}$.114

4.20 Valores calculados para os máximos das bandas no espectro eletrônico de absorção da emodina isolada, em $10^{3} \mathrm{~cm}^{-1}$, calculado com INDO/CIS. Os orbitais podem ser visualizados nas figuras $|4.24| \mathrm{e}|4.25|$ Em parêntese estão mostrados os valores em $n m$. E a abreviação "f. osc" representa a força do oscilador. Na referência [25], o cálculo do espectro foi calculado com o método B3LYP/6-31g(d,p)//PCM-TD-B3LYP/6-31+G(d,p). . 116 
4.21 Valores calculados para os máximos das bandas no espectro eletrônico de absorção da emodina em água em $\left(10^{3} \mathrm{~cm}^{-1}\right)$, calculado com INDO/CIS(SCRF). Em parêntese estão mostrados os valores em $n m$. . . . . . 120

4.22 Valores calculados para os máximos das bandas no espectro eletrônico de absorção da emodina em clorofórmio em $\left(10^{3} \mathrm{~cm}^{-1}\right)$, calculado com

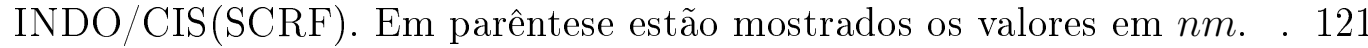

4.23 Valores calculados para os máximos das bandas no espectro eletrônico de absorção da emodina em metanol em $\left(10^{3} \mathrm{~cm}^{-1}\right)$, calculado com INDO/CIS(SCRF). Em parêntese estão mostrados os valores em $\mathrm{nm}$. . . . 121 


\section{Capítulo 1}

\section{Introdução}

Os fármacos derivados de antraquinonas ${ }^{1}$ vêm ganhando um espaço valoroso de estudo na ciência, devidos suas atividades biológicas e farmacológicas, como digestivo [1,2], estimulante do fígado, laxante [3], antibacterial [4-6], antifungal [7], antiparasita [8], antiviral [9,10], anti-inflamatório [11,12], antitumoral [13-15], estimulante cardíaco [16], antiúlcera [17], diurética [18], e etc. Devido essa ampla atividade biológica e farmacológica, diversos estudos científicos vêm buscando entender como esses compostos interagem com o meio biológico. Em particular, recentemente foram analisadas as interações dessas moléculas com membranas modelos [19,20], mostrando que essas moléculas apresentam um comportamento peculiar, aparentando estar dentro da membrana em alguns experimentos e na superfície em outros.

Neste trabalho, estudamos o fármaco emodina(1,3, 8-trihidroxi-6-metil-9, 10antraquinona), (ver figura 1.1), do ponto vista experimental, através do espectro eletrônico de absorção, e teórico, através de técnicas de cálculos quânticos e simulações computacionais para estudar as propriedades estruturais e eletrônica e suas interações com o meio solvente. A emodina(EM) é um produto natural e principal antraquinona do Aloe vera,conhecida popularmente no Brasil como babosa, que é amplamente uti-

\footnotetext{
${ }^{1}$ antraquinona é um composto orgânico aromático de fórmula (C14H8O2). Esse composto foi obtido pela primeira vez em 1827 pela hidrólise do antraceno.
} 
lizado na indústria de produtos alimentícios, de cosmético e farmacêutica [21]. Essa molécula é formada por grupos hidrofóbicos(1 antraceno) e hidrofílicos(3 hidroxilas e 2 carbonilas), o que em princípio podem lhe atribuir um carácter hidrofílico ou lipofílico. Experimentalmente é observado que essa molécula não é solúvel em água, mas

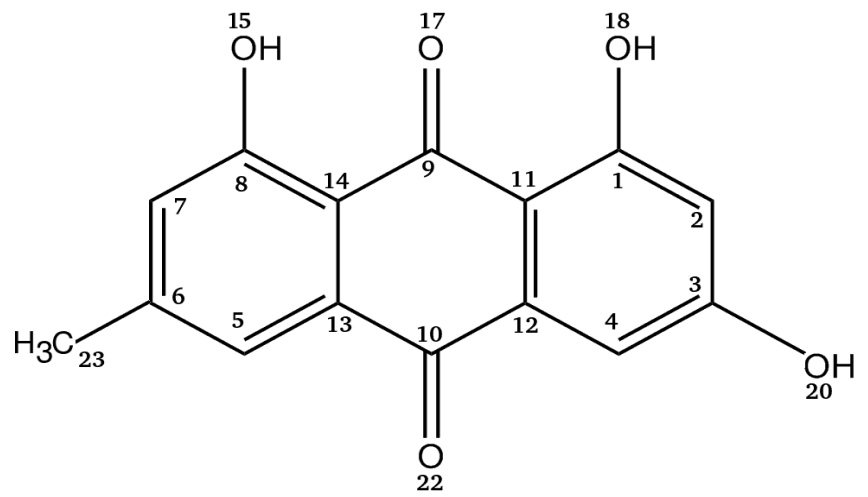

Figura 1.1: Estrutura química da molécula emodina

sim em solventes orgânicos, como acetonitrila, metanol e benzeno [22]. Adicionalmente a essa discussão interessante do carácter hidro/lipofílico dessa molécula, na literatura ainda existem discussões sobre processos de desprotonação e de transferência de próton (tautomerismo).

Sendo assim, o estudo teórico da emodina e suas interações com o meio passa a ser um tema de interesse. Portanto, neste trabalho realizamos um estudo teórico das propriedades estruturais e eletrônicas dessa molécula, no meio solvente (água, clorofórmio e metanol), para auxiliar a compreensão de suas interações em diferentes meios biológicos. Adicionalmente a esses estudos, realizamos também medidas do espectro eletrônico de absorção da EM em água, clorofórmio e metanol.

\subsection{Levantamento bibliográfico da emodina}

A emodina é um composto de cor amarela, com baixa solubilidade em água, $<1 \mathrm{mg} / \mathrm{mL}$ a $19^{\circ} \mathrm{C}$ [23], mas solúvel em vários solventes orgânicos, como metanol, 
etanol, benzeno, tolueno, clorofórmio e tetracloreto de carbono [22]. No entanto no trabalho de Pal et al [22], menciona-se que, em $p H$ alcalino essa molécula é solúvel em água, apresentando uma mudança de cor de amarelo para vermelho. Em 2004, Alves et al [20], mediram o coeficiente de partiçãd ${ }^{2}\left(K_{p}\right)$ da emodina em água/octanol no valor de $(13.93 \pm 2.24) \times 10^{3}$, indicando que essa molécula apresenta uma alta afinidade por ambientes lipídicos. Numa mesma concentração molar em ambos os meios, a cada molécula encontrada na água, cerca de 13900 moléculas serão encontradas em octanol.

Adicionalmente a esses estudos, alguns trabalhos têm sido publicados na literatura, enfatizando que essa molécula pode sofrer alguns processos químicos, como desprotonação e tautomerização, provocando uma descaracterização de suas propriedades intrínsecas, como, estrutural e eletrônica. No trabalho de Wang et al [24], foram determinadas as constantes de dissociação $p K_{a_{1}}=5.7$ e $p K_{a_{2}}=7.9$, para desprotonação nas posições 3 e 8 respectivamente da molécula de emodina em acetonitrila. No trabalho de Pal et al [22], foi determinado o valor de $p K_{a_{1}}$, em solução água-metanol no valor de 7.2. Já no trabalho de Nguyen et al. [25], foi estimado o valor de $p K_{a_{1}}$, através de medidas do espectro de eletrônico de absorção da emodina em solução água-etanol, no valor de 6.24 .

O trabalho de Pal et al [22], corrobora a hipótese de desprotonação da emodina em solução, pois foi realizado um estudo da dependência do espectro eletrônico de absorção dessa molécula com o $p H$ da solução água-metanol, onde a emodina em $p H<6.0$, é caracterizada por uma banda intensa na região $22.7 \times 10^{3} \mathrm{~cm}^{-1}(440 \mathrm{~nm})$. Já em solução com o pH entre 6.0 a 7.5, essa banda sofre um deslocamento para $20.2 \times 10^{3} \mathrm{~cm}^{-1}(496 \mathrm{~nm})$, não mudando mais a posição para mudanças no $p H$ da solução de 7.5 a 10.0. Quando aumenta o $p H$ da solução para 12, essa banda volta a sofrer lentamente um deslocamento para $19.0 \times 10^{3} \mathrm{~cm}^{-1}(526 \mathrm{~nm})$. Esse comportamento está ilustrado na figura 1.2. Nessa figura a direita, está mostrado o efeito do $p H$ na

\footnotetext{
${ }^{2} \mathrm{O}$ valor $\left(K_{p}\right)$, determina o grau de solubilidade diferencial de compostos químicos em dois solventes.
} 
absorbância da emodina, onde os cruzamentos das intensidades das bandas A, B, e C está associados a primeira desprotonação da emodina na posição 3, e a segunda desprotonação na posição 8 .
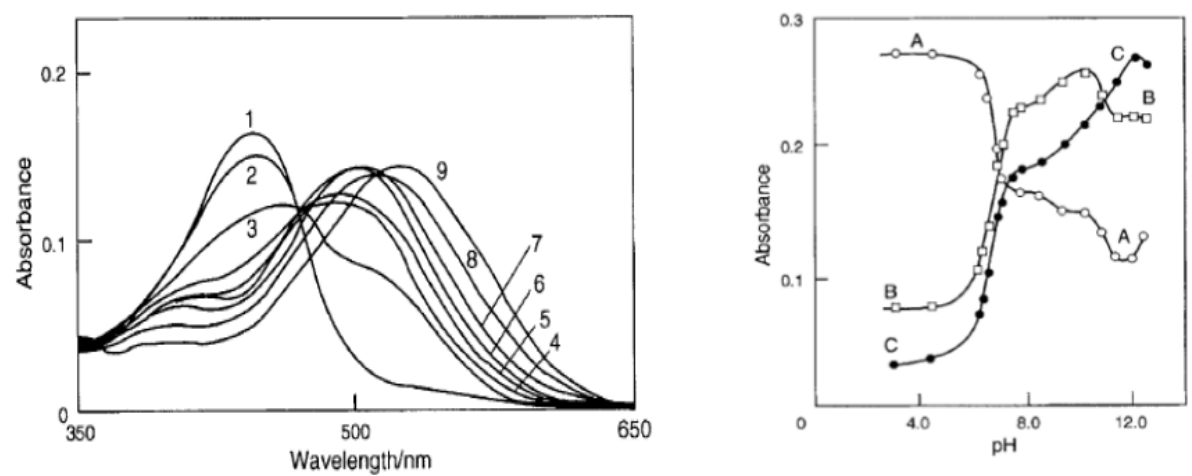

Figura 1.2: Na figura a esquerda, está ilustrado o efeito do $p H$ no espectro de absorção da emodina $\left(2.5 \times 10^{-5} \mathrm{~mol} \mathrm{l}^{-1}\right)$, em água-metanol(1:1). pH: $1,2.23 ; 2,5.25 ; 3,6.04 ; 4,6.80 ; 5$, $8.34 ; 6,9.67 ; 7,10.10 ; 8,10.80 ;$ e $9,11.36$. Na figura a direita, está ilustrado o efeito do $p H$ na absorbância da emodina para diferentes comprimentos de onda intensos, ou seja, para valores de $\lambda_{\max }$. A, 440; B, 496; e C, $526 \mathrm{~nm}$. Essas figuras foram retiradas da referência, [22].

No trabalho de Fain et al [26], é levantada a hipótese de que existem erros na literatura na determinação do grau de desprotonação desses compostos, devido a não consideração de forma tautoméricas. Um exemplo é o caso da emodina, onde a banda de $19.0 \times 10^{3} \mathrm{~cm}^{-1}(526 \mathrm{~nm})$ deveria ser apontada para o composto tautomérico 1,10 mono-desprotonado e não a forma duplamente desprotonada.

O trabalho de Nguyen et al. [25], desperta a atenção ao medir o espectro eletrônico de absorção da emodina na região UV-Vis. Esse trabalho corrobora com a hipótese de desprotonação da emodina, onde indica que a emodina em solução polar, água-etanol, à temperatura ambiente, sofre processos de desprotonação, sendo que em solução ácida encontra-se a emodina neutra, EM, em solução alcalina encontra-se a emodina na sua forma desprotonada EMdp, ou seja, na forma ionizada, e em solução neutra encontra-se uma mistura de ambas as formas da emodina, EM $+\mathbf{E M d p}$, ver figura 1.3. Esse trabalho está em boa concordância com o trabalho de Pal et al [22], 
mencionado anteriormente, onde esse indica que a emodina $p H<6.0$, apresenta a forma neutra.
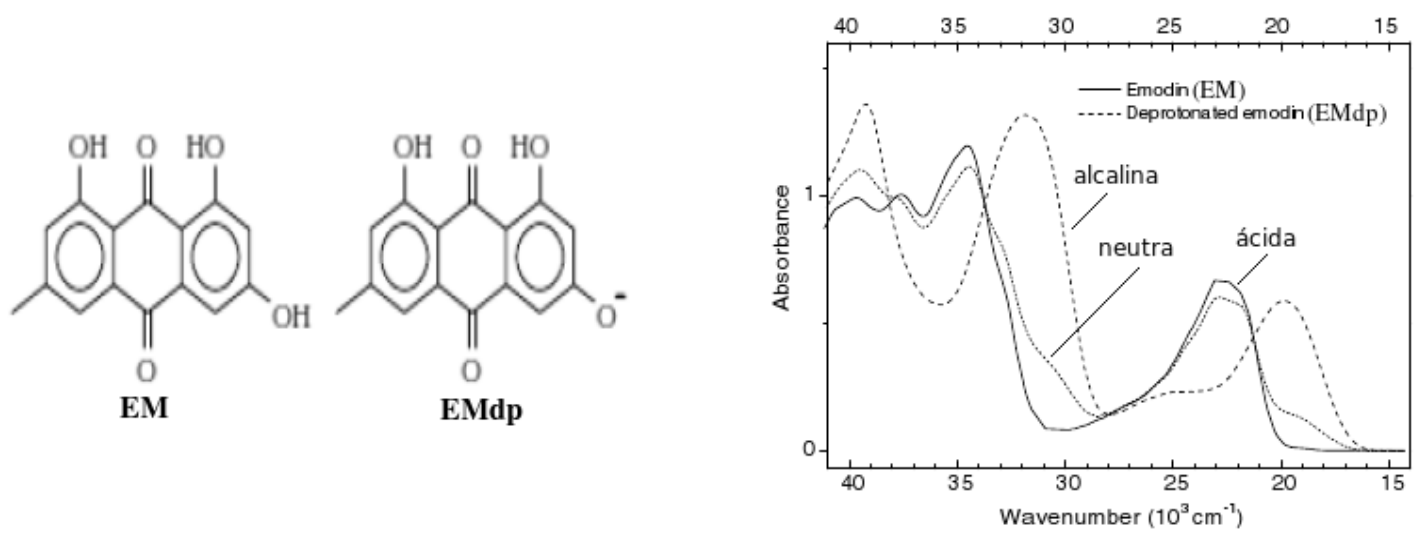

Figura 1.3: A direita, geometria da molécula emodina neutra (EM) e emodina desprotonada (EMdp) a esquerda o espectro eletrônico de absorção de (EM) e (EMdp). Essas figuras foram retiradas da referência [25].

Tabela 1.1: Sumário dos valores para os máximos da $1^{\mathrm{a}}$ banda do espectro eletrônico de absorção, encontrado na literatura para diferentes métodos, em $10^{3} \mathrm{~cm}^{-1}$. Em parênteses estão mostrados os valores em $n m$.

\begin{tabular}{cc}
\hline \hline método & $\lambda_{\max }$ \\
\hline AM1//ZINDO [28] & $27.4(364)$ \\
B3LYP /6-31G(d,p)//PCM-TD-B3LYP/6-31G(d,p) [28] & $22.5(445)$ \\
PCM-PBE0/6-311G(d,p)//PCM-TD-PBE0/6-311G(d,p) [28] & $23.1(433)$ \\
B3LYP/6-31g(d,p)//PCM-TD-B3LYP/6-31+G(d,p) [25] & $22.2(450)$ \\
Exp. agua-etanol [25] & $22.9(437)$ \\
Exp. polímero PVA [25] & $22.5(444)$ \\
Exp. etanol [22] & $22.7(440)$ \\
\hline \hline
\end{tabular}


Do ponto de vista experimental, alguns trabalhos foram encontrados na literatura, indicando que o espectro eletrônico de absorção da emodina é caracterizado por três bandas do tipo $\pi-\pi^{*}[25-27,29]$. Na tabela 1.1 está um sumário dos resultados encontrados na literatura para a $1^{\mathrm{a}}$ banda do espectro eletrônico de absorção da emodina.

\subsection{Métodos de solventes}

Atualmente têm sido demonstrado grande interesse em estudar as interações de moléculas de interesse biológico com o meio solvente, a fim de determinar o efeito do solvente nas propriedades físicas desses moléculas. Esse interesse é gerado pela necessidade em tentar compreender como moléculas interagem com o meio solvente, uma vez que esses meios, podem mudar bastante as propriedades eletrônicas e conformacionais dessas moléculas. Um outro fator que impulsiona a sociedade científica em buscar compreender os processos moleculares em meio solvente, é o fato da maioria das reações químicas ocorrerem nesses meios [30]. Essas reações são de extrema importância nos processos biológicos e químicos, tendo uma vasta aplicação na indústria farmacêutica e cosmética, etc.

Do ponto de vista teórico, cálculos quânticos vêm sendo amplamente utilizados para analisar e determinar propriedades estruturais e eletrônicas de moléculas isoladas e em meio solvente. Atualmente, existem na literatura, dois tipos de modelos bastantes conhecidos, que incluem o solvente nesses cálculos: (i) modelos contínuos de solventes e, (ii) modelos discretos de solvente.

Nos modelos contínuos, a descrição do solvente é dada através de um meio dielétrico caracterizado por parâmetros macroscópicos, tais como a constante dielétrica ou índice de refração. Esses modelos são fundamentados nos trabalhos de Onsager [31], e de Kirkwood [32]. Na prática, o que se faz é colocar a molécula isolada numa cavi- 
dade circundada por um meio dielétrico contínuo polarizável de constante dielétrica $\epsilon$. Assim, o hamiltoniano é alterado por um termo adicional que descreve a interação da molécula com o meio contínuo, conhecido como campo de reação. Portanto ao resolver a equação de Schroedinger, é gerado um processo interativo de autoconsistência, daí o nome do modelo, Campo de Reação Autoconsistente (SCRF). Esse modelo foi introduzido na mecânica quântica por Rivail e Rinaldi [33,34], e Tapia e Goscinski [35], na década de 70 do século XX.

Assim como todo modelo físico, o SCRF apresenta pontos positivos e negativos, ao representar a interação soluto-solvente. Uma vantagem desse modelo é que ele permite um tratamento quântico da interação soluto-solvente. Uma outra vantagem é que a perturbação no soluto provocada pelo solvente, que a longas distâncias é bem representada por um meio dielétrico. Entretanto, as interações de curto alcance, como ligações de hidrogênio e forças de van der Waals, o modelo contínuo de solvente não descreve de forma adequada essas interações. Um outro problema com esse modelo, é a dependência com o forma e tamanho da cavidade em que o soluto é circundado pelo meio dielétrico. Vários trabalhos foram publicados na literatura com intenção de minimizar esses problemas [36-38]. Alguns métodos, adotam a forma da cavidade dada pela junção de esferas centradas nos átomos do soluto, gerando portanto, uma cavidade no formato do soluto. Um método que tem se destacado na literatura, que utiliza esse tipo de cavidade, é o modelo contínuo polarizável (PCM) [39].

Uma outra forma de inserir o solvente nos cálculos quânticos é através de modelos discretos de solvente. Nesses modelos, o solvente é incluído explicitamente nos cálculos. Atualmente, existem duas maneiras de abordar esses modelos, uma através de cálculos quânticos e outra através de simulações computacionais. A técnica de incluir explicitamente as moléculas de solvente nos cálculos quânticos é conhecida na literatura como aproximação de aglomerados otimizados. Nessa aproximação, os cálculos das propriedades são geralmente realizados em um aglomerado formado pela 
molécula de interesse e algumas moléculas de solvente numa conformação de mínima energia.

A aproximação de aglomerados otimizados apresenta alguns pontos negativos ao representar o sistema soluto-solvente. Um desses pontos está na definição do aglomerado a ser otimizado, uma vez que esse é limitado a poucas moléculas de solvente, usualmente uma ou duas moléculas são incluídas, devido a capacidade computacional. Para aglomerados maiores que isso, o esforço computacional necessário para realização dos cálculos quânticos aumenta drasticamente. Um outro ponto está nas interações intermoleculares que não são bem descritas, pois nessa aproximação é levada em conta apenas interações de curto alcance e interações específicas, tal como, ligações de hidrogênio. Já as interações de médio e longo alcance são desprezadas. Adicionalmente, a esses dois pontos, existe um outro ponto a ressaltar, que é a validade dessa aproximação, pois essa descreve apenas aglomerados e não soluções. A aproximação de aglomerados otimizados despreza dois aspectos muito importantes de soluções: a temperatura e a natureza estatística do solvente. Sendo que, em uma solução as moléculas do solvente estão sempre em movimento e, portanto várias conformações são acessíveis ao sistema. Assim, calcular uma propriedade de interesse de um sistema solvatado sobre apenas uma estrutura de mínima energia é uma aproximação questionável. Portanto para um cálculo mais preciso de uma propriedade, essa deve ser obtida através de médias sobre inúmeras estruturas supermoleculares.

Na década de 50 do século XX, surgiu um novo método com o intuito de abordar o estudo de solvente de uma forma mais realista. Este método que permite utilizar um modelo de solvente realista é o de simulação computacional. Historicamente, esse método surgiu com a publicação dos trabalhos de Metropolis e colaboradores [40], com método Monte Carlo(MC) e de Alder e Wainwright [41,42], com o método de Dinâmica Molecular(MD), todos publicados na década de 50 do século XX. Com o desenvolvimento dessas técnicas de simulações computacionais, tornou-se possível, tratar 
de forma realista, sistemas solvatados. Nesses dois métodos, é incluido explicitamente o solvente levando em conta a natureza estatística da solução, e as interações de curto e longo alcance e interações específicas, tal como, ligações de hidrogênio.

A simulação computacional classíca é uma excelente ferramenta para estudar propriedades termodinâmicas de sistemas líquidos. Já as propriedades eletrônicas, como espectros de absorção e emissão, só é possível estudar através de métodos quânticos. Entretanto, métodos híbridos que combinam mecânica quântica(QM) e mecânica molecular(MM), conhecidos como QM/MM [43,44], vem sendo bastante aplicado para estudar tais propriedades. Em particular, o método sequencial QM/MM [45,46], vem obtendo bons resultados quando aplicados no estudos de propriedades eletrônicas e estruturais de líquidos moleculares $[47,48]$. Na prática, o que esse método faz é utilizar sequencialmente o método Monte Carlo ou Dinâmica Molecular para simulação de líquidos e cálculos quânticos para determinar as propriedades eletrônicas. Esse método, utiliza primeiramente a simulação computacional para gerar inúmeras configurações do sistema líquido. Nessas configurações, é realizado uma análise estatística, através da função autocorrelação [49,50], com o intuito de filtrar apenas configurações supermoleculares descorrelacionadas estatisticamente, para realização de cálculos quânticos. Nesses cálculos, o solvente pode ser incluído explicitamente, o que permite um tratamento realista do efeito solvente. Nessa metodologia, as propriedades de interesse são obtidas através de médias sobre os cálculos quânticos das configurações supermoleculares.

\subsection{Organização da dissertação}

Este trabalho está organizado em cinco capítulos. No capítulo seguinte, mostraremos a metodologia teórica aplicada neste trabalho, onde na seção 2.2, apresentaremos os métodos de química quântica, e na seção 2.3. descreveremos os métodos de simu- 
lação computacionais (Dinâmica Molecular(MD) e Monte Carlo(MC)). No capítulo 3 , apresentaremos e discutiremos nossas medidas do espectro eletrônico de absorção da emodina em diferentes meios, e faremos comparações dessas medidas com resultados encontrados na literatura. No capítulo 4, mostraremos e discutiremos os resultados teóricos obtidos, através de aplicação das técnicas de cálculos quânticos e simulação computacionais para o estudo da molécula de emodina. Neste capítulo apresentaremos uma análise conformacional da molécula de emodina em fase gasosa, e em meio solvente; mostraremos o estudo da solvatação diferencial dessa molécula em água, clorofórmio e metanol; apresentaremos também os resultados do cálculo do espectro eletrônico de absorção da emodina isolada e em meio líquido, como também faremos comparações desses resultados com os resultados experimentais mostrados no capítulo 3. No capítulo 5, fecharemos este trabalho expondo nossas conclusões e perspectivas. 


\section{Capítulo 2}

\section{Métodos Teóricos}

\subsection{Introdução}

Neste capítulo descreveremos de forma sucinta os métodos de Química Quântica e Simulação Computacional utilizados para estudar sistemas atômicos e moleculares. Iniciaremos fazendo uma introdução aos métodos aproximados de Química Quântica (Hartree-Fock e Teoria do Funcional da Densidade, ambos na aproximação de Born-Oppenheimer) para resolver a equação de Schrödinger de um sistema molecular. Depois, descreveremos os dois métodos de simulação computacional de sistemas moleculares: Dinâmica Molecular(MD) e Monte Carlo (MC).

\subsection{Química Quântica}

Desde a década de 20 do século XX, estudar sistemas moleculares através da Mecânica Quântica (QM), com a resolução da equação de Schrödinger para obtenção dos auto-funções e auto-energias, vem tornando-se uma atividade de grande interesse. A equação de Schrödinger para sistemas moleculares é dada por:

$$
\hat{\mathbf{H}} \Psi=E \Psi
$$


onde $\hat{\mathbf{H}}$ é hamiltoniano do sistema dado por:

$$
\hat{\mathbf{H}}(\mathbf{r}, \mathbf{R})=-\sum_{i=1}^{N} \frac{1}{2} \nabla_{i}^{2}-\sum_{A=1}^{M} \frac{1}{2 M_{A}} \nabla_{A}^{2}-\sum_{i=1}^{N} \sum_{A=1}^{M} \frac{Z_{A}}{r_{i A}}+\sum_{i<j}^{N} \frac{1}{r_{i j}}+\sum_{A<B}^{M} \frac{Z_{A} Z_{B}}{r_{A B}}
$$

onde $\mathbf{r} \equiv\left\{r_{i}\right\}$ corresponde ao vetor de posição do elétron $i, \mathbf{R} \equiv\left\{\mathbf{R}_{A}\right\}$ representa a posição do núcleo $A$ e $r_{i A} \equiv\left|\mathbf{r}_{i}-\mathbf{R}_{A}\right|$ corresponde a distância entre o elétron $i$ e o núcleo $A$. As constantes $Z_{A}$ e $M_{A}$ correspondem o número atômico e massa atômica do núcleo $A$. Em sistemas atômicos, a solução exata para a equação 2.1 só é factível para o átomo de hidrogênio, vem daí a necessidade de recorrer a métodos aproximados para trabalhar com sistemas multi-eletrônicos [51]. Atualmente existem na literatura diversos métodos para solucionar esses problemas. No entanto vamos nos limitar aos métodos mais importantes encontrados na literatura, Hartree-Fock(HF) e Teoria dos Funcionais da Densidade (DFT, de Density Functional Theory).

Apesar dos métodos HF e DFT terem sido desenvolvidos com os mesmos objetivos, apresentam formulações bem distintas, onde o método de HF está fundamentado na Mecânica Quântica baseado em funções de onda, desenvolvido por Hartree e Fock [52] e DFT está fundamentado na Mecânica Quântica, porém baseada na densidade eletrônica do sistema, desenvolvido em 1964 por Walter Kohn e Hoberberg [53]. Mas antes de entrar em detalhes nesses métodos, vamos fazer uma breve introdução da aproximação de Born-Oppenheimer, uma vez que Hartree e Kohn aderiram essa aproximação para o desenvolvimento de seus métodos.

\subsubsection{A aproximação de Born-Oppenheimer(BO)}

A aproximação de Born-Oppenheimer foi proposto nos primórdios da mecânica quântica por Born e Oppenheimer (1927) e ainda hoje é uma ferramenta indispensável em química quântica [54]. Em termos básicos, essa aproximação permite separar as auto-energias e auto-funcões em dois termos, uma correspondente a parte eletrônica e 
a outra a parte nuclear,

$$
\Psi_{\text {total }}(\mathbf{r}, \mathbf{R})=\chi_{k}(\mathbf{r} ; \mathbf{R}) \phi_{n}(\mathbf{R})
$$

com as equações de movimento eletrônico e nuclear dado por:

$$
\begin{gathered}
\hat{H}_{\text {elet }}(\mathbf{r} ; \mathbf{R}) \chi_{k}(\mathbf{r} ; \mathbf{R})=\varepsilon_{k} \chi_{k}(\mathbf{r} ; \mathbf{R}) \\
\hat{H}_{\text {núcl }}(\mathbf{R}) \phi_{n}(\mathbf{R})=E \phi_{n}(\mathbf{R}),
\end{gathered}
$$

onde os hamiltonianos $\hat{H}_{\text {elet }}(\mathbf{r} ; \mathbf{R})$ e $\hat{H}_{\text {núcl }}(\mathbf{R})$ são dados por:

$$
\begin{gathered}
\hat{H}_{\text {elet }}(\mathbf{r} ; \mathbf{R})=-\sum_{i=1}^{N} \frac{1}{2} \nabla_{i}^{2}-\sum_{i=1}^{N} \sum_{A=1}^{M} \frac{Z_{A}}{r_{i A}}+\sum_{i<j}^{N} \frac{1}{r_{i j}} \\
\hat{H}_{\text {núcl }}(\mathbf{R})=-\sum_{A=1}^{M} \frac{1}{2 M_{A}} \nabla_{A}^{2}+E_{T}(\mathbf{R}),
\end{gathered}
$$

onde $E_{T}(\mathbf{R})$, corresponde o potencial para o movimento nuclear. Mais detalhes do desenvolvimento da aproximação de Born-Oppenheimer estão mostrados no apêndice $\mathrm{A}$.

O sucesso dessa aproximação se deve fortemente ao fato das massas dos elétrons serem bem menores que as massas dos núcleos, permitindo que os elétrons se adaptem a qualquer arranjo dos núcleos, quase instantaneamente. A aproximação de BornOppenheimer é válida para a maioria dos sistemas moleculares e atômicos. No entanto, essa aproximação não é válida para casos em que existe um acoplamento significativo entre diferentes estados eletrônicos, ou seja, para estados degenerados.

\subsubsection{Método de Hartree-Fock}

Em 1928 Douglas Hartree propôs uma das aproximações mais importante para tratamento de sistemas moleculares a nível quântico. Essa aproximação consiste em 
considerar o movimento dos elétrons independentes uns dos outros, onde a função de onda eletrônica é dada como um produto de funções de onda de um elétron,

$$
\Psi(\mathbf{r})=\phi_{1}\left(\mathbf{r}_{1}\right) \phi_{2}\left(\mathbf{r}_{2}\right) \phi_{3}\left(\mathbf{r}_{2}\right) \ldots \phi_{N}\left(\mathbf{r}_{N}\right)
$$

onde $\phi_{i}\left(\mathbf{r}_{i}\right)$, são conhecidos também como spin-orbitais eletrônicos dados por:

$$
\phi_{i}\left(\mathbf{r}_{i}\right)=\varphi_{i}\left(\mathbf{r}_{i}\right) \xi\left(\omega_{i}\right)
$$

onde

$$
\xi\left(\omega_{i}\right)=\left\{\begin{array}{l}
\alpha\left(\omega_{i}\right) \uparrow \\
\beta\left(\omega_{i}\right) \downarrow
\end{array} .\right.
$$

Essa aproximação é conhecida na literatura como modelo das Partículas Independentes. O problema crucial nessa aproximação está no fato de Hartree não levar em conta o princípio de antissimetria, conhecido também como o princípio de exclusão de Pauli, do qual resulta que a função de onda total de um sistema de férmions deve ser antissimétrica na troca de coordenadas espaciais e de spin para algum par de férmions idênticos.

Em 1930 Fock modificou o modelo das Partículas Independentes de Hartree, inserindo a inclusão da antissimetria através do determinante de Slater dado por:

$$
\Psi(\mathbf{r})=\frac{1}{\sqrt{N !}}\left|\begin{array}{ccccc}
\phi_{1}\left(\mathbf{r}_{1}\right) & \phi_{2}\left(\mathbf{r}_{1}\right) & \phi_{3}\left(\mathbf{r}_{1}\right) & \ldots & \phi_{N}\left(\mathbf{r}_{1}\right) \\
\phi_{1}\left(\mathbf{r}_{2}\right) & \phi_{2}\left(\mathbf{r}_{2}\right) & \phi_{3}\left(\mathbf{r}_{2}\right) & \ldots & \phi_{N}\left(\mathbf{r}_{2}\right) \\
\phi_{1}\left(\mathbf{r}_{3}\right) & \phi_{2}\left(\mathbf{r}_{3}\right) & \phi_{3}\left(\mathbf{r}_{3}\right) & \ldots & \phi_{N}\left(\mathbf{r}_{3}\right) \\
\vdots & \vdots & \vdots & \ddots & \vdots \\
\phi_{1}\left(\mathbf{r}_{N}\right) & \phi_{2}\left(\mathbf{r}_{N}\right) & \phi_{3}\left(\mathbf{r}_{N}\right) & \ldots & \phi_{N}\left(\mathbf{r}_{N}\right)
\end{array}\right|
$$

onde todos os spin-orbitais eletrônicos $\phi_{i}\left(\mathbf{r}_{i}\right)$ são ortonormais, o fator $\frac{1}{\sqrt{N !}}$ corresponde uma constante de normalização para a função de onda $\Psi(\mathbf{r})$. Esse determinante pode ser escrito na forma simplificada dado por:

$$
\Psi(\mathbf{r})=\left|\phi_{1} \phi_{2} \phi_{3} \ldots \phi_{N}\right\rangle
$$


onde o fator $\frac{1}{\sqrt{N !}}$ está implícito. O método de Hartree só passou a ser conhecido como Método de Hartree-Fock depois da introdução do princípio variacional e da antissimetria $[55,56]$. Portanto as equações de Hartree-Fock são obtidas através do método variacional $[57,58]$, onde a energia $E_{0}$ do estado fundamental é dada através do funcional,

$$
E_{0}=\left\langle\Psi_{0}|\hat{\mathbf{H}}| \Psi_{0}\right\rangle
$$

onde $\left|\Psi_{0}\right\rangle$ é função de onda para o estado fundamental. Escrevendo $\left|\Psi_{0}\right\rangle$ na forma,

$$
\left|\Psi_{0}\right\rangle=\frac{1}{\sqrt{N !}} \sum_{i=1}^{N !}(-1)^{\mathrm{p}_{i}}\left|\hat{\mathbf{P}}_{i} \phi_{1}\left(\mathbf{r}_{1}\right) \phi_{2}\left(\mathbf{r}_{2}\right) \phi_{3}\left(\mathbf{r}_{2}\right) \ldots \phi_{N}\left(\mathbf{r}_{N}\right)\right\rangle,
$$

onde $\hat{\mathbf{P}}_{i}$ é o operador permutação, pode-se escrever o valor esperado do operador $\hat{\mathbf{H}}$ para o estado fundamental $\left|\Psi_{0}\right\rangle$ como,

$$
E_{0}=\sum_{a}^{N}\left\langle\phi_{a}\left(\mathbf{r}_{1}\right)\left|h\left(\mathbf{r}_{1}\right)\right| \phi_{a}\left(\mathbf{r}_{1}\right)\right\rangle+\frac{1}{2} \sum_{a}^{N} \sum_{b}^{N}\left\langle\phi_{a}\left(\mathbf{r}_{1}\right) \phi_{b}\left(\mathbf{r}_{2}\right) \| \phi_{a}\left(\mathbf{r}_{1}\right) \phi_{b}\left(\mathbf{r}_{2}\right)\right\rangle,
$$

onde $h\left(\mathbf{r}_{1}\right)$ corresponde ao operador hamiltoniano de um elétron dado por:

$$
h\left(\mathbf{r}_{1}\right)=-\frac{1}{2} \nabla_{1}^{2}-\sum_{A=1}^{M} \frac{1}{r_{i A}} .
$$

O segundo termo da equação 2.15, representa o operador hamiltoniano de dois elétrons, onde o termo,

$\left\langle\phi_{a}\left(\mathbf{r}_{1}\right) \phi_{b}\left(\mathbf{r}_{2}\right) \| \phi_{a}\left(\mathbf{r}_{1}\right) \phi_{b}\left(\mathbf{r}_{2}\right)\right\rangle=\left\langle\phi_{a}\left(\mathbf{r}_{1}\right) \phi_{b}\left(\mathbf{r}_{2}\right) \mid \phi_{a}\left(\mathbf{r}_{1}\right) \phi_{b}\left(\mathbf{r}_{2}\right)\right\rangle-\left\langle\phi_{a}\left(\mathbf{r}_{1}\right) \phi_{b}\left(\mathbf{r}_{2}\right) \mid \phi_{b}\left(\mathbf{r}_{1}\right) \phi_{a}\left(\mathbf{r}_{2}\right)\right\rangle$,

onde,

$$
\left\langle\phi_{a}\left(\mathbf{r}_{1}\right) \phi_{b}\left(\mathbf{r}_{2}\right) \mid \phi_{a}\left(\mathbf{r}_{1}\right) \phi_{b}\left(\mathbf{r}_{2}\right)\right\rangle=\int \phi_{a}^{*}\left(\mathbf{r}_{1}\right) \phi_{b}^{*}\left(\mathbf{r}_{2}\right) \frac{1}{r_{12}} \phi_{a}\left(\mathbf{r}_{1}\right) \phi_{b}\left(\mathbf{r}_{2}\right) d^{3} r_{1} d^{3} r_{2}
$$

Usando a condição de vínculo de que todos os spin-orbitais moleculares permaneçam ortonormais, pode-se utilizar a técnica dos multiplicadores de Lagrange [59], a 
fim de minimizar o funcional,

$$
\begin{aligned}
\mathcal{L} & =\sum_{a}^{N}\left\langle\phi_{a}\left(\mathbf{r}_{1}\right)\left|h\left(\mathbf{r}_{1}\right)\right| \phi_{a}\left(\mathbf{r}_{1}\right)\right\rangle+\frac{1}{2} \sum_{a}^{N} \sum_{b}^{N}\left\langle\phi_{a}\left(\mathbf{r}_{1}\right) \phi_{b}\left(\mathbf{r}_{2}\right) \| \phi_{a}\left(\mathbf{r}_{1}\right) \phi_{b}\left(\mathbf{r}_{2}\right)\right\rangle \\
& -\sum_{a}^{N} \sum_{b}^{N} \epsilon_{a b}\left(\left\langle\phi_{a}\left(\mathbf{r}_{1}\right) \mid \phi_{b}\left(\mathbf{r}_{2}\right)\right\rangle-\delta_{a b}\right),
\end{aligned}
$$

onde os coeficientes $\epsilon_{a b}$ são os multiplicadores de Lagrange. Impondo que o funcional $\mathcal{L}$ seja real, mostra-se que a matriz formada pelos $\epsilon_{a b}$ é hermitiana,

$$
\epsilon_{a b}^{*}=\epsilon_{b a} .
$$

Se cada um dos spin-orbitais sofrer uma pequena variação $\delta \phi$, o funcional $\mathcal{L}$ sofrerá uma variação dada por:

$$
\delta \mathcal{L}=\sum_{a}^{N}\left\langle\delta \phi _ { a } ( \mathbf { r } _ { 1 } ) \left|\left\{\left[h\left(\mathbf{r}_{1}\right)+\sum_{b}^{N}\left[\mathcal{J}_{b}\left(\mathbf{r}_{1}\right)-\mathcal{K}_{b}\left(\mathbf{r}_{1}\right)\right]\right]\left|\phi_{a}\left(\mathbf{r}_{1}\right)\right\rangle-\sum_{b}^{N} \epsilon_{a b}\left|\phi_{b}\left(\mathbf{r}_{1}\right)\right\rangle\right\}+c c\right.\right.
$$

onde o termo $c c$ corresponde ao complexo conjugado e $\mathcal{J}_{b}\left(\mathbf{r}_{1}\right)$ e $\mathcal{K}_{b}\left(\mathbf{r}_{1}\right)$ são os operadores de Coulomb e de troca respectivamente e estão definidos através das expressões,

$$
\begin{aligned}
\mathcal{J}_{b}\left(\mathbf{r}_{1}\right) \phi_{a}\left(\mathbf{r}_{1}\right) & =\left\{\int \phi_{b}^{*}\left(\mathbf{r}_{2}\right) \frac{1}{r_{12}} \phi_{b}\left(\mathbf{r}_{2}\right) d^{3} r_{2}\right\} \phi_{a}\left(\mathbf{r}_{1}\right) \\
\mathcal{K}_{b}\left(\mathbf{r}_{1}\right) \phi_{a}\left(\mathbf{r}_{1}\right) & =\left\{\int \phi_{b}^{*}\left(\mathbf{r}_{2}\right) \frac{1}{r_{12}} \phi_{a}\left(\mathbf{r}_{2}\right) d^{3} r_{2}\right\} \phi_{b}\left(\mathbf{r}_{1}\right),
\end{aligned}
$$

Impondo que $\delta \mathcal{L}=0$, ou seja, que o funcional $\mathcal{L}$ seja um mínimo, obtem-se o operador de Fock $\mathcal{F}\left(\mathbf{r}_{1}\right)$,

$$
\mathcal{F}\left(\mathbf{r}_{1}\right) \phi_{a}\left(\mathbf{r}_{1}\right)=\sum_{b}^{N} \epsilon_{a b} \phi_{b}\left(\mathbf{r}_{1}\right)
$$

onde $\mathcal{F}\left(\mathbf{r}_{1}\right)$ é dado por:

$$
\mathcal{F}\left(\mathbf{r}_{1}\right)=h\left(\mathbf{r}_{1}\right)+\sum_{b}\left[\mathcal{J}_{b}\left(\mathbf{r}_{1}\right)-\mathcal{K}_{b}\left(\mathbf{r}_{1}\right)\right]
$$


Mostra-se que a soma dos operadores $\mathcal{J}_{b}\left(\mathbf{r}_{1}\right)$ e $\mathcal{K}_{b}\left(\mathbf{r}_{1}\right)$, e conseqüentemente, $\mathcal{L}$ são invariantes sob a fransformação unitária dada por:

$$
\phi_{a}^{\prime}\left(\mathbf{r}_{1}\right)=\sum_{c} \phi_{c}\left(\mathbf{r}_{1}\right) \mathcal{U}_{c a}
$$

onde $\mathcal{U}_{c a}$ é um elemento de uma matriz unitária $\mathcal{U}$. Usando a equação 2.26, é possível diagonalizar a matriz formada pelos elementos $\epsilon_{a b}$, para obter um conjunto de spinorbitais que são os autovetores do operador de Fock e os autovalores $\epsilon_{a}$ que são as energias associadas aos orbitais moleculares. Portanto a equação 2.24, pode ser escrita da forma,

$$
\mathcal{F}\left(\mathbf{r}_{1}\right) \phi_{a}\left(\mathbf{r}_{1}\right)=\epsilon_{a} \phi_{a}\left(\mathbf{r}_{1}\right),
$$

conhecida na literatura como equação canônica de Hartree-Fock. Usando a equação 2.25 e 2.27, pode-se obter os autovalores $\epsilon_{a}$ dados por:

$$
\epsilon_{a}=\left\langle\phi_{a}\left(\mathbf{r}_{1}\right)\left|h\left(\mathbf{r}_{1}\right)\right| \phi_{a}\left(\mathbf{r}_{1}\right)\right\rangle+\sum_{b}^{N}\left\langle\phi_{a}\left(\mathbf{r}_{1}\right) \phi_{b}\left(\mathbf{r}_{2}\right) \| \phi_{a}\left(\mathbf{r}_{1}\right) \phi_{b}\left(\mathbf{r}_{2}\right)\right\rangle .
$$

Usando a equação 2.15, mostra-se que,

$$
E_{0}=\sum_{a}^{N} \epsilon_{a}-\frac{1}{2} \sum_{a}^{N} \sum_{b}^{N}\left\langle\phi_{a}\left(\mathbf{r}_{1}\right) \phi_{b}\left(\mathbf{r}_{2}\right) \| \phi_{a}\left(\mathbf{r}_{1}\right) \phi_{b}\left(\mathbf{r}_{2}\right)\right\rangle .
$$

Como o operador de Fock $\mathcal{F}\left(\mathbf{r}_{1}\right)$ depende dos operadores de Coulomb $\mathcal{J}_{b}\left(\mathbf{r}_{1}\right)$ e de troca $\mathcal{K}_{b}\left(\mathbf{r}_{1}\right)$, e esses dependem das soluções da equação dos spin-orbitais. Portanto, a equação de Hartree-Fock deve ser resolvida iterativamente, ou seja, de forma acoplada através de aproximações sucessivas [55,56]. Vem dai o nome do processo utilizado para resolver a equação de Hartree-Fock, que é chamado de método do Campo Autoconsistente $(\mathrm{SCF})$.

A solução numérica da equação de Hartree-Fock só é factível para sistemas atômicos ou moleculares com poucos elétrons, porém para sistemas maiores é recomendável recorrer a métodos proposto por Slater [60] e posteriormente formalizado por Roothaan [61]. Esse método é conhecido na literatura como LCAO, que tem como 
essência a expansão dos orbitais moleculares em termos de um conjunto de funçõesbase conhecidas. Então, escrevendo os orbitais moleculares como,

$$
\phi_{i}(\mathbf{r})=\sum_{\mu}^{k} C_{\mu p} g_{\mu}(\mathbf{r}),
$$

onde $k$ é o número de funções do conjunto, $C_{\mu p}$ 's são os coeficientes da expansão, e $g_{\mu}(\mathbf{r})$ são as funções-bases. Em sistemas moleculares as funções-base mais utilizadas são as funções tipo gaussianas, devido a facilidade em resolver numericamente integrais dessas funções. Substituindo a equação 2.30 na equação de Hartree-Fock, obtem-se,

$$
\mathbf{F C}=\mathbf{S C} \epsilon
$$

Esta é uma equação matricial, conhecida na literatura como a equação de HartreeFock-Roothaan. A matriz de Fock $\mathbf{F}$ e a matriz de overlap $\mathbf{S}$ são dadas por

$$
\begin{gathered}
F_{\mu \nu}=\int \phi_{\mu}^{*}\left(\mathbf{r}_{\mathbf{1}}\right) \mathcal{F}\left(\mathbf{r}_{1}\right) \phi_{\nu}\left(\mathbf{r}_{\mathbf{1}}\right) d^{3} r_{1} \\
S_{\mu \nu}=\int \phi_{\mu}^{*}\left(\mathbf{r}_{\mathbf{1}}\right) \phi_{\nu}\left(\mathbf{r}_{\mathbf{1}}\right) d^{3} r_{1} .
\end{gathered}
$$

Os elementos da matriz $\mathbf{C}$ são dados pela equação 2.30 e os elementos da matriz $\epsilon$, que é uma matriz diagonal que contém as energias orbitais são dados por: $\epsilon_{p q}=\epsilon_{p} \delta_{p q}$.

A equação de Hartree-Fock-Roothaan deve ser resolvida de forma autoconsistente, uma vez que a matriz $\mathbf{F}$ depende da matriz $\mathbf{C}$. Um outro fato importante a mencionar é que o conjunto de funções-base geralmente não é ortogonal como conseqüência a matriz $\mathbf{S}$ não é diagonal. No entanto a matriz $\mathbf{S}$ é hermitiana, podendo ser diagonalizada por uma matriz unitária U. Realizando uma transformada unitária na matriz de Fock F, a equação Hartree-Fock-Roothaan pode ser escrita na sua forma matricial canônica. Essa nova equação pode ser resolvida com mais facilidade, apenas ortogonalizando-se a nova matriz de Fock.

A precisão dos resultados de um calculo com nível Hartree-Fock, depende da escolha do conjunto de funções-base. Esse conjunto de funções-base deve ser completo, 
ou seja, deve possuir um número grande de funções para obter o limite da energia eletrônica ou solução de HF, o que se torna esse cálculo impossível de ser realizado computacionalmente. Na prática, o que se faz é escolher um conjunto de funções-base finito, o que torna a energia eletrônica variacional, quanto melhor for esse conjunto, mas precisos serão os resultados, até que se atinja o limite de Hartree Forck.

Pelo princípio variacional, o valor limite da energia de Hartree-Fock $\left(E_{H F}\right)$ está acima da energia exata ( $\left.E_{\text {exata }}\right)$ (não-relativística), dentro da aproximação de Aproximação de Born-Oppenheimer. Portanto, define-se como energia de correlação eletrônica $\left(E_{\text {corr }}\right)$ a diferença entre a energia exata e energia de Hartree-Fock $[56,58]$.

$$
E_{\text {corr }}=E_{\text {exata }}-E_{H F} \text {. }
$$

Apesar da energia de correlação ser geralmente pequena em comparação a energia de Hartree-Fock, ela é essencial para a descriação de processos eletrônicos. Devido a isso, vários métodos tem sido desenvolvidos com o objetivo incluir a energia de correlação eletrônica. Dentro desses métodos estão, o método de interação de configurações (CI) [55], o de campo autoconsistente de multireferencial [56], os métodos perturbativos [57] e método do funcional da densidade que será apresentado neste capítulo.

\subsubsection{Métodos semi-empíricos}

Os métodos semi-empíricos surgiram da necessidade em reduzir o custo computacional, de cálculos que utilizam as equações de Hartree-Fock, para tratamento de sistema moleculares contendo uma grande quantidade de átomos [56]. Uma vez que o custo computacional em se realizar um cálculo de Hartree-Fock é da ordem de $K^{4}$, onde $K$ corresponde ao número de funcões-base [55,62].

Todos os métodos semi-empíricos, buscam resolver, de forma autoconsistente, aproximações às equações de Hartree-Fock-Roothaan, utilizando parâmetros obtidos por ajuste numérico, ou baseado em dados experimentais. Esses métodos consideram 
apenas os elétrons de valência, os demais são considerado através do efeito de redução da carga nuclear efetiva que provocam [62]. Esses métodos utilizam um conjunto de base mínima para representar os elétrons de valência, onde geralmente essa base é formado por funções do tipo Slater

Uma aproximação comum entre os métodos semi-empíricos é a aproximação ZDO (Zero Differential Overlap) [63]. Essa aproximação considera nulo todos os produtos entre dois orbitais atômicos diferentes, o que simplifica bastante as equações de Hartree-Fock-Roothaan, implicando que a matriz de overlap $\hat{\mathbf{S}}$, se torne uma matriz identidade. E como vantagem, a equação de autovalores de Hartree-Fock-Roothaan pode ser simplificada e resolvida a partir de uma diagonalização da matriz de Fock.

A grande limitação dos métodos semi-empíricos estava ligado ao fato desses métodos serem restritos ao tratamento de sistemas com moléculas planas considerando apenas os elétrons $\pi$ [64]. Para superar essas limitações, Pople e colaboradores publicaram uma série de trabalhos [65-68], onde desenvolveram propostas como, os métodos CNDO (Complete Neglect of Differential Overlap), NDDO (Neglect of Diatomic Differential Overlap) e INDO (Intermediate Neglect of Differential Overlap).

Dentre as três aproximações propostas por Pople, a NDDO é citada na literatura como a melhor das três, devido ao fato dessa aproximação considerar um números maior de integrais a serem calculadas $[56,62]$. Nessa aproximação, todas as integrais de repulsão eletrônica, para os orbitais centrados em núcleos diferentes são considerados nulas. Assim, as integrais com os orbitais sobre o mesmo núcleo são consideradas diferente de zero, ou seja,

$$
\left\langle\phi_{A} \phi_{B} \mid \phi_{A} \phi_{B}\right\rangle \neq 0
$$

Na aproximação CNDO, considera desprezível todas as integrais de repulsão eletrônica que possuam produtos envolvendo orbitais diferentes $[65,66]$, sobrando apenas 
integrais monoatômicas do tipo Coulomb, $\left\langle\phi_{a} \phi_{a} \mid \phi_{b} \phi_{b}\right\rangle$. A grande desvantagem dessa aproximação é a não inclusão de integrais de exchange de um centro. Como conseqüência, essa aproximação é incapaz de distinguir estados provenientes de uma mesma configuração eletrônica. Esses problemas não aparecem na aproximação NDDO, no entanto essa aproximação exige um cálculo de um número muito grande de integrais de dois centros. A solução para esses problemas veio com a aproximação INDO, onde essa, inclui integrais de exchange, tipo $\left\langle\phi_{a} \phi_{b} \mid \phi_{a} \phi_{b}\right\rangle$, considerando apenas as integrais de um centro [68].

Depois dos trabalhos de Pople [65-68], várias propostas de parametrização desses métodos surgiram na literatura [69-72]. Uma parametrização importante para o nosso trabalho é a parametrização espectrocópica desenvolvida por Del Bene e Jaffe [73], para o CNDO, que mais tarde, Zerner e colaboradores implementaram essa parametrização no método INDO [68], e produziram o programa ZINDO [74], utilizado neste trabalho. Essa parametrização é conhecida na literatura como INDO/S, recomendável para o tratamento de transições eletrônicas.

\subsubsection{Teoria do Funcional da Densidade (DFT)}

Uma forma de estudar sistema de muitos elétrons incluindo a energia de correlação eletrônica é através da Teoria do Funcional da Densidade(DFT). Modelos como o Drude-Sommerfeld [75] e Thomas-Fermi [76] serviram como pontos de partidas para o desenvolvimento da Teoria do Funcional da Densidade por Hohenberg e Kohn em 1964 [53]. Essa teoria está fundamentada em dois teoremas, que usa a densidade eletrônica $\rho(\mathbf{r})$ como variável fundamental, em vez da função de onda total $\Psi(\mathbf{r})$, como na teoria de Hartree-Fock(HF). Esses dois teoremas asseguram que existe um funcional de energia exato da densidade eletrônica $E[\rho]$ e um princípio variacional exato para este funcional $[56,77]$.

No trabalho de Hohenberg e Kohn [53] eles consideraram o mesmo sistema des- 
crito pelo hamiltoniano da equação 2.2, com M núcleos e $\mathrm{N}$ elétrons dentro da aproximação de Born-Oppenheimer, desprezando-se os efeitos relativísticos, pode-se escrever o hamiltoniano como,

$$
\hat{\mathbf{H}}=\hat{\mathbf{T}}+\hat{\mathbf{U}}+\hat{\mathbf{V}}
$$

onde $\hat{\mathbf{T}}$ é o operador de energia cinética dos elétrons, Û o operador de repulsão elétronelétron e $\hat{\mathbf{V}}$, o operador correspondente ao potencial externo sentido pelos elétrons, que normalmente devido às cargas dos núcleos $Z_{A}$. Usando a definição de densidade eletrônica [51], é factível mostrar que a energia total do sistema é dada por,

$$
E=\langle\Psi|\hat{\mathbf{T}}+\hat{\mathbf{U}}+\hat{\mathbf{V}}| \Psi\rangle \equiv T[\rho]+U[\rho]+V[\rho]
$$

onde cada funcional corresponde a

$$
\begin{aligned}
& \hat{\mathbf{V}} \equiv \int v(\mathbf{r}) \Psi^{*}(\mathbf{r}) \Psi(\mathbf{r}) d^{3} r=\int v(\mathbf{r}) \rho(\mathbf{r}) d^{3} r \\
& \hat{\mathbf{U}} \approx \hat{\mathbf{U}}_{H} \equiv \frac{1}{2} \iint \frac{1}{\left|\mathbf{r}-\mathbf{r}^{\prime}\right|} \Psi^{*}(\mathbf{r}) \Psi^{*}\left(\mathbf{r}^{\prime}\right) \Psi(\mathbf{r}) \Psi\left(\mathbf{r}^{\prime}\right) d^{3} r d^{3} r^{\prime} \\
&= \frac{1}{2} \iint \frac{1}{\left|\mathbf{r}-\mathbf{r}^{\prime}\right|} \rho(\mathbf{r}) \rho\left(\mathbf{r}^{\prime}\right) d^{3} r d^{3} r^{\prime} \\
& \hat{\mathbf{T}} \equiv \frac{1}{2} \int \nabla \Psi^{*}(\mathbf{r}) \nabla \Psi(\mathbf{r}) d^{3} r .
\end{aligned}
$$

Torna-se evidente que a expressão para o funcional $V[\rho]$ (ver equação 2.38) é única ou seja exata além de uma constante aditiva. Já o funcional $U[\rho]$ correspondente a repulsão elétron-elétron é dado por uma aproximação da interação clássica entre as densidades eletrônicas, (ver equação 2.39). Essa expressão na literatura é conhecida como a energia de interação de Hartree. As principais implicações em escrever essa expressão dessa forma é que os elétrons podem interagir com eles mesmos e a interação de exchange é excluída, ou seja, desconsidera o principio da antissimetria. A correção energética devido a não interação de exchange é dada por

$$
E_{x c}[\rho]=E[\rho]-\left(U_{H}[\rho]+T_{0}[\rho]\right)
$$


onde $E_{x c}[\rho]$ é um funcional da densidade $[\rho]$, onde nesse funcional, já está incluso a parte que contém a correção da energia cinética.

Uma aproximação de imediato para o funcional $T[\rho]$ da energia cinética de um sistema de elétrons é considerar $T[\rho] \approx T_{0}[\rho]$, onde esses elétrons não interagem entre se, desprezando portanto o termo de interação de exchange. Uma proposta para essa aproximação foi dada em 1920 por Thomas e fermi [55].

Devido a dificuldade em incluir a correlação eletrônica e interação de exchange nos funcionais $U[\rho]$ e $T[\rho]$, desenvolver esses funcionais de modo a incluir os efeitos da correlação eletrônica e interação de exchange, tem sido um grande desafio da DFT, desde a sua formulação. Em 1965, Kohn e Sham [78] foram os primeiros a apresentar um posposta de atacar esse problema.

\subsubsection{Aproximação de Kohn-Sham}

Escrevendo a equação 2.37 para o funcional da energia total do sistema em termos da densidade eletrônica como,

$$
E[\rho]=F[\rho]+\langle\Psi|\hat{\mathbf{V}}| \Psi\rangle
$$

onde definiu-se $F[\rho]$ como um funcional universal válido para qualquer sistema coulombiano, dado por

$$
F[\rho]=\langle\Psi|\hat{\mathbf{T}}+\hat{\mathbf{U}}| \Psi\rangle=\frac{1}{2} \iint \frac{1}{\left|\mathbf{r}-\mathbf{r}^{\prime}\right|} \rho(\mathbf{r}) \rho\left(\mathbf{r}^{\prime}\right) d^{3} r d^{3} r^{\prime}+G[\rho],
$$

onde $G[\rho]$ também é um funcional universal. Esse funcional pode ser escrito da seguinte forma,

$$
G[\rho] \equiv T_{0}[\rho]+E_{x c}[\rho]
$$

onde a expressão exata para o funcional $E_{x c}[\rho]$ não é facil obter, entretanto pode-se obter através de aproximações. Usando a equação 2.42, 2.43 e 2.44 , pode-se escrever 
o funcional da energia como,

$$
E[\rho]=\int v(\mathbf{r}) \rho(\mathbf{r}) d^{3} r+\frac{1}{2} \iint \frac{1}{\left|\mathbf{r}-\mathbf{r}^{\prime}\right|} \rho(\mathbf{r}) \rho\left(\mathbf{r}^{\prime}\right) d^{3} r d^{3} r^{\prime}+T_{0}[\rho]+\int \rho(\mathbf{r}) E_{x c}[\rho(\mathbf{r})],
$$

Usando a condição de vínculo em que a carga eletrônica total seja fixa, ou seja,

$$
\int \rho(\mathbf{r}) d^{3} r=N
$$

onde $\mathrm{N}$ é número de elétrons e escrevendo o funcional $T_{0}[\rho]$ em termos de orbitais $\phi_{i}(\mathbf{r})$ de um sistema de elétrons não interagentes de densidade $\rho$,

$$
T_{0}[\rho]=-\frac{1}{2} \sum_{i} \int \phi_{i}^{*}(\mathbf{r}) \nabla^{2} \phi_{i}(\mathbf{r}) d^{3} r
$$

pode fazer uso do teorema variacional [59], a fim de minimizar o funcional de energia $E[\rho]$, sujeito a equação de vínculo 2.46. Esse mesmo processo foi realizado para obber a equação de Hartree-Fock, portanto realizando esse esquema, obtem-se a equação de Konh-Sham dada por

$$
h^{K S} \phi_{i}(\mathbf{r})=\epsilon_{i} \phi_{i}(\mathbf{r})
$$

onde $h^{K S}$ é o operador de Kohn-Sham de uma partícula, onde ele é dado por,

$$
h^{K S}=-\frac{1}{2} \nabla^{2}+v^{K S}[\rho],
$$

onde $v^{K S}[\rho]$ é definido como o potencial efetivo de Kohn-Sham dado por,

$$
v^{K S}[\rho]=v(\mathbf{r})+\int \frac{1}{\left|\mathbf{r}-\mathbf{r}^{\prime}\right|} \rho\left(\mathbf{r}^{\prime}\right) d^{3} r^{\prime}+v_{x c}(\rho) .
$$

Assim como no método Hartree-Fock, a solução da equação de Kohn-Sham deve ser obtida através de um cálculo autoconcistente e a qualidade dos resultados depende fortemente da escolha do funcional de exchange-correlação, $E_{x c}[\rho]$. Na literatura existem várias propostas baseadas em aproximações para esse funcional, entre elas, estão as com aproximação de densidade local: LDA (Local Density Approximation) [79], LSDA (Local Spin Density Approximation) [80,81]. Nessas aproximações, a energia 
de exchange-correlação para um sistema eletrônico homogêneo de densidade $\rho(\mathbf{r})$, no ponto $\mathbf{r}$ é assumida igual à energia de exchange-correlação de um sistema eletrônico homogêneo de mesma densidade.

Considerar a densidade eletrônica homogênea não é uma boa aproximação para estudar sistemas moleculares, portanto a LDA falha nesse aspecto. Um melhoramento na aproximação LDA é a GGA(Generalized Gradient Approximation) [82,83], onde nessa aproximação, escreve o funcional $E_{x c}[\rho]$ em termos do gradiente da densidade de carga total.

Além das aproximações LDA, LSDA e GGA, existem na literatura várias outras propostas para o funcional $E_{x c}[\rho]$ [84-86]. Atualmente os funcionais híbridos são os que mais se destacam na Teoria do Funcional da Densidade [79,87-89]. A principal característica desses funcionais é que misturam uma fração de exchange de HartreeFock no funcional de exchange do DFT. Esse procedimento é semelhante ao utilizado na obtenção dos métodos semi-empíricos, onde a formulação do funcional $E_{x c}[\rho]$ é baseado em dados experimentais de sistemas moleculares bem conhecidos. Um exemplo desse tipo de funcional é o B3LYP (Becke, three-parameter, Lee-Yang-Parr) [90, 91]. No B3LYP, o funcional de exchange-correção $E_{x c}$ é escrito da seguinte forma

$$
E_{x c}^{B 3 L Y P}=\left(1-a_{0}\right) E_{x}^{L S D A}+a_{0} E_{x}^{H F}+a_{x} \Delta E_{x}^{B 88}+a_{c} E_{c}^{L Y P}+\left(1-a_{c}\right) E_{c}^{V W N},
$$

onde os termos $\Delta E_{x}^{B 88}$, corresponde ao gradiente de correção do funcional de exchange de Becke de 1988 [79]. $E_{c}^{L Y P}$ e $E_{c}^{V W N}$, correspondem ao funcional de correlação de LeeYang-Parr [88], Vosko-Wilk-Nusair [92] respectivamente. Os coeficientes $a_{0}=0.20$, $a_{x}=0.72$ e $a_{c}=0.81$, são os três parâmetros empíricos sugerido em 1993 por Becke [81], baseado em análise de propriedades Termodinâmicas obtidas experimentalmente de pequenas moléculas.

Atualmente na literatura existe uma gama de proposta de funcionais $E_{x c}[\rho]$. O 
estudo desses funcionais é um campo da Química Quântica em aberto, bastante ativo e propício a receber contribuições que venha melhorar a precisão do método DFT. O sucesso desse método se deve a eficiência à inclusão da correlação eletrônica na implementação computacional, o que possibilita uma descrição de sistemas moleculares mais complexos com uma boa precisão.

\subsubsection{Ajuste de cargas parciais-CHELPG}

Um cuidado importante que se deve tomar na realização de uma simulação de líquidos moleculares é representar bem as propriedades eletrostáticas. Existem na literatura várias formas de representar essas propriedades para sistemas moleculares [93-96]. Uma forma simples é através do potencial gerado por cargas parciais centradas nos átomos da molécula. Essa técnica é conhecida na literatura como análise populacional de Mulliken [93]. O problema dessa técnica está em tomar os valores médios das cargas sobre os átomos, uma vez que esses valores são tomados sobre os orbitais atômicos. Como conseqüência os valores médios das cargas são dependentes da escolha do conjunto de funções-base.

Devido à necessidade em representar adequadamente o potencial eletrostático, várias técnicas foram propostas a fim de representar a densidade de carga molecular por um conjunto de cargas parciais. Um método que tem se destacado nessa área é o CHELPG(Charges from Electrostatic Potential Grid based, desenvolvido por Breneman e Wiberg no final da década de 80 [97]. O procedimento para obtenção das cargas parciais nesse método é dado por: (i) Defini-se uma grade retangular em torno da molécula e uma função de onda apropriada. (ii) Obtém-se o potencial eletrostático para cada átomo dentro dessa grade. (iii) Ajustam-se cargas parciais nas posições dos núcleos atômicos de modo a reproduzir o potencial eletrostático, de forma que a carga total tem que ser igual a carga efetiva da molécula que gerou o potencial.

Um conjunto de cargas parciais obtido do procedimento CHELPG, tem conse- 
guido reproduzir adequadamente as propriedades eletrostáticas de sistemas moleculares, em particular em sistemas líquidos [98] . Atualmente na literatura, existem vários resultados satisfatórios da obtenção das cargas através do método CHELPG para realização de uma simulação molecular [99-103]. Neste trabalho, utilizamos esse método para gerar as cargas parciais que utilizamos na realização das simulações computacionais.

\subsection{Simulação computacional}

Atualmente, uma ferramenta poderosa para estudar sistemas moleculares é a simulação computacional. Essa ferramenta permite-nos estudar propriedades fundamentais de sistemas moleculares. Apesar de que nem todas propriedades podem ser obtidas diretamente via simulação, podemos obter propriedades através de simulação de difícil acesso experimental $[49,104]$. Um exemplo típico: a simulação computacional de um líquido, onde podemos obter todas as posições e velocidades instantâneas de todas as moléculas no líquido. No entanto, o experimental é capaz de fornecer uma propriedade média desse sistema, medida sobre uma grande quantidade de moléculas, ou sobre um tempo prolongado. Na simulação computacional essas médias são realizadas baseadas nos princípios da mecânica estatística, sendo portanto possível obter propriedades macroscópicas, como pressão e energia interna, a partir de informações microscópicas.

Assim, para realizar uma simulação computacional é necessário escolher o tipo de média que deseja realizar sobre o sistema. Pode-se realizar uma média sobre as configurações do sistema, conhecida também como uma média sobre o ensemble, ou uma média temporal, realizada sobre uma série de medidas durante um certo intervalo de tempo. Numa simulação computacional de líquidos, onde o sistema é representado por $N$ átomos, ou moléculas, descrito pelo um hamiltoniano $\mathcal{H}$, o valor médio de uma 
propriedade $\mathcal{A}$ sobre o ensemble é dada por:

$$
\langle\mathcal{A}\rangle_{N P T}=\frac{\int_{V} \int_{\mathbf{p}^{N}} \int_{\mathbf{r}^{N}} \mathcal{A}\left(\mathbf{p}^{N}, \mathbf{r}^{N}\right) \exp \{-\beta(\mathcal{H}+p V)\} d V d \mathbf{p}^{N} d \mathbf{r}^{N}}{\int_{V} \int_{\mathbf{p}^{N}} \int_{\mathbf{r}^{N}} \exp \{-\beta(\mathcal{H}+p V)\} d V d \mathbf{p}^{N} d \mathbf{r}^{N}},
$$

onde a média é realizada no ensemble NPT, conhecido também como ensemble das pressões. O valor médio dessa propriedade $\mathcal{A}$ na posição $r$, pode ser também obtido através de uma média temporal dada por:

$$
\overline{\mathcal{A}}=\lim _{t \rightarrow \infty} \frac{1}{t} \int_{0}^{t} d t^{\prime} \mathcal{A}\left(r ; t^{\prime}\right)
$$

onde a propriedade $\mathcal{A}(r ; t)$ pode ser obtida, através das equações de Newton, a partir de uma configuração inicial do sistema, dado pelas posições e momentos iniciais, $\mathbf{r}(\mathbf{0})^{N}$ e $\mathbf{p}(\mathbf{0})^{N}$ de todas as moléculas. Na equação 2.53. foi assumido implicitamente que, para tempo suficientemente longo, a média temporal não depende da condição inicial. Uma vez especificado o $N, P$ e $T$, e assumido que a média temporal não depende das posições e momentos iniciais, então o valor $\overline{\mathcal{A}}$ não mudará se realizar uma média sobre o conjunto formado por diferentes condições iniciais do sistema, ou seja,

$$
\overline{\mathcal{A}}=\frac{1}{N_{c}} \sum_{c_{i}}\left(\lim _{t \rightarrow \infty} \frac{1}{t} \int_{0}^{t} d t^{\prime} \mathcal{A}\left(r ; \mathbf{r}(\mathbf{0})^{N}, \mathbf{p}(\mathbf{0})^{N} ; t^{\prime}\right)\right),
$$

onde $N_{c}$ é o número de condições iniciais e $c_{i}$ corresponde a condição inicial.

No caso limite, a média sobre todas as condições inicial compatível com os valores impostos de $N, P$ e T, pode ser escrita, substituindo a soma sobre $c_{i}$ por uma integral, no espaço de configurações, ou melhor, no espaço de fase, formado pelas coordenadas do sistema $\mathbf{r}^{N}$ e $\mathbf{p}^{N}$. Portanto a equação 2.54, pode ser escrita da seguinte forma:

$$
\overline{\mathcal{A}}=\lim _{t \rightarrow \infty} \frac{1}{t} \int d t^{\prime}\left\langle\mathcal{A}\left(r ; \mathbf{r}(\mathbf{0})^{N}, \mathbf{p}(\mathbf{0})^{N} ; t^{\prime}\right)\right\rangle_{N P T},
$$

como a média sobre o ensemble não depende do tempo $t^{\prime}$, portanto a média sobre todas as condições iniciais no espaço de fase é equivalente à média temporal, ou seja,

$$
\overline{\mathcal{A}}=\langle\mathcal{A}\rangle_{N P T} .
$$


A equação 2.56 diz que, se desejarmos calcular a média de uma propriedade sobre um sistema de muitas partículas, essa média pode ser calculada através de duas metodologias diferentes: pode ser calculada através de uma média temporal, usando simulação de Dinâmica Molecular(MD), ou pode também ser obtida através de uma média sobre o ensemble, através de simulação Monte Carlo(MC). A equivalência entre os resultados obtidos dessas duas metodologias só ocorre para tempos longos, ou melhor, para simulações "infinitamente" longas, quando todo o espaço de configurações é visitado, ou seja, todas as configurações acessíveis pertencentes ao espaço de configurações são geradas pela simulação.

Apesar da equivalência entre os resultados obtidos dos métodos, Dinâmica Molecular e Monte Carlo, em estudos de sistemas moleculares, esses dois métodos são bem distintos. Sendo que a principal diferença entre eles é que, a MD é um método determinístico, apresenta as configurações do sistema organizadas cronologicamente. Enquanto no MC, as configurações são apresentadas numa ordem aleatória, e é um método puramente estocástico [105]. A vantagem da Dinâmica molecular em relação ao método Monte Carlo, é que a MD pode ser usada para estudar dependências temporais de propriedades de um sistema, enquanto o MC, esse estudo não é possível. Entretanto o Método Monte Carlo é mais "barato" computacionalmente e mais simples para implementação computacional. Neste trabalho realizamos simulações com moléculas flexíveis, utilizando o método de Dinâmica Molecular e com moléculas rígidas, utilizando o método Monte Carlo. Introduziremos a seguir esses dois métodos voltados para simulação em sistemas líquidos moleculares.

\subsubsection{Dinâmica Molecular(MD)}

A Dinâmica Molecular é uma técnica de simulação computacional que permite calcular propriedades clássicas de um sistema de muitas moléculas no estado de equilíbrio, onde o movimento dessas moléculas obedece às leis da mecânica clássica. Essa 
técnica assemelha bastante a um experimento real. Quando um experimental deseja realizar um experimento, ele procede da seguinte maneira: prepara a amostra do material que deseja estudar, depois através de um instrumento capaz de medir a propriedade de interesse, realiza as medidas dessa propriedade durante um certo intervalo de tempo. Como as medições estão sujeitos a um erro estatístico, se realiza uma média sobre as medidas obtidas, tornando-se a medida mais precisa. Na Dinâmica Molecular segue assemelhadamente assim: primeiramente, prepara a amostra, depois escolhe um sistema modelo, composto por $N$ moléculas e então resolve as equações de Newton para o movimento dessas moléculas até as propriedades do sistema já não mudar com o tempo, ou seja, até atingir o equilíbrio. Depois do equilíbrio calculam-se as propriedades que deseja obter.

Assim, realizar uma simulação de um sistema molecular através das técnicas da MD é necessário seguir um algoritmo, onde cada etapa do processo é realizada para um dado instante de tempo. Na figura 2.1 está uma ilustração de um algoritmo da Dinâmica Molecular de uma forma bem simplificado.

Para iniciar uma Dinâmica Molecular, o primeiro passo é gerar uma configuração inicial do sistema que se deseja estudar, com todas as posições e velocidades iniciais. As posições iniciais dos átomos devem ser escolhidas de tal forma, que sejam compatíveis com o sistema estudado, ou seja, de modo que a densidade numérica, $N / V$ corresponda com a densidade do sistema real para uma dada caixa inicial. Essa caixa é conhecida como a "caixa de simulação", e pode ser cúbica, ortorrômbica e etc. Afim de minimizar efeitos de fronteira, ou seja, efeitos de bordas, se emprega condições periódicas de contornos na caixa de simulação. Existem várias maneiras de escolher as velocidades iniciais, uma forma comum em simulação é através de uma distribuição de MaxwellBoltzmann em que a energia cinética do sistema é determinada pela temperatura 


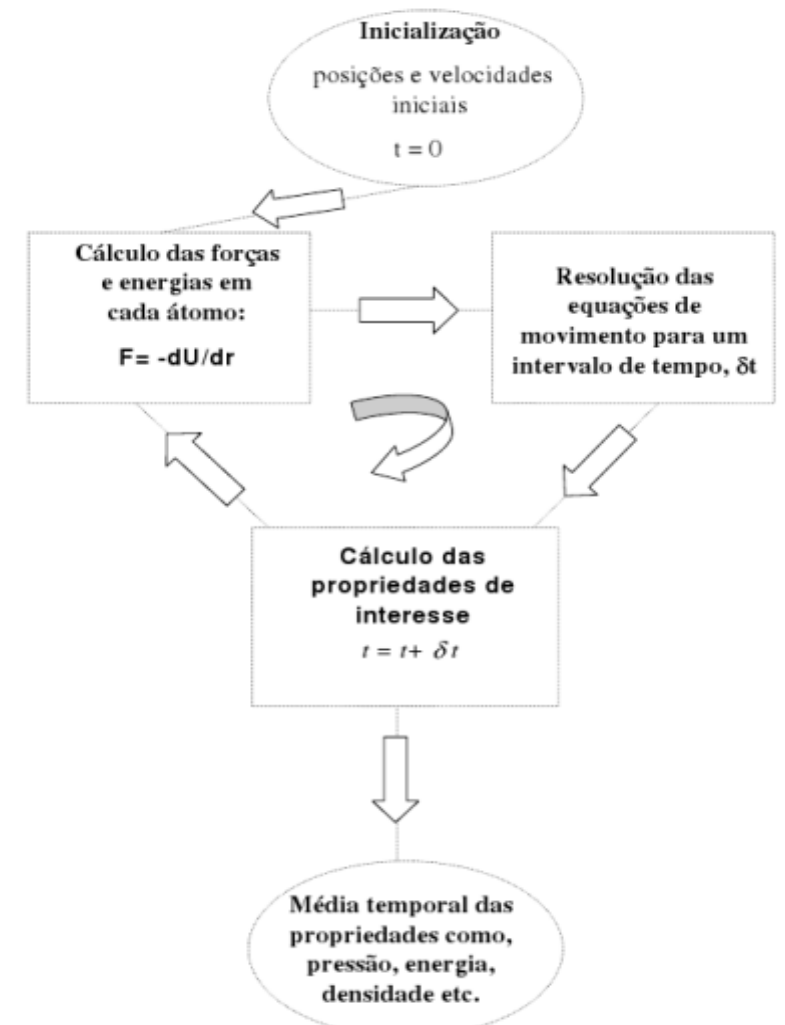

Figura 2.1: Ilustração do algoritmo da Dinâmica Molecular

especificada:

$$
\frac{3}{2} N k_{B} T=\frac{1}{2} \sum_{i=1}^{N} m_{i} v_{i}^{2},
$$

onde $N$ é o número de átomos, e $m_{i}$ e $v_{i}$ são a massa e a velocidade do átomo $i$, respectivamente. Essa equação é também usada para definir a temperatura instantânea para um instante de tempo $t$, onde $t>t_{0}$, para uma nova velocidade $v_{i}(t)$.

Definido as condições iniciais da simulação, o próximo passo é calcular a força que atua sobre cada átomo da molécula em um instante de tempo $t$, através da equação dada por:

$$
f_{i}(t)=-\frac{\partial \mathcal{U}\left(r_{i}\right)}{\partial r_{i}}
$$

onde $\mathcal{U}\left(r_{i}\right)$ corresponde ao potencial de interação entre os átomos, que é formado por 
um termo de interação intermolecular e intramolecular, que serão discutido na subseção 2.3.3. Uma vez definido o potencial de interação, se calcula, portanto as forças em cada átomo.

Determinado a força em cada átomo, o próximo passo é determinar as posições e velocidades para um instante de tempo $t$, onde $t>t_{0}$. Esse passo é realizado através da resolução das equações diferenciais de movimento, que governa o sistema sob ação do potencial de interação entre os átomos do sistema. Usando equação 2.58, é possível obter, a partir das posições e velocidades iniciais, as posições dos átomos em qualquer instante de tempo, através da resolução das equações de movimento de Newton dada por:

$$
m_{i} \ddot{r}_{i}+\nabla_{i} \mathcal{U}\left(r^{N}\right)=0 .
$$

A solução dessas equações é realizada através de métodos de diferenças finitas. Atualmente, existem na literatura diversos métodos de integração para resolver essas equações diferenciais. Neste trabalho, usamos o algoritmo de Verlet $[49,104,106]$ para resolver essas equações implementado no programa TINKER. Este algoritmo é obtido através da expansão de Taylor das coordenadas dos átomos, no instante de tempo $t$,

$$
r_{i}(t+\Delta t)=r_{i}(t)+v_{i}(t) \Delta t+\frac{f_{i}(t)}{2 m_{i}} \Delta t^{2}+\frac{\Delta t^{3}}{3 !} \dddot{r}_{i}+\mathcal{O}\left(\Delta t^{4}\right),
$$

e similarmente,

$$
r_{i}(t-\Delta t)=r_{i}(t)-v_{i}(t) \Delta t+\frac{f_{i}(t)}{2 m_{i}} \Delta t^{2}-\frac{\Delta t^{3}}{3 !} \dddot{r}_{i}+\mathcal{O}\left(\Delta t^{4}\right)
$$

somando as equações 2.60 e 2.61, se obtem,

$$
r_{i}(t+\Delta t)=2 r_{i}(t)-r_{i}(t-\Delta t)+\frac{f_{i}(t)}{2 m_{i}} \Delta t^{2}+\mathcal{O}\left(\Delta t^{4}\right)
$$

Esta nova posição contém um erro que é da ordem $\Delta t^{4}$, onde $\Delta t$ é intervalo de tempo da Dinâmica Molecular, que geralmente é da ordem de $1 \mathrm{fs}$. Como se observa na equação 2.62, o algoritmo de Verlet não utiliza a velocidade para calcular as novas 
posições dos átomos. No entanto, é possível obter a velocidade da trajetória usando a relação:

$$
v_{i}(t)=\frac{r_{i}(t+\Delta t)-r_{i}(t-\Delta t)}{2 \Delta t}+\mathcal{O}\left(\Delta t^{2}\right)
$$

onde a velocidade, $v_{i}(t)$ possui uma precisão da ordem de $\Delta t^{2}$, porém é possível obter uma velocidade com maior precisão através do algoritmo Verlet-velocidade [104,106].

Calculado as novas posições e velocidades, é gerada automaticamente uma nova configuração do sistema. Nessa nova configuração é realizado um cálculo das propriedades correntes como, temperatura, energia potencial, pressão, energia cinética, energia total, densidade, e etc. A energia total do sistema deve se conservar durante a simulação, ou seja, devem permanecer constantes durante o movimento, onde a soma das energias potencial e cinética do sistema é uma constante.

\subsubsection{Método Monte Carlo}

O método de Monte Carlo é uma técnica de simulação computacional que permite calcular integral, de forma numérica, através de amostragem aleatória. Essa técnica pode ser utilizada para resolver integrais do tipo da equação 2.52. Um exemplo é o calculo da função canônica de partição, $Z(T, V, T)$. Calcular analiticamente essa função para um sistema líquido molecular é inviável, devido ao potencial de interação, $\mathcal{U}$ entre as moléculas, sendo que o hamiltoniano do sistema é dado por $\mathcal{H}=\mathcal{K}+\mathcal{U}$, onde $\mathcal{K}$, corresponde ao termo cinético do sistema, que é resolvido analiticamente sem problemas, resultando a função canônica de partição na forma

$$
Z(T, V, N)=\frac{1}{N !}\left(\frac{2 \pi m}{\beta h^{2}}\right)^{3 N / 2} \int \exp \left\{-\beta \mathcal{U}\left(\mathbf{r}^{N}\right)\right\} d \mathbf{r}^{N}
$$

Portanto tomar o valor médio sobre o ensemble $N V T$, por exemplo de uma propriedade $\mathcal{A}$, será dado por

$$
\langle\mathcal{A}\rangle_{N V T}=\frac{\int \mathcal{A}\left(\mathbf{r}^{\mathcal{N}}\right) \exp \left\{-\beta \mathcal{U}\left(\mathbf{r}^{N}\right)\right\} d \mathbf{r}^{N}}{\int \exp \left\{-\beta \mathcal{U}\left(\mathbf{r}^{N}\right)\right\} d \mathbf{r}^{N}}
$$


Portanto um método de integração numérica, usando amostragens é uma ótima opção para calcular o valor médio da propriedade $\mathcal{A}$, para um dado modelo de potencial de interação. Entretanto, para sistema líquidos moleculares, é necessário uma quantidade enorme de configurações espaciais para se obter uma caracterização adequada do sistema, sendo, portanto inviável o cálculo da função de partição através desse método. Esse problema é contornado utilizando a amostragem de Metropolis e colaboradores [40], implementado no método Monte Carlo. A idéia da metodologia de Metropolis é selecionar configurações do sistema de modo probabilístico com um peso estatístico coerente energeticamente, dado pela distribuição de Boltzmann [107]. Como a densidade de probabilidade de encontrar o sistema numa configuração em torno de $\mathbf{r}^{N}$ é dada por:

$$
\mathcal{N}\left(\mathbf{r}^{N}\right)=\frac{\exp \left\{-\beta \mathcal{U}\left(\mathbf{r}^{N}\right)\right\}}{\int \exp \left\{-\beta \mathcal{U}\left(\mathbf{r}^{N}\right)\right\} d \mathbf{r}^{N}}
$$

A idéia agora é gerar aleatoriamente pontos no espaço de configurações de acordo com esta distribuição de probabilidade $\mathcal{N}\left(\mathbf{r}^{N}\right)$. Isto significa que, em média, o número de pontos $n_{i}$ gerados por unidade de volume em torno da configuração, $\mathcal{N}\left(\mathbf{r}^{N}\right)$, é igual a $L \mathcal{N}\left(\mathbf{r}^{N}\right)$, onde $L$ é o número total de pontos gerados aleatoriamente. Portanto a integral da equação 2.65. pode ser calculada numericamente através de uma aproximação por uma soma efetuada sobre o número de pontos gerados,

$$
\langle\mathcal{A}\rangle \approx \frac{1}{L} \sum_{i=1}^{L} n_{i} \mathcal{A}\left(\Gamma_{i}\right) .
$$

Portanto para obter o valor de $\langle\mathcal{A}\rangle$, usando a equação 2.66, não será necessário calcular a função canônica de partição, porém se deve conhecer o fator de Boltzmann, $\exp \left\{-\beta \mathcal{U}\left(\mathbf{r}^{N}\right)\right\}$. Para gerar uma nova configuração do sistema, $\mathbf{r}^{\prime N}$, adiciona-se um pequeno deslocamento, $\Delta_{\mathrm{r}^{N}}$, aleatório na configuração $\mathbf{r}^{N}$, onde o fator de Boltzmann, para esta nova configuração será, $\exp \left\{-\beta \mathcal{U}\left(\mathbf{r}^{\prime N}\right)\right\}$. A configuração $\mathbf{r}^{N}$, que é a configuração old, será chamada de $o$ e a configuração $\mathbf{r}^{\prime N}$, que é a configuração new, será chamada de $n$. A decisão se aceita ou rejeita a nova configuração é tomada com base 
na metodologia de Metropolis [40], onde é inserido uma probabilidade de transição $\pi(o \rightarrow n)$, do sistema sair de uma configuração $o$ para $n$. No equilíbrio é conveniente impor que o número médio de configurações aceitas do sistema sair de uma configuração $o$ para $n$ é exatamente igual o número médio da ocorrência inversa, ou seja, $n$ para $o$.

$$
\mathcal{N}(o) \pi(o \rightarrow n)=\mathcal{N}(n) \pi(n \rightarrow o)
$$

Existem muitas formas possíveis da matriz de transição, $\pi(o \rightarrow n)$ satisfazer a equação 2.68. Na prática, o que se faz é gerar uma cadeia de Markov, onde a matriz de Markov, $\alpha(o \rightarrow n)$, determina a probabilidade de realizar um pequeno deslocamento da configuração $o$ para $n$. Portanto a probabilidade de transição, $\pi(o \rightarrow n)$, será dada por:

$$
\pi(o \rightarrow n)=\alpha(o \rightarrow n) \gamma(o \rightarrow n)
$$

onde $\gamma(o \rightarrow n)$ é a probabilidade de aceitação do pequeno deslocamento da configuração $o$ para $n$. Na metodologia de Metropolis, a matriz $\alpha$ é escolhida de tal forma que seja simétrica, ou seja, $\{\alpha(o \rightarrow n)=\alpha(n \rightarrow o)\}$. Se a matriz $\alpha$ é simétrica, então a equação 2.68, pode ser escrita da seguinte forma,

$$
\mathcal{N}(o) \gamma(o \rightarrow n)=\mathcal{N}(n) \gamma(n \rightarrow o)
$$

onde a equação 2.70, pode ser escrita da forma,

$$
\frac{\gamma(o \rightarrow n)}{\gamma(n \rightarrow o)}=\frac{\mathcal{N}(n)}{\mathcal{N}(o)}=\exp \{-\beta[\mathcal{U}(n)-\mathcal{U}(o)]\}
$$

Existem outras formas de escolher a probabilidade de aceitação, $\gamma(o \rightarrow n)$, tal que satisfaça a equação 2.71, uma condição óbvia é que $\gamma(o \rightarrow n) \leqslant 1$. Na metodologia de Metropolis, $\gamma(o \rightarrow n)$ é dada por:

$$
\gamma(o \rightarrow n)=\left\{\begin{array}{cl}
\frac{\mathcal{N}(n)}{\mathcal{N}(o)}, & \text { se } \mathcal{N}(n)<\mathcal{N}(o) \\
1, & \text { se } \mathcal{N}(n) \geqslant \mathcal{N}(o)
\end{array}\right.
$$


Existem outras formas de escolher a probabilidade $\gamma(o \rightarrow n)$ [49], mas a forma mais usual é através da escolha de Metropolis. Usando a equação 2.72, a probabilidade de transição pode ser escrita da seguinte forma:

$$
\begin{aligned}
& \pi(o \rightarrow n)=\left\{\begin{array}{cc}
\alpha(o \rightarrow n), & \text { se } \mathcal{N}(n) \geqslant \mathcal{N}(o) \\
\alpha(o \rightarrow n) \frac{\mathcal{N}(n)}{\mathcal{N}(o)}, & \text { se } \mathcal{N}(n)<\mathcal{N}(o)
\end{array}\right. \\
& \pi(o \rightarrow o)=1-\sum_{n \neq 0} \pi(o \rightarrow n),
\end{aligned}
$$

onde a matriz, $\alpha$ é simétrica e geralmente considerada $\alpha(o \rightarrow n)=1$.

O procedimento para decidir se aceita ou rejeita o deslocamento de um estado $o$ para $n$, é dado da seguinte forma: suponha que é realizado um pequeno deslocamento de um estado $o$ para $n$, onde $\mathcal{U}(n)>\mathcal{U}(o)$. Usando as equação 2.71, a probabilidade de aceitar esse deslocamento é dada por:

$$
\gamma(o \rightarrow n)=\exp \{-\beta[\mathcal{U}(n)-\mathcal{U}(o)]\}<1
$$

Portanto, para decidir se aceita ou rejeita o deslocamento, é gerado um número aleatório $\xi$, através de um gerador de números aleatório, a partir de uma distribuição uniforme no intervalo [0,1]. Obviamente, a probabilidade de que $\xi$ seja inferior a $\gamma(o \rightarrow n)$ é igual a própria probabilidade de aceitação, $\gamma(o \rightarrow n)$. Portanto o deslocamento só é aceito se $\xi<\gamma(o \rightarrow n)$, e rejeitado se $\xi \geqslant \gamma(o \rightarrow n)$. Essa regra garante que a probabilidade de aceitar um pequeno deslocamento de um estado $o$ para $n$ seja realmente igual a $\gamma(o \rightarrow n)$. Uma consideração importante, é que o gerador de números aleatórios escolhido, deve gerar números uniformemente no intervalo [0,1], a fim de garantir amostragens mais representativas do sistemas, com isso mais eficiência no método Monte Carlo. 


\subsubsection{O algoritmo}

Neste trabalho, utilizamos o programa DICE [108], para realizar simulações de sistemas líquidos moleculares, através de técnicas de Monte Carlo. Nesse programa a metodologia de metropolis é utilizada para gerar novas configurações do sistema. O algoritmo implementado no progrma DICE seguiu o seguinte esquema:

1. Inicialização: Gera-se, uma configuração inicial do sistema, aleatório ou ordenada, dentro de uma caixa retangular com o volume dado através da densidade inicial fornecida do sistema. Depois, replica-se essa caixa em todas as direções, impondo condições de contorno periódicas [49], a fim de eliminar os efeitos de borda.

2. Nova configuração: Na configuração atual, seleciona-se uma molécula aleatoriamente, e calcula a sua energia $\mathcal{U}\left(\mathbf{r}^{N}\right)$. Portanto é gerada uma nova configuração, realizando um pequeno deslocamento aleatório na molécula dado por , $\mathbf{r}^{\prime}=\mathbf{r}+\Delta_{\mathbf{r}}$, e é calculada a nova energia $\mathcal{U}\left(\mathbf{r}^{\prime N}\right)$.

3. Aceitação ou rejeição da nova configuração: Apartir da nova configuração é calculada a diferença de energia, dada por:

$$
\Delta \mathcal{U}=\mathcal{U}\left(\mathbf{r}^{\prime N}\right)-\mathcal{U}\left(\mathbf{r}^{N}\right)
$$

Se $\Delta \mathcal{U} \leqslant 0$, então, essa nova configuração é aceita. Caso contrário, ou seja, se $\Delta \mathcal{U}>0$, é gerado um número aleatório $\xi$, a partir de uma distribuição uniforme no intervalo $[0,1]$. Se $\xi \leqslant \exp \{-\beta \Delta \mathcal{U}\}$, essa nova configuração é aceita, caso contrário, essa nova configuração é rejeitada.

4. Cálculo das propriedades termodinâmicas: Em cima da nova configuração do sistema é realizado um cálculo de algumas grandezas como energia interna, primeiro virial, segundo virial $[49,104]$. Realizado esse calculo, são acumulados 
esses valores para a média, e rotorna-se para a etapa 2 do processo. Esse cálculo marca o encerramento de um passo de monte Carlo. No final da simulação é utilizado o valor acumulado para o calculo das propriedades termodinâmicas, tal como, calor específico a volume ou pressão constante, compressibilidade isotérmica, etc.

\subsubsection{Potencial de interação molecular}

Um dos maiores desafios na realização de uma simulação em sistemas líquidos moleculares é a escolha do potencial de interação $\mathcal{U}\left(\mathbf{r}^{N}\right)$. Tanto para Dinâmica Molecular como para método Monte Carlo, essa escolha é feita através de um campo de força, onde esse é caracterizado por seu potencial de interação e pelos parâmetros usado nas equações desse potencial. Em sistemas líquidos esse potencial de interação é dividido em duas partes: intramolecular ("para átomos ligados") e intermolecular ("para átomos não ligados").

Nos métodos MD e MC, o potencial de interação representa uma parte essencial na descrição do sistema, uma vez que, para realização de uma Dinâmica Molecular, os potenciais de interação intramoleculares e intermoleculares determinam as forças que atuam em cada molécula e conseqüentemente, determinam a evolução do sistema no tempo, através das equações de Newton. Já para realização de uma simulação com o método de Monte Carlo, com as moléculas consideradas rígidas durante a simulação, se utiliza apenas o potencial de interação intermolecular, com esse potencial, determina as novas configurações favoráveis energicamente do sistema em estudo.

\subsubsection{Potencial intramolecular}

O potencial intramolecular descreve as mudanças geométricas ou distorções moleculares. Esse potencial é representado por uma soma dos três termos correspondente 
as deformações na ligação, nos angulos e nos diedros dado por:

$$
\mathcal{U}_{\text {intra }}=\underbrace{\sum \mathcal{U}_{\text {ligação }}+\sum \mathcal{U}_{\text {angular }}+\sum \mathcal{U}_{\text {torção }}}_{\text {átomos ligados }}+\underbrace{\mathcal{U}_{L J}+\mathcal{U}_{C}}_{\text {atomos não ligados }}
$$

onde o termo $\mathcal{U}_{\text {ligação, }}$, corresponde ao estiramento de uma ligação química, e $\mathcal{U}_{\text {angular }}$ e $\mathcal{U}_{\text {torção }}$, correspondem as deformações angulares e diedrais, respectivamente. Os termos $\mathcal{U}_{L J}$ e $\mathcal{U}_{C}$, correspondem ao potencial de Lennard-Jones(LJ) [49] e Coulomb, respectivamente. Cada termo desses é dado por:

$$
\begin{gathered}
\mathcal{U}_{\text {ligação }}=\frac{1}{2} k_{i j}^{r}\left(r_{i j}-r_{e q}\right)^{2} \\
\mathcal{U}_{\text {angular }}=\frac{1}{2} k_{i j k}^{\theta}\left(\theta_{i j k}-\theta_{e q}\right)^{2} \\
\mathcal{U}_{\text {torção }}=\sum_{n} \frac{\mathcal{U}_{n}}{2}\left[1+\cos \left(n \psi_{i j k l}-\gamma\right)\right] .
\end{gathered}
$$
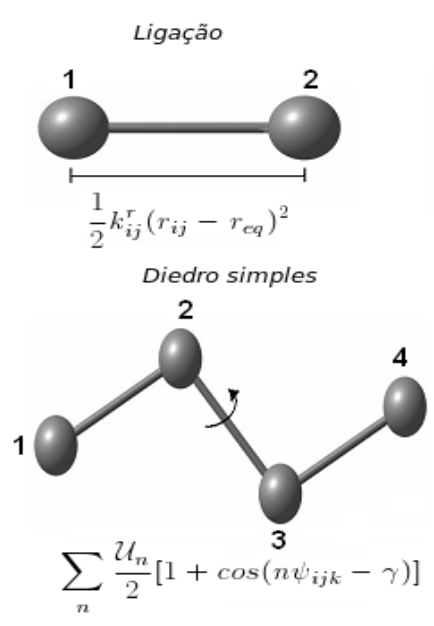
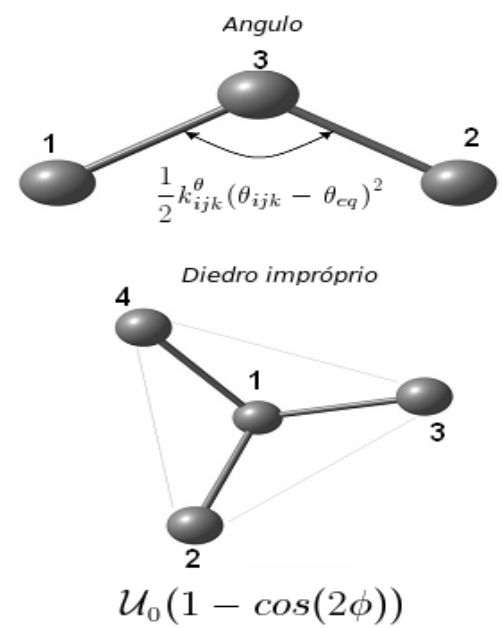

Figura 2.2: Ilustração dos termos do potencial de interação intramolecular mostrado na equação 2.76 .

Na figura 2.2, ilustramos os três termos do potencial intramolecular. O desenho com 2 átomos, o primeiro a esquerda, representa o termo correspondente a vibração 


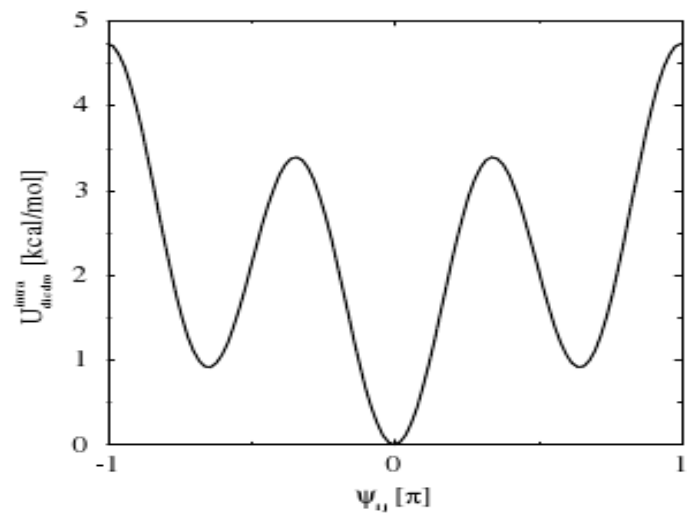

Figura 2.3: Ilustração do potencial de torção intramolecular para o ângulo diedro da molécula de n-butano. Figura retirada da referência, [109].

na ligação química entre os átomos 1 e 2, que é representado por um potencial harmônico com posição de equilíbrio $r_{e q}$. O primeiro desenho à direita representa o termo correspondente a vibrações angulares entre os três átomos $1-2-3$ que é também representado por um potencial harmônico com ângulo de equilíbrio $\theta_{e q}$. O segundo desenho da esquerda, representa o termo da torção nos diedros simples que corresponde ao terceiro termo na equação 2.76, onde os átomos 1,2 e 3 estão ligados e fixos no plano do papel, enquanto o átomo 4 está livre para girar em torno do eixo definido pelos átomos 2 e 3. Como se pode ver na equação 2.79, esse potencial é representado por um termo contínuo em todo o intervalo de torção $[0,2 \pi]$, e é representado por uma expansão em série de Fourier. Na figura 2.3. está uma ilustração para esse potencial de torção para o ângulo diedro da molécula de n-butano. Dependendo do tipo dos quatros átomos envolvidos na torção, este potencial pode ser representado por uma série truncada em apenas um, dois ou uma série com três termos. No campo de força OPLS [110], essa expansão de três termos é implementada da seguinte forma,

$$
\mathcal{U}_{\text {torção }}\left(\phi_{i j k l}\right)=\mathcal{U}_{0}+\frac{1}{2}\left[\mathcal{U}_{1}(1+\cos (\phi))+\mathcal{U}_{2}(1-\cos (2 \phi))+\mathcal{U}_{3}(1+\cos (3 \phi))\right] .
$$

onde $\phi=\psi-\psi_{0}$. 
Existem outros termos que contribuem para o potencial intramolecular, como, por exemplo, o termo que descrevem as deformações dos ângulos impróprios, ver figura 2.2. O termo correspondente a esses ângulos é utilizado para manter os grupos planos no seu devido plano (por exemplo: anéis aromáticos) ou para prevenir que as moléculas deformem-se em suas imagens espectrais. Esse potencial é dado pela seguinte equação,

$$
\mathcal{U}_{\text {impróprio }}=\mathcal{U}_{0}(1-\cos (2 \phi)) \text {. }
$$

Outros termos que contribuem para o potencial intramolecular são os potenciais especiais. Esses são usados para impor restrições no movimento do sistema, tanto para evitar desvios desastrosos ou para incluir conhecimento de dados experimentais. Esses potenciais correspondem a restrições na posição, nos ângulos, nas distâncias e nas orientações.

\subsubsection{Potencial intermolecular}

O potencial intermolecular descreve as interações entre as moléculas do sistema. Esse potencial entre duas moléculas pode ser dado por uma soma de interações entre cada par de átomos, onde essas interações dependem apenas da distância que separa estes átomos. Na figura 2.4, está ilustrado um modelo de potencial de interação entre duas moléculas $a$ e $b$. O potencial de interação intermolecular entre essas duas moléculas é dado pela soma das interações entre cada par de átomos destas moléculas, que é descrito da seguinte forma:

$$
\mathcal{U}_{\text {inter }}^{a b}=\sum_{i} \sum_{j} \mathcal{U}_{i j}\left(r_{i j}\right)
$$

onde cada par de átomos $i$ e $j$, pertence as moléculas $a$ e $b$, respectivamente e $r_{i j}$ corresponde a distância entre os átomos $i$ e $j$. O potencial intermolecular, $\mathcal{U}_{i j}\left(r_{i j}\right)$ mais usado na descrição do sistema em fase líquida é o potencial de Lennard-Jones(LJ) [49], acrescido do termo correspondente às interações eletrostáticas entre cada par de 


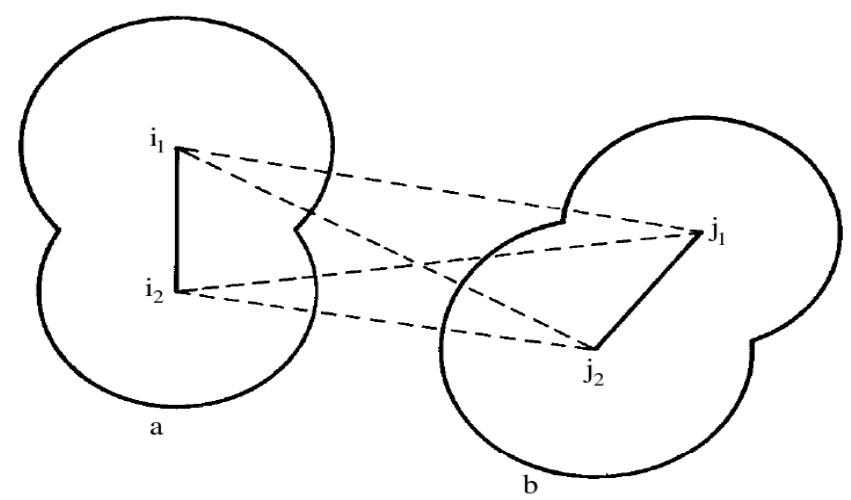

Figura 2.4: Ilustração da interação entre duas moléculas com dois sitios cada. O potencial entre a e b é composto pelos quatro termos; $i_{1} j_{1}, i_{1} j_{2}, i_{2} j_{1}$ e $i_{2} j_{2}$. Figura retirada da referência, [49]

átomos.

$$
\mathcal{U}_{i j}\left(r_{i j}\right)=\mathcal{U}_{L J}\left(r_{i j}\right)+\mathcal{U}_{c}\left(r_{i j}\right)
$$

O potencial LJ é representado da seguinte forma:

$$
\mathcal{U}_{L J}\left(r_{i j}\right)=4 \epsilon_{i j}\left(\left(\frac{\sigma_{i j}}{r_{i j}}\right)^{12}-\left(\frac{\sigma_{i j}}{r_{i j}}\right)^{6}\right),
$$

onde $\epsilon_{i j}$ e $\sigma_{i j}$, correspondem aos parâmetros de energia de ligação e o diâmetro de Lennard-Jones, respectivamente, e $r_{i j}$ é distância de separação entre os dois átomos $i$ e $j$ de moléculas distintas. Alguns campo de força, entre eles o OPLS, que está implementado no programa DICE, define os parâmetros, $\epsilon_{i j}$ e $\sigma_{i j}$, através do critério geométrico, dado por:

$$
\epsilon_{i j}=\sqrt{\epsilon_{i i} \epsilon_{j j}} \quad \text { e } \quad \sigma_{i j}=\sqrt{\sigma_{i i} \sigma_{j j}} .
$$

O potencial de Lennard-Jones é formado por dois termos, como pode ser visto na equação 2.84 um atrativo, e outro repulsivo. O termo atrativo a grande distância, $\left(\frac{1}{r}\right)^{6}$ , é devido a correlação entre as nuvens eletrônica dos átomos. Esse termo é conhecido como interação de van der Waals. O termo repulsivo, $\left(\frac{1}{r}\right)^{12}$, domina o potencial de LJ, apenas para curtas distâncias, e é causado pelo princípio de exclusão de Pauli. 
O termo do potencial de interação de Coulomb entre dois átomos carregados é dado por:

$$
\mathcal{U}_{c}\left(r_{i j}\right)=\frac{q_{i} q_{j}}{4 \pi \varepsilon_{0} r_{i j}}
$$

onde $q_{i}$ e $q_{j}$ correspondem as cargas dos átomos e $i$ e $j$, respectivamente. Esse potencial descreve as interações eletrostáticas entre cada par de átomos. As cargas pontuais para representação do potencial de Coulomb são geralmente obtidas de cálculos ab initio, ou diretamente de um conjunto de parâmetros estabelecidos na literatura, conhecido como campo de força. Essa última opção não é uma boa recomendação, uma vez que, as cargas na maioria das vezes não podem ser transferidas, tal como, os parâmetros $\epsilon_{i j}$ e $\sigma_{i j}$, do potencial de Lennard-Jones. Apesar de ser mais usual obter os parâmetros LJ de um campo de força, esse procedimento deve ser realizado com cautela, uma vez que esses parâmetros são desenvolvidos para determinadas condições de pressão e temperatura.

\subsubsection{Cálculo da energia livre}

O estado termodinâmico de um sistema líquido molecular é definido através de poucos parâmetros, como o número de moléculas $N$, a pressão $P$ e temperatura $T$. O conjunto de configurações com esses mesmos parâmetros, representa um ensemble, no caso, o NPT. A energia livre para esse sistema pode ser da seguinte forma:

$$
G=-k_{B} T \ln [Y(N, P, T)]
$$

onde $Y(N, P, T)$ é função de partição nas variáveis $\mathrm{T}, \mathrm{P}$ e $\mathrm{N}$, e é dada por:

$$
Y(N, P, T)=\int_{V} \int_{\mathbf{p}^{N}} \int_{\mathbf{r}^{N}} \exp \{-\beta(\mathcal{H}+p V)\} d V d \mathbf{p}^{N} d \mathbf{r}^{N}
$$

Embora a energia livre possa ser obtida teoricamente de uma forma bem simples, a obtenção dessa grandeza através de simulação computacional é bem complicada. 
Neste trabalho, realizamos simulações com o método de Monte Carlo (MC) para calcular a energia livre de um sistema molecular. Em simulação com o método MC com amostragem de Metropolis, a dificuldade da obtenção da energia livre ainda preexiste. Isso porquê, na simulação com método MC, não se calcula a função de partição envolvida no processo. Vários trabalhos tem sido publicados na literatura com intuito de contornar esse problema, através de desenvolvimentos de métodos de calculos de energia livre em simulações computacionais [111-116]. Dentre as metodologias existentes na literatura, abordaremos a Teoria de Perturbação Termodinâmica, introduzido por Zwanzig [117].

O método perturbativo pode ser usado para calcular a diferença de energia livre $\Delta G$, entre dois sistemas $B$ e $A$, onde a diferença de energia para esses dois sistemas é dado por:

$$
\Delta \mathcal{H}=\mathcal{H}_{B}-\mathcal{H}_{A}
$$

Usando as equações 2.87 e 2.88, a diferença da energia livre entre $B$ e $A$, pode ser dada por:

$$
\begin{aligned}
\Delta G_{A B} & =G_{B}-G_{A}=-k_{B} T \ln \left(\frac{Y_{B}}{Y_{A}}\right) \\
& =-k_{B} T \ln \left[\frac{\int_{V} \int_{\mathbf{p}^{N}} \int_{\mathbf{r}^{N}} \exp \{-\beta \Delta \mathcal{H}\} \exp \left\{-\beta\left(\mathcal{H}_{A}+p V\right)\right\} d V d \mathbf{p}^{N} d \mathbf{r}^{N}}{\int_{V} \int_{\mathbf{p}^{N}} \int_{\mathbf{r}^{N}} \exp \left\{-\beta\left(\mathcal{H}_{A}+p V\right)\right\} d V d \mathbf{p}^{N} d \mathbf{r}^{N}}\right],
\end{aligned}
$$

onde foi introduzido no numerador da equação 2.90, o termo $\exp \left\{\beta \mathcal{H}_{A}\right\} \exp \left\{-\beta \mathcal{H}_{A}\right\}$, para obtenção da equação 2.91. Essa equação, como se pode observar, trata-se do valor esperado da grandeza $\exp \{-\beta \Delta \mathcal{H}\}$, sobre o ensemble NPT para o sistema $A$. Portando a equação 2.91, pode ser escrita da seguinte forma:

$$
\Delta G_{A B}=-k_{B} T \ln \langle\exp \{-\beta \Delta \mathcal{H}\}\rangle_{A}
$$

Na equação 2.92, o termo da energia cinética, que contribui para a energia livre, pode ser separado, e resolvido analiticamente. Na prática, é geralmente assumido que 
está contribuição para $\Delta G$, é muito pequena, e, portanto é ignorada no cálculo. Assim, o hamiltoniano, $\mathcal{H}\left(\mathbf{p}^{N}, \mathbf{r}^{N}\right)$ na equação mestra, reduz-se ao potencial de interação, $\mathcal{U}\left(\mathbf{r}^{N}\right)$, então a equação 2.92 , pode ser escrita como,

$$
\Delta G_{A B}=-k_{B} T \ln \langle\exp \{-\beta \Delta \mathcal{U}\}\rangle_{A}
$$

onde $\Delta \mathcal{U}=\mathcal{U}_{B}-\mathcal{U}_{A}$.

Definindo os dois pontos $A$ e $B$, a diferença de energia livre, entre esses dois pontos, pode ser obtida através do método Monte Carlo, calculando o valor esperado da grandeza, $\exp \{-\beta \Delta \mathcal{U}\}$. Na prática, o que se faz em simulações com métodos perturbativos, é definir uma série de pontos intermediários, entre os dois pontos conhecidos $A$ e $B$. Portanto, o potencial de interação, torna-se uma função de um novo parâmetro $\lambda$, que recebe valores discretos no intervalo de $[0,1]$, tal que,

$$
\mathcal{U}\left(\lambda=0, \mathbf{r}^{N}\right)=\mathcal{U}_{A}\left(\mathbf{r}^{N}\right) \quad, \quad \mathcal{U}\left(\lambda=1, \mathbf{r}^{N}\right)=\mathcal{U}_{B}\left(\mathbf{r}^{N}\right),
$$

onde o potencial $\mathcal{U}\left(\lambda, \mathbf{r}^{N}\right)$ é contínuo nas duas variáveis $\lambda$ e $\mathbf{r}^{N}$. A dependência do parâmetro $\lambda$ no potencial de interação, $\mathcal{U}(\lambda)$, pode ser imposta por várias maneiras. A forma mais simples, embora não necesariamente a melhor em termos de melhorar a convergência de $\Delta G$ na simulação, é dada por:

$$
\mathcal{U}(\lambda)=(1-\lambda) \mathcal{U}_{A}+\lambda \mathcal{U}_{B}
$$

onde $\mathcal{U}(\lambda)$, pode ser também interpretado como o i-ésimo estado intermediário do percurso de $A$ a $B$, mudando na equação 2.95, $\lambda$ por $\lambda_{i}$. Sendo assim, o estado anterior e posterior a $\mathcal{U}\left(\lambda_{i}\right)$ é dado por:

$$
\mathcal{U}\left(\lambda_{i+1}\right)=\mathcal{U}\left(\lambda_{i}+\delta \lambda_{i}\right) \quad, \quad \mathcal{U}\left(\lambda_{i-1}\right)=\mathcal{U}\left(\lambda_{i}-\delta \lambda_{i}\right)
$$

Fazendo $\lambda$ variar gradativamente no intervalo [0,1], o sistema sai do estado inical, $\mathcal{U}_{A}$, e gradualmente é transformado no estado final $\mathcal{U}_{B}$. Portanto a diferença energia 
livre total do processo é dada por:

$$
\Delta G_{t o t}=\sum_{i=1}^{M} \Delta G_{\left(\lambda_{i-1} \rightarrow \lambda_{i}\right)}
$$

Usando a equação 2.93 , pode-se escrever a diferença de energia livre, $\Delta G_{\lambda_{i-1} \rightarrow \lambda_{i}}$ como,

$$
\Delta G_{\left(\lambda_{i-1} \rightarrow \lambda_{i}\right)}=-k_{B} T \ln \left\langle\exp \left\{-\beta\left[\mathcal{U}\left(\lambda_{i}, \mathbf{r}^{N}\right)-\mathcal{U}\left(\lambda_{i-1}, \mathbf{r}^{N}\right)\right]\right\}\right\rangle_{\lambda_{i-1}}
$$

Portanto, a diferença de energia livre total é calculada através de uma soma de várias diferenças de energia livre intermediárias, $\Delta G_{\left(\lambda_{i-1} \rightarrow \lambda_{i}\right)}$. Para cada novo valor de $\lambda_{i}$, o potencial de interação, $\mathcal{U}\left(\lambda_{i}\right)$ sofre uma pequena perturbação, sendo portanto, necessário esperar o sistema a se reequilibrar ao novo potencial de interação, para poder realizar o acumulo de propriedades de interesse termodinâmica, tal como, energia livre, pressão, densidade, e etc. Assim, o procedimento para o cálculo da diferença de energia livre, do sistema sair de um estado $A$ para um $B$ é dado por:

1. Seleciona um valor de $\lambda_{i}$, com o potencial $\mathcal{U}\left(\lambda_{i}\right)$.

2. Permita que o sistema entre em equilíbrio, realiza o acumulo de $\Delta G$.

3. Realize um pequeno deslocamento no valor de $\lambda_{i}$, tal que, $\lambda_{i} \rightarrow \lambda_{i+1}$, volte ao passo 2 e repita tudo novamente até determinar o valor total da diferença de energia livre, do sistema sair de um estado $A$ para um $B$.

Portanto, a média sobre o ensemble é calculada por uma simples média sobre o números de deslocamento, $\lambda_{i} \rightarrow \lambda_{i+1}$,

$$
\Delta G_{t o t}=-k_{B} T \ln \left\{\frac{1}{M} \sum_{i=1}^{M} \exp \left\{-\beta \Delta \mathcal{U}\left(\mathbf{r}^{N}\right)\right\}\right\}
$$




\section{Capítulo 3}

\section{Resultados Experimentais}

\subsection{Introdução}

Neste capítulo apresentaremos e discutiremos nossas medidas do espectro eletrônico de absorção da emodina em água, clorofórmio e metanol. Todas as medidas do espectro foram realizadas na região do visível nas condições normais de pressão e temperatura em soluções ácida, alcalina e neutra.

\subsection{Material utilizado}

As medidas do espectro eletrônico de absorção da emodina foram realizadas num espectrofotômetro digital UV-Vis Varian Cary 50 Bio. Utilizamos papel indicador de $p H$ para verificar se a solução em análise era ácida ou alcalina. Utilizamos também tubos de ensaios, pipetas automáticas e cubetas de quartzo de caminho óptico de 1.0 $\mathrm{cm}$. As medidas do espectro UV-Vis foram realizadas nas amostras de emodina em água, clorofórmio e metanol, obtidas a partir de uma solução Stock de $20 \mathrm{mM}$ de emodina. 


\subsection{Preparação das soluções}

A partir da solução Stock, preparamos diferentes soluções, (ácida e alcalina), de emodina para os solventes água e metanol numa concentração de 0.1mM. Para garantir a acidez e basicidade das soluções, adicionamos ácido clorídrico $(\mathrm{HCl})$ e hidróxido de sódio $(\mathrm{NaOH})$ nas soluções de emodina em água e metanol. Desse procedimento, resultou-se em 4 amostras, uma ácida e uma básica para cada solvente. Além dessas amostras, preparamos 3 amostras para os solventes água, clorofórmio e metanol em solução neutra de emodina usando a mesma contração de $0.1 \mathrm{mM}$.

\subsection{Resultados e discussões}

A emodina é um composto de cor amarela, com baixa solubilidade em água, $<1$ $\mathrm{mg} / \mathrm{mL}$ a $19^{\circ} \mathrm{C}$ [23], mas solúvel em metanol e clorofórmio (em concordância com a literatura [22,25]). Entretanto, verificamos que a emodina é solúvel em solução aquosa alcalina e insolúvel em solução aquosa ácida.

Levamos em conta algumas considerações encontrada na literatura [22,25], descritas no capítulo de introdução, onde mostra que a emodina em solução de etanol-água à temperatura ambiente sofre processo de desprotonação. Sendo que em solução ácida, encontra-se a emodina neutra, EM, em solução alcalina, encontra-se a emodina na forma desprotonada, EMdp e em solução neutra, encontra-se uma mistura de ambas formas, EM+EMdp.

Os resultados das medidas do espectro eletrônico de absorção da emodina estão mostrados na figuras 3.1 e 3.2, e tabela 3.1. Na figura 3.1, está mostrado o gráfico do espectro eletrônico de absorção da molécula de emodina em metanol. Nessa figura, são identificadas 3 bandas, uma na região de 16 a $28 \times 10^{3} \mathrm{~cm}^{-1}$, outra de 28 a $36 \times 10^{3} \mathrm{~cm}^{-1}$, e a outra a partir de $36 \times 10^{3} \mathrm{~cm}^{-1}$. Nessa figura pode-se observar que a mudança de $p H$ da solução, desloca muito as bandas na região de menor energia, onde a medida 


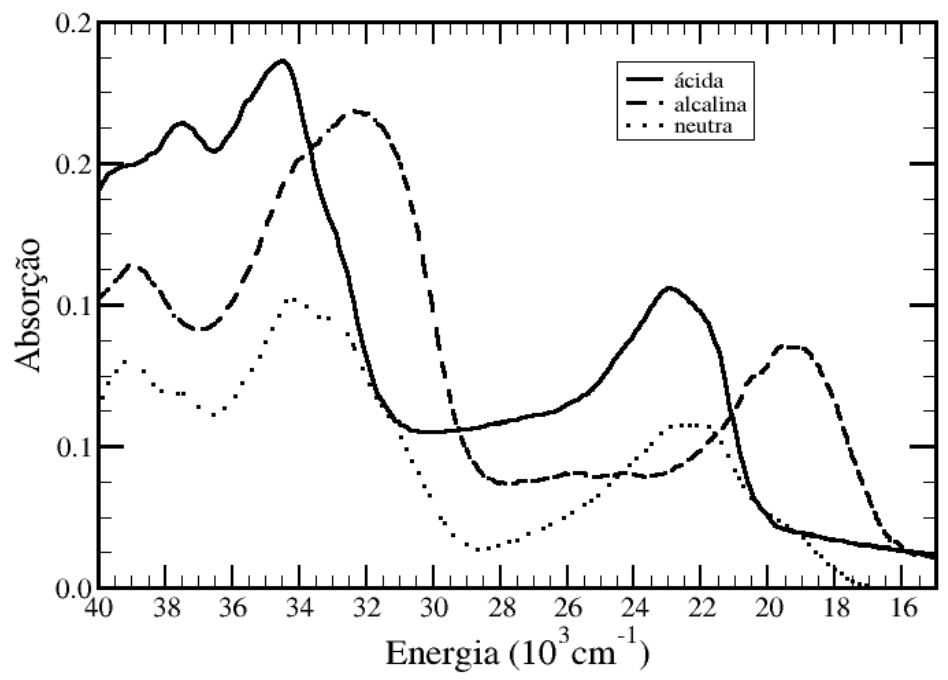

Figura 3.1: Gráfico do espectro eletrônico de absorção da molécula emodina em solução metanol na forma ácida (EM), alcalina (EMdp) e neutra (EM+EMdp), na concentração de $0.1 m M$

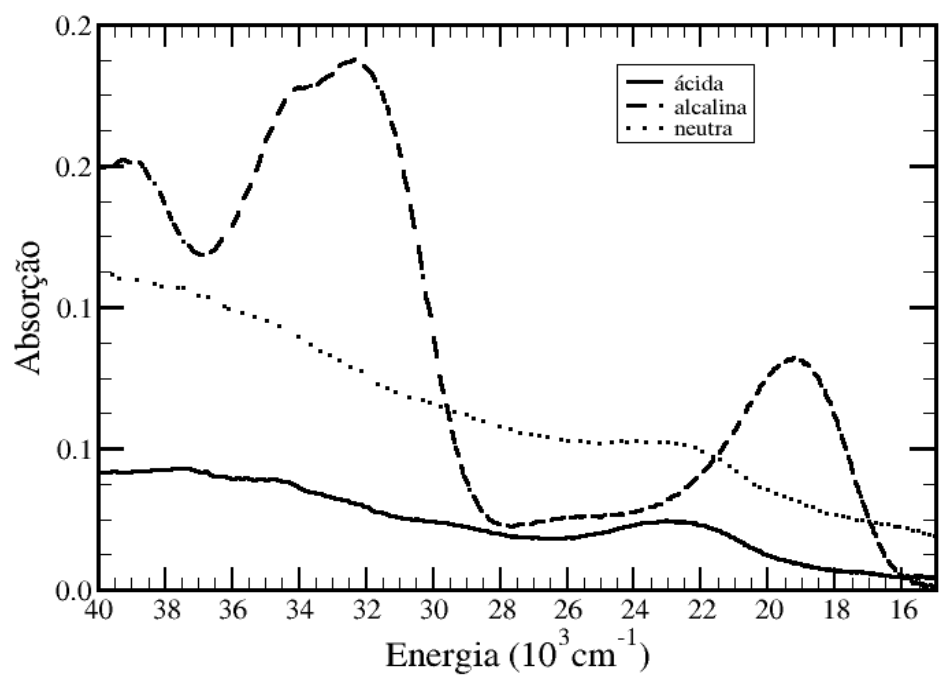

Figura 3.2: Gráfico do espectro eletrônico de absorção da molécula de emodina em solução aquosa na forma ácida (EM), alcalina (EMdp) e neutra (EM+EMdp), na concentração de $0.1 \mathrm{~m} M$. 
que o $p H$ aumenta, a energia tende, $E_{\text {acida }}^{\text {transicôes }}>E_{\text {neutra }}^{\text {transões }}>E_{\text {alcalina }}^{\text {transés }}$. Já a relação de intensidade não segue nenhuma relação com o $p H$. A solução ácida apresenta maior absorbância, depois vem a alcalina e por último com menor absorbância a neutra.

Na figura 3.2, está ilustrado o gráfico do espectro eletrônico de absorção da molécula de emodina em água. Nesse solvente, as três bandas estão localizadas na região de 16 a $26 \times 10^{3} \mathrm{~cm}^{-1}$, outra 26 a $36 \times 10^{3} \mathrm{~cm}^{-1}$, e a última a partir de $36 \times 10^{3} \mathrm{~cm}^{-1}$. A mudança de $p H$ da solução, provocou um deslocamento nas bandas, com a mesma tendência que em metanol. Nessa figura, pode observa-se que, em $p H$ neutro e ácido,

Tabela 3.1: Valores medidos para os máximos das bandas do espectro eletrônico de absorção da emodina em solução na forma ácida, alcalina (água e metanol) e neutra (água, metanol e clorofórmio), em $10^{3} \mathrm{~cm}^{-1}$. Em parênteses os valores são apresentados em $n m$.

\begin{tabular}{|c|c|c|c|c|}
\hline solução & bandas & água & metanol & clorofórmio \\
\hline \multirow{3}{*}{ ácida } & $1^{\mathrm{o}}$ & $23.0(434)$ & $22.9(436)$ & --- \\
\hline & $2^{\mathrm{o}}$ & --- & $34.5(290)$ & --- \\
\hline & $3^{\circ}$ & $37.6(266)$ & $37.4(267)$ & --- \\
\hline \multirow{3}{*}{ alcalina } & $1^{\mathrm{o}}$ & $19.2(520)$ & $19.5(513)$ & $-\ldots$ \\
\hline & $2^{\circ}$ & $32.4(309)$ & $32.4(309)$ & 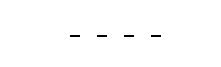 \\
\hline & $3^{\circ}$ & $38.9(257)$ & $39.1(256)$ & --- \\
\hline \multirow{3}{*}{ neutra } & $1^{\circ}$ & $23.0(434)$ & $22.7(440)$ & $22.6(442)$ \\
\hline & $2^{\circ}$ & --- & $34.0(294)$ & $34.5(290)$ \\
\hline & $3^{\circ}$ &.-- & $39.1(256)$ & $37.3(268)$ \\
\hline
\end{tabular}

existe uma grande diminuição da absorbância, sendo as bandas de menores energias, ou seja, maiores comprimentos de onda, são as mais afetadas. Esse comportamento é característico do espalhamento de luz e isso indica que houve uma agregação das 
moléculas de emodina nessas soluções, mesmo não tendo sido observado nenhuma precipitação.

Na tabela 3.1, mostramos os valores medidos para os máximos das bandas do espectro eletrônico de absorção da emodina em água, metanol e clorofórmio. Em solução aquosa e metanol com diferentes acidez (ácida, alcalina e neutra), os deslocamentos nas bandas do espectro eletrônico de absorção, ocorre devido ao processo de desprotonação da emodina, compare a figura 1.3 com as figuras $3.1 \mathrm{e} 3.2$.

Uma análise coerente desses resultados é obtida, através da análise separada do espectro eletrônico de absorção da emodina em solução ácida e alcalina. Sendo em solução ácida, analisamos a EM e em solução alcalina a EMdp. Essas bandas, também foram observadas nos trabalhos de Nguyen et al. [25], de Fain et al. [27] [29] e de Jacquemin et al. [28].

Em solução ácida de água e metanol, observamos nitidamente a $1^{\mathrm{a}}$ banda do espectro eletrônico de absorção da EM, com o máximo da banda em 23.0 e $22.9 \times 10^{3} \mathrm{~cm}^{-1}$ (434 e $436 \mathrm{~nm}$ ), respectivamente. Já em solução alcalina de água e metanol, identificamos a $1^{\text {a }}$ banda com o máximo em 19.2 e $19.5 \times 10^{3} \mathrm{~cm}^{-1}(520$ e $513 \mathrm{~nm})$, respectivamente, que está associado com a molécula EMdp. Esses resultados estão em boa concordância com os valores de 22.9 e $22.5 \times 10^{3} \mathrm{~cm}^{-1}$ (436.7 e $444.4 \mathrm{~nm}$ ), medidos por Nguyen et al. [25], para EM em solução água-etanol e num polímero de PVA, respectivamente, e 19.8 e $19.8 \times 10^{3} \mathrm{~cm}^{-1}$ (505.0 e $505.0 \mathrm{~nm}$ ), para EMdp respectivamente. A dificuldade em identificar os máximos da $2^{\text {a }}$ e $3^{\text {a }}$ banda do espectro eletrônico de absorção da emodina, em solução aquosa ácida e neutra, é devido a agregação dessa molécula.

Em clorofórmio a medida foi realizada apenas em solução neutra, o resultado está mostrado na tabela 3.1 e na figura 3.3. Analisando os valores medidos para os máximos das 3 bandas do espectro eletrônico de absorção da emodina em clorofórmio, observamos que esses 3 valores estão em boa concordância com os valores dos máximos 
das bandas medidos em solução ácida para água e metanol.

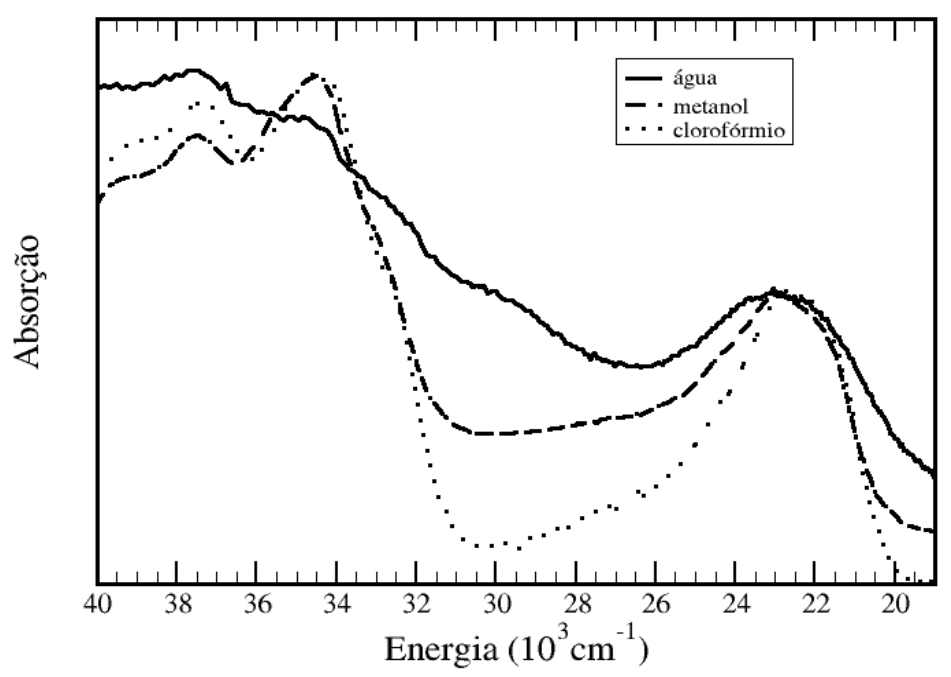

Figura 3.3: Gráfico do espectro eletrônico de absorção da EM em água, clorofórmio e metanol, na concentraçấo de $0.1 n M$, normalizado pela intensidade da $1^{a}$ banda.

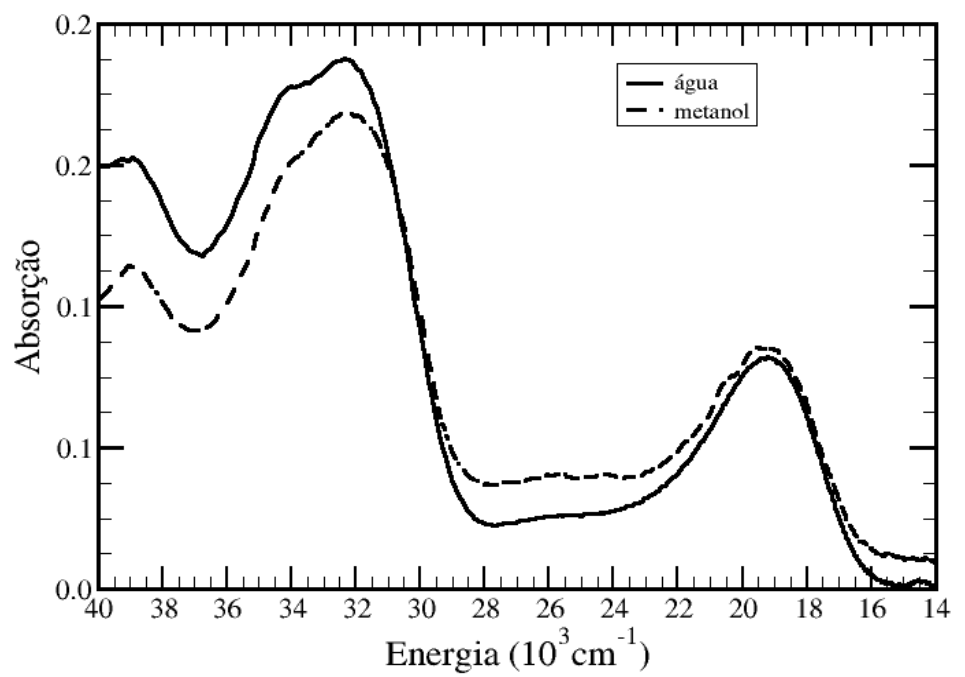

Figura 3.4: Gráfico do espectro eletrônico de absorção da EMdp em água e metanol, na concentração de $0.1 n M$. 
Nas figuras 3.3 e 3.4, estão mostrados, separadamente os gráficos do espectro eletrônico de absorção da EM e EMddp, respectivamente. Na figura 3.3, o gráfico está normalizado pela intensidades de absorção da $1^{\text {a }}$ banda da emodina em aproximadamente $22.5 \times 10^{3} \mathrm{~cm}^{-1}$. Analisando a figura 3.3 , observamos que o solvente provoca pouco efeito nos deslocamentos das bandas, para a emodina neutra. Os deslocamentos observados para os máximos da $1^{\mathrm{a}}, 2^{\mathrm{a}}$ e $3^{\mathrm{a}}$ bandas foram de 417, 11 e $140.0 \mathrm{~cm}^{-1}(\mathrm{~nm})$ $(8.0,0.1$ e $1.0 \mathrm{~nm})$. Na figura 3.4 , observamos também que o solvente provoca pouco efeito nos deslocamentos das bandas para a emodina desprotonada. Os deslocamentos para os máximos da $1^{\mathrm{a}}, 2^{\mathrm{a}}$ e $3^{\mathrm{a}}$ bandas foram de 262,0 e $152.0 \mathrm{~cm}^{-1}(\mathrm{~nm})(7.0,0.0$ e 1.0 $n m$ ). Porém comparando ambos gráficos, observamos que o efeito da desprotonação é bastante pronunciado e desloca a $1^{\text {a }}$ banda de $22.5 \times 10^{3} \mathrm{~cm}^{-1}(\mathbf{E M})$, para cerca de $19.5 \times 10^{3} \mathrm{~cm}^{-1}$ (EMdp). Isso totaliz um deslocamento de cerca de $-3000 \mathrm{~cm}^{-1}$, quando a molécula de emodina é desprotonada.

Esse deslocamento para menor energia (vermelho), está em concordância com a seguinte análise: retirando um $H^{+}$da molécula esperasse que os elétrons de valência ficassem menos ligados. Portanto para promover uma excitação para o $1^{\circ}$ estado excitado, esperasse uma menor gasto energético e, portanto isso acarretaria num deslocamento da banda para o vermelho.

Assim, apresentamos e discutimos nossas medidas do espectro de absorção da EM e EMdp. No entanto estamos interessados em estudar teoricamente, apenas a emodina neutra, ou seja, EM. Assim sendo, realizamos cálculos do espectro eletrônico de absorção da EM em fase gasosa, água, clorofórmio e metanol. Os resultados teóricos apresentaremos e discutiremos no capítulo 4. 


\section{Capítulo 4}

\section{Resultados e Discussões}

\subsection{Introdução}

Neste capítulo apresentaremos e discutiremos nossos resultados teóricos, obtidos do estudo da molécula emodina (EM) isoladamente e em solventes, (água, clorofórmio, metanol), através de cálculos quânticos e simulações clássicas. Todos os cálculos quânticos apresentados neste trabalho, foram realizados com os programas GAUSSIAN [118] e ZINDO [74]. E todas as simulações computacionais foram realizadas com o programa DICE [108], usando o método Monte Carlo e TINKER [119], usando o método de Dinâmica Molecular.

\subsection{Análise conformacional}

\subsubsection{Molécula isolada}

Existe um grande interesse tanto teórico como experimental em saber quais conformações, mais prováveis, uma determinada molécula se encontra no estado fundamental. Alguns trabalhos encontrados na literatura indicam que a conformação da emodina formando duas ligações de hidrogênio intramolecular é a conformação mais favorável energeticamente [25] [120]. Outros trabalhos levantam a hipótese 
que essa conformação da EM pode sofrer processos de tautomerização e desprotonação [25] [27] [26]. Como estamos interessados na EM, (ver a estrutura química e numeração dos átomos na figura 4.1), realizamos inicialmente um estudo teórico sistemático das propriedades estruturais dessa molécula isolada.

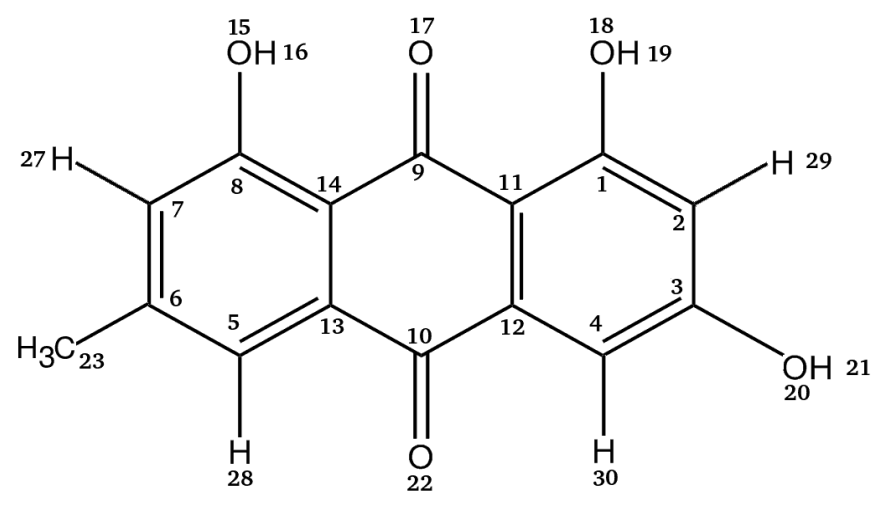

Figura 4.1: Estrutura química da molécula emodina

Nossa primeira abordagem neste trabalho, foi analisar o quão forte são as ligações de hidrogênio intramolecular da emodina em fase gasosa. Para tal estudo, otimizamos a geometria dessa molécula isolada com cálculos de mecânica quântica (QM), com método de cálculo de estrutura eletrônica B3LYP e a função de base 6-31G*.

Na tabela 4.1. listamos as distâncias atômicas da geometria otimizada da molécula emodina. Comparando os valores das distâncias atômica obtida com nível de cálculo B3LYP/6-31G*, com as distâncias atômicas extraída do trabalho de Nguyen e colaboradores [25], com nível B3LYP/6-31G(d,p), podemos observar que estão em boa concordância. Nessa geometria otimizada, o rotâmero da emodina se encontra na conformação formando duas ligações de hidrogênio intramolecular, ou seja, 2 HB (H16 e H19 com O17). Além desse rotâmero, otimizamos a geometria da emodina formando os seguintes rotâmeros: 1 HB - EM formando uma ligação de hidrogênio intramolecular (H16 com O17 ou H19 com O17). 0 HB - EM formando nenhuma ligação de hidrogênio. 1 HB TS - EM formando uma ligação de hidrogênio, (H16 
Tabela 4.1: Comparação das distâncias atômicas obtidas para a geometria otimizada da emodina, neste trabalho, com nível B3LYP/6-31G* com o trabalho de Nguyen e colaboraderes [25] com nível B3LYP/6-31G(d,p). Os valores estão em $\AA$ e a numeração dos átomos está mostrada na figura 4.1 .

\begin{tabular}{cccccc}
\hline \hline Átmos & EM & Ref [25] & Átmos & EM & Ref [25] \\
\hline C1 - C2 & 1.399 & 1.400 & C8 - O15 & 1.345 & 1.338 \\
C1 - C11 & 1.424 & 1.425 & C9 - C11 & 1.469 & 1.454 \\
C1 - O18 & 1.348 & 1.337 & C9 - C14 & 1.476 & 1.460 \\
C2 - C3 & 1.394 & 1.392 & C9 - O17 & 1.252 & 1.268 \\
C2 - H29 & 1.090 & 1.083 & C10 - C12 & 1.495 & 1.495 \\
C3 - C4 & 1.403 & 1.407 & C10 - C13 & 1.484 & 1.491 \\
C3 - O20 & 1.350 & 1.356 & C10 - O22 & 1.231 & 1.226 \\
C4 - C12 & 1.388 & 1.385 & C11 - C12 & 1.421 & 1.416 \\
C4 - H30 & 1.087 & 1.086 & C13 - C14 & 1.413 & 1.418 \\
C5 - C6 & 1.404 & 1.410 & O15 - H16 & 0.999 & 0.990 \\
C5 - C13 & 1.392 & 1.386 & O18 - H19 & 0.991 & 0.991 \\
C5 - H28 & 1.087 & 1.085 & O20 - H21 & 0.991 & 0.967 \\
C6 - C7 & 1.394 & 1.389 & C23 - H24 & 1.096 & 1.096 \\
C6 - C23 & 1.510 & 1.508 & C23 - H25 & 1.094 & 1.092 \\
C7 - C8 & 1.404 & 1.408 & C23 - H26 & 1.098 & 1.096 \\
C7 - H27 & 1.089 & 1.085 & O17 .. O15 & 2.584 & 2.571 \\
\hline \hline
\end{tabular}


com O17 ou H19 com O17), e o outro átomo de hidrogênio, (H19 ou H16, respectivamente), no estado de transição, entre as formas com e sem ligação de hidrogênio com o O17, ou seja, numa conformação perpendicular ao plano do anéis aromáticos. Na figura 4.2 mostramos as conformações desses rotâmeros da emodina.

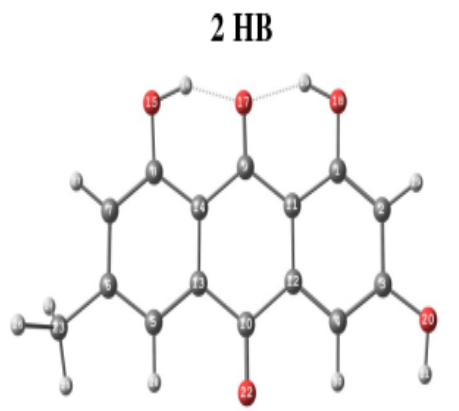

$0 \mathrm{HB}$

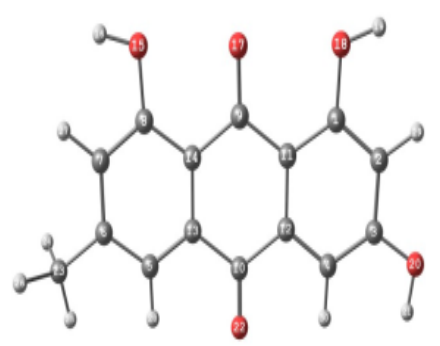

$1 \mathrm{HB}(19)$

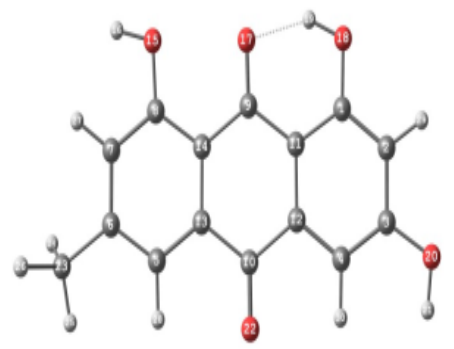

$1 \mathrm{HB}(19) \mathrm{TS}$
$1 \mathrm{HB}(16)$

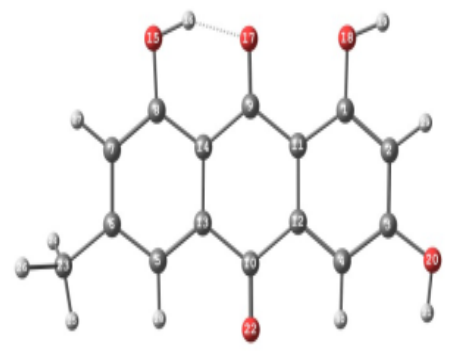

$1 \mathrm{HB}$ (16) TS

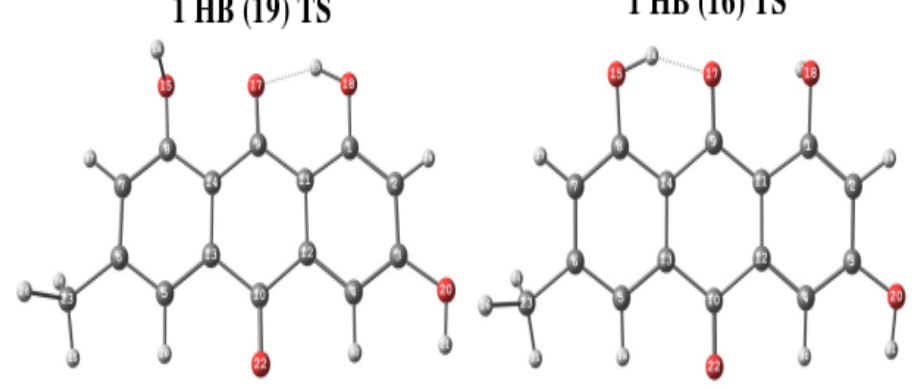

Figura 4.2: Os rotâmeros da $\boldsymbol{E} \boldsymbol{M}$ nas conformaçôes estudadas.

Na tabela 4.2 mostramos as energias relativas, e os momentos de dipolos desses rotâmeros calculados. Analisando esses resultados, observamos como esperado que a conformação mais favorável energeticamente da EM é a conformação que forma duas ligações de hidrogênio. Para a molécula sair dessa conformação para a conformação de uma ligação de hidrogênio é necessário fornecer uma energia em torno de 13.0 $\mathrm{kcal} / \mathrm{mol}$ com uma barreira de ativação de $\sim 17.6 \mathrm{kcal} / \mathrm{mol}$. É interessante notar nesa tabela que a quebra de uma ligação de hidrogênio, 1 HB(19), pode aumentar em quase $84 \%$ o momento de dipolo da molécula. 
Tabela 4.2: Energias relativas dos rotâmeros e seus respectivos momentos de dipolo, obtidos com a otimização de geometria com método B3LYP/6$31 \mathrm{G}^{*}$. Ver os rotâmeros estudados da figura 4.2

\begin{tabular}{ccc}
\hline \hline emodina & $\Delta E(k c a l / m o l)$ & $\mu(D)$ \\
\hline 2 HB & 0.00 & 2.48 \\
1 HB(19) & 13.24 & 4.56 \\
1 HB(16) & 12.99 & 2.87 \\
0 HB & 28.18 & 1.45 \\
1 HB (H19) TS & 17.63 & 3.08 \\
1 HB (H16) TS & 17.57 & 2.48 \\
0 HB TS & 31.75 & 1.00 \\
\hline \hline
\end{tabular}

\subsubsection{Molécula com modelo contínuo de solvente}

Adicionalmente, analisamos o efeito do solvente na estrutura eletrônica da EM. Realizamos novos cálculos quânticos para determinar a energia relativa e os momentos de dipolo sobre o efeito do solvente em meio aquoso e clorofórmio com a descrição do solvente com modelo contínuo polarizável (PCM).

Analisando os resultados obtidos em meio solvente, listados na tabela 4.3, observamos que a emodina necessita de $\sim 6.0 \mathrm{kcal} / \mathrm{mol}$ e $\sim 8.3 \mathrm{kcal} / \mathrm{mol}$ para quebrar uma ligação de hidrogênio com uma barreira de $\sim 11.5 \mathrm{kcal} / \mathrm{mol}$ e $\sim 13.4 \mathrm{kcal} / \mathrm{mol}$, em água e clorofórmio respectivamente. Como podemos observar é mais fácil quebrar essa ligação de hidrogênio em meio aquoso que em clorofórmio. Esse fato pode ser explicado devido à água ser mais polar que o clorofórmio, e a quebra da ligação de hidrogênio intramolecular gerar configuração com maior momento de dipolo. Portanto a interação da água com a EM nas conformações 1 HB é favorecida em relação a 
conformação 2 HB.

Tabela 4.3: Energias relativas dos rotâmeros e seus respectivos momentos de dipolo, obtidos com método B3LYP /6-31G* e o solvente descrito com o modelo contínuo polarizável, PCM. Ver os rotâmeros estudados da figura 4.2 .

\begin{tabular}{ccccc}
\hline \hline & água & \multicolumn{2}{c}{ clorofórmio } \\
\hline emodina & $\Delta E(k c a l / m o l)$ & $\mu(D)$ & $\Delta E(k c a l / m o l)$ & $\mu(D)$ \\
\hline 2 HB & 0.00 & 3.20 & 0.00 & 2.97 \\
1 HB(19) & 6.02 & 5.96 & 8.47 & 5.51 \\
1 HB(16) & 6.15 & 4.40 & 8.28 & 3.88 \\
0 HB & 13.68 & 1.78 & 18.76 & 1.65 \\
1 HB (H19) TS & 11.48 & 4.76 & 13.37 & 4.45 \\
1 HB (H16) TS & 11.54 & 3.56 & 13.37 & 3.18 \\
0 HB TS & 18.45 & 1.38 & 22.90 & 1.18 \\
\hline \hline
\end{tabular}

O solvente descrito com modelo PCM não foi capaz de fornecer energia suficiente para quebrar as ligações de hidrogênio intramolecular da molécula emodina. Portanto resolvemos realizar simulações moleculares com a emodina, utilizando um modelo de solvente, onde as moléculas são incluídas explicitamente [49]. A realização dessas simulações revelará se a interação soluto-solvente e a formação de ligações de hidrogênio intermolecular irão favorecer energeticamente a quebra das ligações de hidrogênio intramolecular.

\subsubsection{Molécula com modelo explícito de solvente}

Para realizar uma simulação computacional é necessário escolher um campo de força apropriado para molécula de interesse. Na realização deste trabalho, escolhemos 
os parâmetros de interação intramolecular e intermolecular do campo de força OPLS [110]. No conjunto de parâmetros dos campos de forças, as cargas atômicas são os parâmetros mais dependentes da conformação molecular. Por isso, optamos por testar esses parâmetros. Escolhemos três conjuntos diferentes de cargas atômicas: OPLS - cargas do campo de força OPLS adotando a sistemática de neutralizar os grupos químicos diferentes; CONF - cargas obtidas do ajuste do potencial eletrostático com o método B3LYP/6-31G*/CHELPG da configuração de mínima energia, conformação 2 HB; MÉDIA - cargas obtidas do ajuste do potencial eletrostático de 21 rotâmeros, que serão apresentados em seguida.

Os rotâmeros da emodina foram obtidos rotacionando os diedros Dh16, Dh19 e Dh21, que correspondem aos ângulos de torção formados pelos seguintes átomos C7C8-O15-H16, C2-C1-O18-H19 e C2-C3-O20-H21 respectivamente (ver figura 4.3, para numeração dos átomos). A rotação das hidroxilas foram realizada separadamente, uma

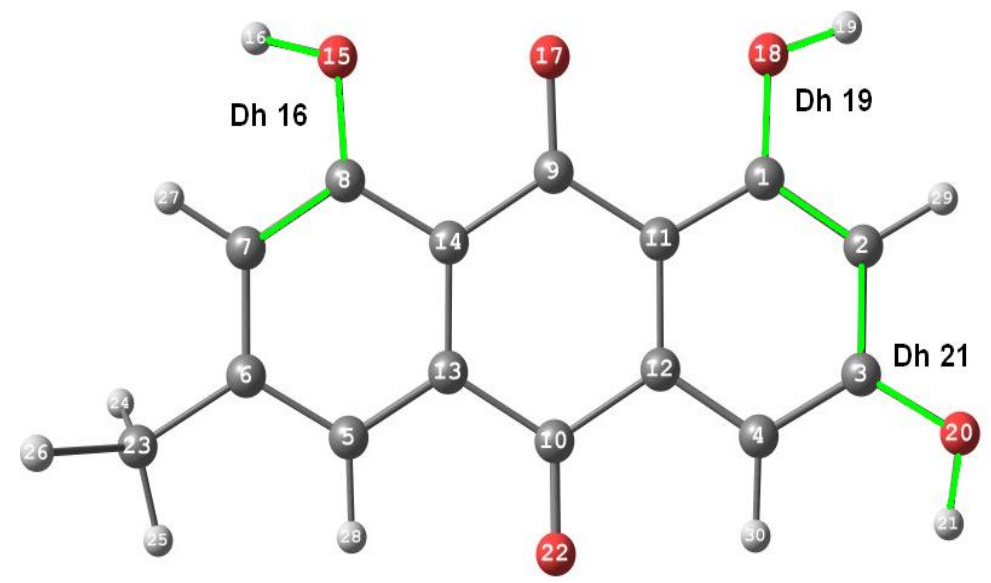

Figura 4.3: Geometria da emodina, indicando os diedros Dh16, Dh19 e Dh21, que foram rotacionado para gerar as configuraçôes dos rotâmeros. Nessa conformação, os valores dos diedros são: $D h 16=0^{\circ}, D h 19=0^{\circ}$ e Dh21 $=180^{\circ}$.

por vez, permanecendo as demais fixas em suas posições iniciais. Na figura 4.3, os valores iniciais dos diedros Dh16, Dh19 e Dh21 são $0^{\circ}, 0^{\circ}$ e $180^{\circ}$ respectivamente. Cada diedro foi rotacionado de $0^{\circ}$ a $180^{\circ}$ com intervalo de $30^{\circ}$. Nas tabelas 4.4 e 4.5. mostra- 
mos as cargas atômicas, para os oxigênios, obtidas do ajuste do potencial eletrostático gerado com método B3LYP/6-31G*/CHELPG para cada um dos rotâmeros.

Tabela 4.4: As cargas nos oxigênios pertencentes às hidroxilas para cada cálculo QM com método B3LYP/6-31G*/CHELPG. Ver definição dos diedros na figura 4.3 .

\begin{tabular}{ccccccccccc}
\hline \hline & \multicolumn{3}{c}{ O15 } & \multicolumn{3}{c}{ O18 } & \multicolumn{3}{c}{ O20 } \\
\hline$\theta\left(^{\circ}\right)$ & Dh16 & Dh19 & Dh21 & Dh16 & Dh19 & Dh21 & Dh16 & Dh19 & Dh21 \\
\hline 0 & -0.597 & -0.612 & -0.615 & -0.609 & -0.579 & -0.586 & -0.608 & -0.603 & -0.615 \\
30 & -0.577 & -0.617 & -0.615 & -0.601 & -0.564 & -0.586 & -0.610 & -0.605 & -0.615 \\
60 & -0.588 & -0.612 & -0.615 & -0.601 & -0.580 & -0.586 & -0.611 & -0.602 & -0.615 \\
90 & -0.670 & -0.609 & -0.610 & -0.649 & -0.601 & -0.590 & -0.675 & -0.596 & -0.606 \\
120 & -0.594 & -0.603 & -0.610 & -0.601 & -0.592 & -0.590 & -0.607 & -0.599 & -0.606 \\
150 & -0.579 & -0.602 & -0.612 & -0.594 & -0.577 & -0.583 & -0.604 & -0.605 & -0.597 \\
180 & -0.674 & -0.620 & -0.612 & -0.649 & -0.626 & -0.579 & -0.673 & -0.609 & -0.603 \\
\hline \hline
\end{tabular}

Analisando os resultados obtidos para as cargas atômicas observamos que as cargas nos oxigênios, durante a rotação dos diedros não varia significativamente, o que pode ser visto nas tabelas 4.4 e 4.5 e na figura 4.4. Observamos também que a formação das ligações de hidrogênio intramolecular provocam uma carga mais negativa no O17. Essa separação de carga que deixa o átomo O17 mais negativo, favorece a interação intramolecular das ligações de hidrogênios, uma vez que a carga nos átomos H16 e H19 é positiva. Um outro fator interessante a mencionar é que as cargas do campo de força OPLS listada na figura 4.4, são ligeiramente menores em módulo que as das cargas obtidas dos cálculos ab initio.

Analisando o momento de dipolo para cada rotâmero, (mostrados na tabela 4.6), observamos que a rotação nos diedros é capaz de provocar uma variação no momento 
Tabela 4.5: As cargas nos oxigênios pertencentes aos carbonilas para cada cálculo QM com método B3LYP/6-31G*/CHELPG. Ver definição dos diedros na figura 4.3

\begin{tabular}{ccccccc}
\hline \hline \multicolumn{3}{c}{ O17 } & \multicolumn{3}{c}{ O22 } \\
\hline$\theta\left(^{\circ}\right)$ & Dh16 & Dh19 & Dh21 & Dh16 & Dh19 & Dh21 \\
\hline 0 & -0.498 & -0.540 & -0.543 & -0.512 & -0.509 & -0.513 \\
30 & -0.511 & -0.552 & -0.543 & -0.512 & -0.510 & -0.513 \\
60 & -0.518 & -0.551 & -0.543 & -0.514 & -0.512 & -0.513 \\
90 & -0.537 & -0.536 & -0.537 & -0.531 & -0.512 & -0.515 \\
120 & -0.514 & -0.531 & -0.537 & -0.514 & -0.510 & -0.515 \\
150 & -0.516 & -0.543 & -0.540 & -0.512 & -0.508 & -0.513 \\
180 & -0.592 & -0.607 & -0.540 & -0.528 & -0.506 & -0.509 \\
\hline \hline
\end{tabular}

Tabela 4.6: Momento de dipolo $(D)$ para cada rotâmero obtido da rotação dos diedros. Ver definição dos diedros na figura 4.3 .

\begin{tabular}{cccc}
\hline \hline$\theta\left({ }^{\circ}\right)$ & Dh16 & Dh19 & Dh21 \\
\hline 0 & 1.72 & 4.87 & 5.51 \\
30 & 1.97 & 4.73 & 5.51 \\
60 & 2.60 & 4.40 & 5.51 \\
90 & 3.28 & 3.94 & 4.75 \\
120 & 3.77 & 3.39 & 4.75 \\
150 & 4.40 & 3.08 & 4.82 \\
180 & 4.87 & 3.11 & 4.87 \\
\hline \hline
\end{tabular}




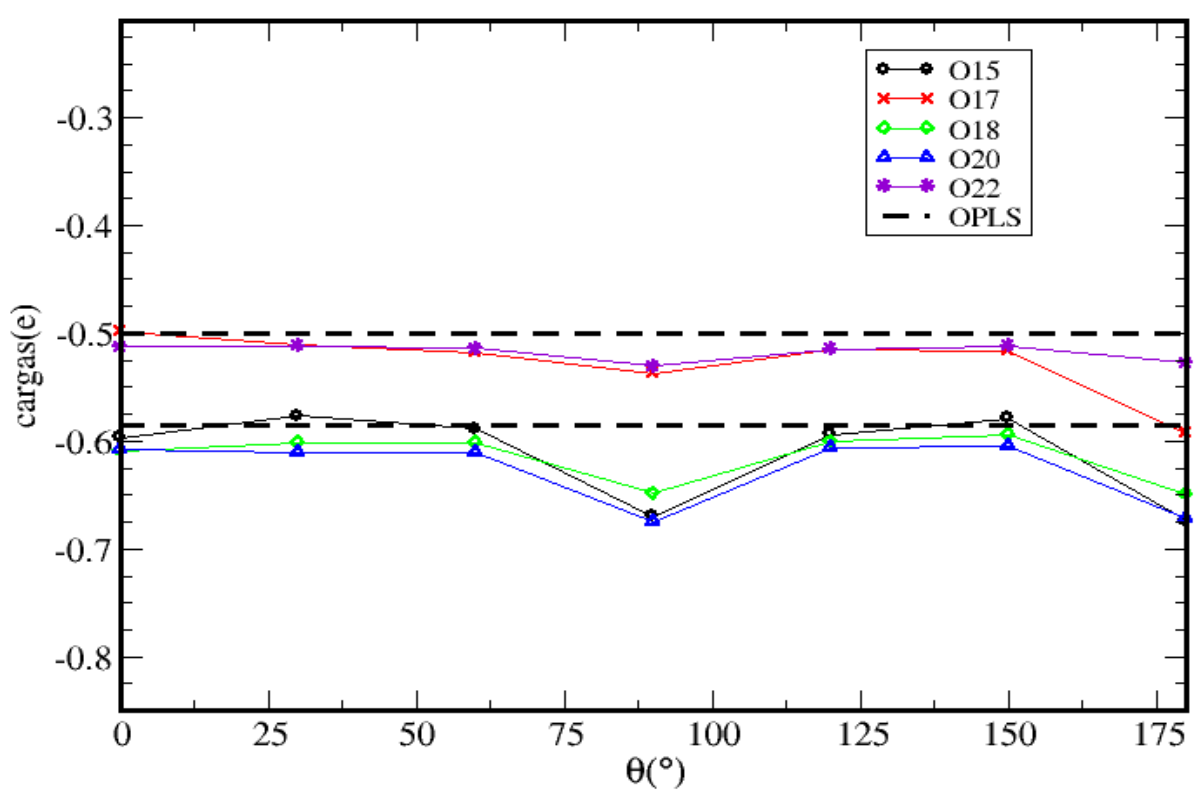

Figura 4.4: Variação das cargas nos oxigênios da emodina, referente a rotação do Dh16, mostradas nas tabelas 4.4 e 4.5 .

de dipolo $(\mu)$ de $1.7 D$ a $5.5 D$, ver figura 4.5. Essa variação no momento de dipolo da emodina pode ser capaz de mudar seu caráter hidrofóbico/hidrofílico, sendo que com $\mu=5.5 \mathrm{D}$ a emodina interagem bem mais forte com a água que com $\mu=1.7 \mathrm{D}$. Sendo assim é necessário realizar uma simulação molecular com a molécula flexível para analisar as posições mais prováveis das hidroxilas em solução aquosa.

Verificando que as cargas nos oxigênios e também nos outros átomos não são muito sensíveis as mudanças rotacionais nos ângulos diedros, assim, para cada átomo calculamos a média das cargas sobre os 21 rotâmeros gerados. Na tabela 4.7, apresentamos os três conjuntos de cargas atômicas geradas, OPLS, CONF e MÉDIA, que foram utilizadas para testar o termo coulombiano do campo de força OPLS, através de simulações computacionais em meio aquoso. 
Tabela 4.7: Cargas atômicas obtidas do campo de força (OPLS), do ajuste do potencial eletrostático da geometria de mínima energia (CONF) e da média sobre os 21 rotâmeros(MÉDIA).

\begin{tabular}{cccccccc}
\hline \hline Átomos & OPLS & CONF & MÉDIA & Átomos & OPLS & CONF & MÉDIA \\
\hline C1 & 0.150 & 0.458 & 0.455 & H16 & 0.435 & 0.440 & 0.445 \\
C2 & -0.115 & -0.463 & -0.433 & O17 & -0.500 & -0.540 & -0.539 \\
C3 & 0.150 & 0.499 & 0.488 & O18 & -0.585 & -0.579 & -0.596 \\
C4 & -0.115 & -0.338 & -0.325 & $\mathrm{H} 19$ & 0.435 & 0.474 & 0.472 \\
C5 & -0.115 & -0.249 & -0.250 & O20 & -0.585 & -0.603 & -0.613 \\
C6 & 0.000 & 0.245 & 0.248 & $\mathrm{H} 21$ & 0.435 & 0.486 & 0.480 \\
C7 & -0.115 & -0.344 & -0.346 & $\mathrm{O} 22$ & -0.500 & -0.509 & -0.513 \\
C8 & 0.150 & 0.464 & 0.448 & $\mathrm{C} 23$ & -0.180 & -0.241 & -0.273 \\
C9 & 0.500 & 0.587 & 0.571 & $\mathrm{H} 24$ & 0.060 & 0.075 & 0.087 \\
C10 & 0.500 & 0.484 & 0.479 & $\mathrm{H} 25$ & 0.060 & 0.084 & 0.092 \\
C11 & 0.000 & -0.287 & -0.277 & $\mathrm{H} 26$ & 0.060 & 0.079 & 0.089 \\
C12 & 0.000 & 0.019 & 0.020 & $\mathrm{H} 27$ & 0.115 & 0.187 & 0.186 \\
C13 & 0.000 & 0.025 & 0.016 & $\mathrm{H} 28$ & 0.115 & 0.135 & 0.139 \\
C14 & 0.000 & -0.351 & -0.303 & $\mathrm{H} 29$ & 0.115 & 0.215 & 0.205 \\
O15 & -0.585 & -0.612 & -0.612 & $\mathrm{H} 30$ & 0.115 & 0.160 & 0.161 \\
\hline \hline
\end{tabular}




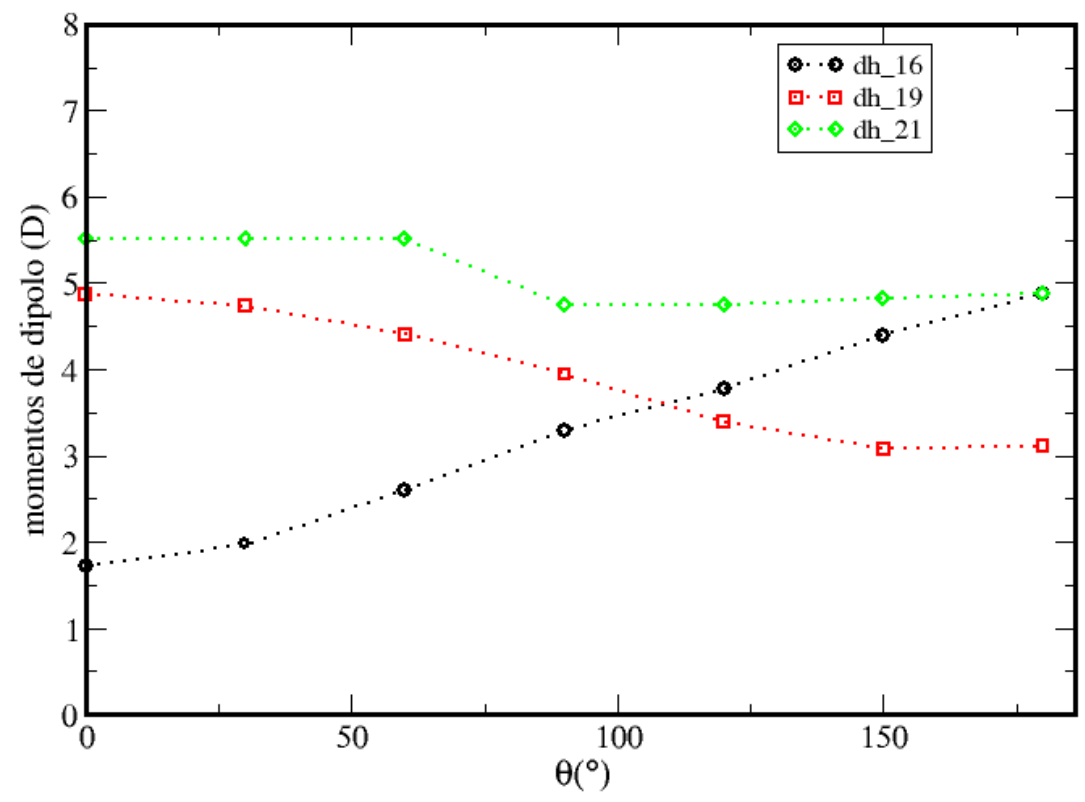

Figura 4.5: Gráfico dos momentos os dipolo versus diedro para cada rotâmero estudado para os valores mostrados na tabela 4.6

Na tabela 4.7, observamos que as cargas do OPLS e as obtidas do cálculo $a b$ intitio concordam em sinal para todos os átomos, e que as maiores diferenças são observados nos carbonos C1-C8, C11 e C14, onde as cargas do OPLS são menores. Os conjuntos de cargas CONF e MÉDIA são muito semelhantes. Já as cargas nos oxigênios estão em boa concordância para os três conjuntos de cargas estudados. Portanto esperamos que a interação soluto-solvente e as ligações de hidrogênios entre a emodina e a água serão semelhantes para os três conjuntos de cargas estudados.

Antes de realizarmos as simulações da emodina solvatada em água, realizamos uma análise energética das rotações das hidroxilas para compararmos com os valores obtidos quanticamente para molécula isolada. Essa análise foi realizada através do programa TINKER, onde foi calculada a energia potencial para os 21 rotâmeros descritos no início desta seção. Analisando a figura 4.6, observamos que a formação da ligação 


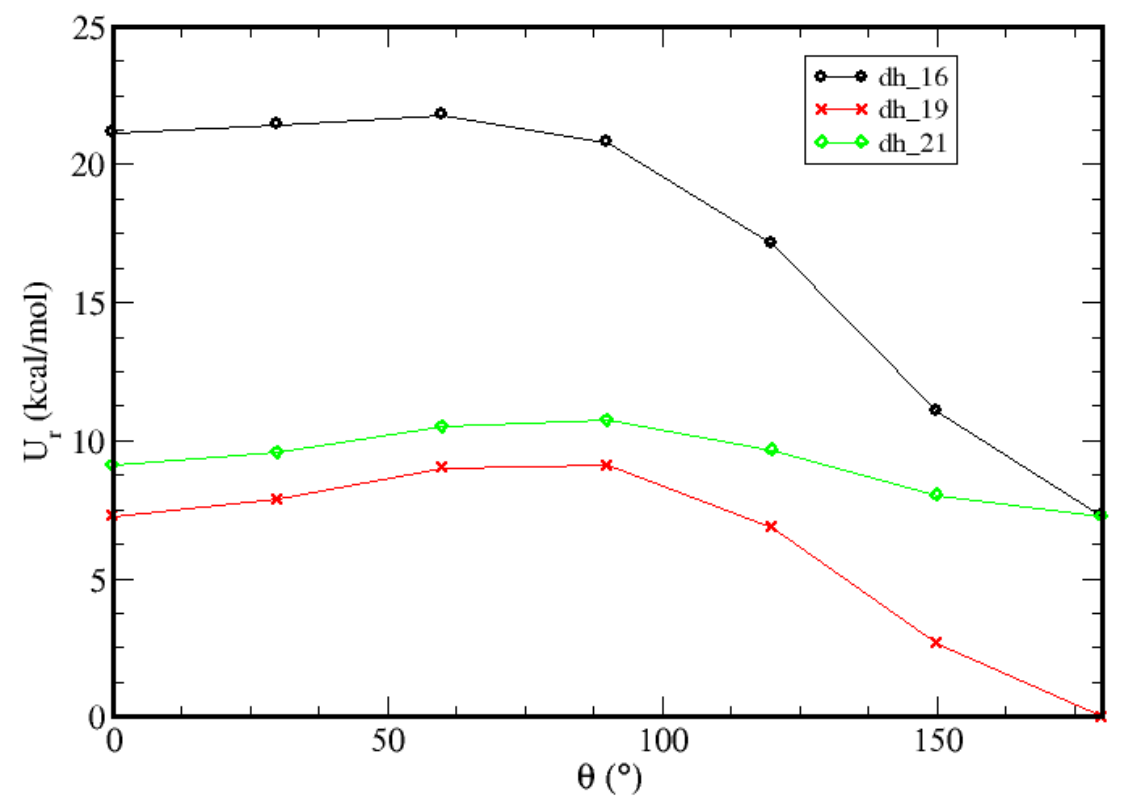

Figura 4.6: Gráfico da energia potencial versus diedro para cada rotâmero estudado, para oconjunto de carga OPLS. Para os demais conjuntos de cargas, os resultados são semelhantes.

de hidrogênio intramolecular provoca diminuição da energia potencial, sendo portanto o rotâmero, formando duas ligações de hidrogênio intramolecular, o de menor energia. Comparando os valores listados na tabela 4.2 , com os valores mostrados na figura 4.6 , observamos que os resultado obtidos com método quântico (B3LYP/6-31G*) e com potencial clássico (OPLS) estão em boa concordância. Portanto a representação da molécula emodina com o potencial clássico é um bom modelo para o estudo dessa molécula.

\subsubsection{Simulação com moléculas flexíveis}

Realizamos simulações computacionais com Dinâmica Molecular(MD) para molécula de emodina numa caixa cúbica com 500 moléculas de água no ensemble NPT, nas condições normais de temperatura e pressão. Utilizamos condições periódicas de 
contorno para caixa cúbica de aresta inicial de $24.98 \AA$, o que gerou uma densidade inicial de $1\left(\mathrm{~g} / \mathrm{cm}^{3}\right)$. Para manter a temperatura e pressão constante, empregamos o termostato e barostato de Berendsen [121] a temperatura de 298K e pressão de $1 \mathrm{~atm}$.

O modelo utilizado para a água foi o SPC [123]. O cálculo da interação intermolecular foi realizado para moléculas com distâncias menores que o raio de corte de $12.49 \AA$, que é aproximadamente a metade da aresta da caixa. Para interações além do raio de corte, foi realizada uma correção de longe alcance (CLA) para o termo eletrostático através do método PME (Particle Mesh Ewald) [124]. As equações de movimento do sistema, foram integradas usando o algoritmo de Verlet [122] com as moléculas flexíveis, usando o intervalo de tempo $\Delta t$ de integração. Usamos os parâmetros $\left(\epsilon, \sigma, q, k_{r}, r_{e q}, k_{\theta}, \theta_{e q}, n, \mathcal{U}_{n}\right.$ e $\left.\gamma\right)$ do campo de força OPLS para o potencial de interação intermolecular e intramolecular (todos os parâmetros estão listados no arquivo B.0.2, mostrados no apêncice B), com as cargas atômicas geradas de diferentes formas: OPLS, CONF e MÉDIA.

O processo da simulação foi dividido em duas etapas: (i) A termalização, partindo de uma configuração totalmente aleatória. Nesse processo usamos 100.000 passos de MD com o intervalo de tempo $\Delta t=2 f s$, totalizando uma termalização de 200 ps. (ii) A simulação propriamente dita no equilíbrio, partindo da última configuração do processo de termalização. Na simulação no equilíbrio usamos 3.000.000 passos de MD com o intervalo de tempo $\Delta t=1 \mathrm{fs}$, totalizando uma dinâmica $3.000 \mathrm{ps}=3 \mathrm{~ns}$.

Nas tabelas 4.8 e 4.9 e figuras 4.7, 4.8 e 4.9 estão alguns resultados obtidos nas simulações com MD. Na tabela 4.8 mostramos um sumário da análise estatística da energia total, potencial e cinética e, na tabela 4.9, a densidade e temperatura do sistema em equilíbrio. Nas figuras 4.7, 4.8 e 4.9, os gráficos dessas propriedades são apresentados para as configurações salvas num intervalo de $100 \mathrm{ft}$.

Analisando os resultados obtidos para MD da emodina, em água, verificamos que: i) A densidade apresenta uma pequena flutuação como esperado, e não é sensível 
Tabela 4.8: Energia total $(\mathcal{E} / N)$, potencial $(\mathcal{U} / N)$ e cinética $(\mathcal{K} / N)$ por molécula em $\mathrm{kcal} / \mathrm{mol}$, das simulações para os conjuntos de cargas CONF, MÉDIA e OPLS.

\begin{tabular}{cccccccccc}
\hline \hline & \multicolumn{3}{c}{ CONF } & \multicolumn{3}{c}{ MÉDIA } & \multicolumn{3}{c}{ OPLS } \\
\hline & $\mathcal{E} / N$ & $\mathcal{U} / N$ & $\mathcal{K} / N$ & $\mathcal{E} / N$ & $\mathcal{U} / N$ & $\mathcal{K} / N$ & $\mathcal{E} / N$ & $\mathcal{U} / N$ & $\mathcal{K} / N$ \\
\hline Média & -7.19 & -9.90 & 2.72 & -7.19 & -9.91 & 2.72 & -7.11 & -9.83 & 2.72 \\
Mínimo & -7.38 & -10.06 & 2.65 & -7.37 & -10.10 & 2.64 & -7.28 & -10.05 & 2.65 \\
Máximo & -6.78 & -9.61 & 2.83 & -6.78 & -9.60 & 2.82 & -6.69 & -9.50 & 2.81 \\
Desvio & 0.30 & 0.23 & 0.09 & 0.30 & 0.24 & 0.09 & 0.30 & 0.24 & 0.08 \\
\hline \hline
\end{tabular}

Tabela 4.9: Temperatura $(K)$ e densidade $\left(\mathrm{g} / \mathrm{cm}^{3}\right)$, obtidas das simulações para os diferentes conjuntos de cargas: CONF, MÉDIA e OPLS.

\begin{tabular}{ccccccc}
\hline \hline & \multicolumn{2}{c}{ CONF } & \multicolumn{2}{c}{ MÉDIA } & \multicolumn{2}{c}{ OPLS } \\
\hline & $T$ & $\rho$ & $T$ & $\rho$ & $T$ & $\rho$ \\
\hline Média & 297.91 & 1.00 & 297.92 & 1.00 & 297.92 & 1.00 \\
Mínimo & 290.30 & 0.98 & 289.87 & 0.98 & 290.19 & 0.98 \\
Máximo & 310.39 & 1.02 & 309.90 & 1.02 & 308.20 & 1.02 \\
Desvio & 1.92 & 0.01 & 1.91 & 0.01 & 1.93 & 0.01 \\
\hline \hline
\end{tabular}


ao modelo de cargas atômicas do soluto $\left(1.00 \pm 0.01 \mathrm{~g} / \mathrm{cm}^{3}\right.$, para os 3 modelos de cargas). ii) A temperatura apresenta uma flutuação de apenas $1.9 K$, e também não é sensível ao modelo de cargas atômicas do soluto(297.8 $\pm 1.9 \mathrm{~K}$, para os 3 modelos de cargas). iii) As energias total, potencial e cinética por molécula apresentam pouca flutuação, (cinética, cerca de $0.08 \mathrm{kcal} / \mathrm{mol}$ e potencial cerca de $0.24 \mathrm{kcal} / \mathrm{mol}$ ). Isso ocorre devido ao grande número de moléculas de água.

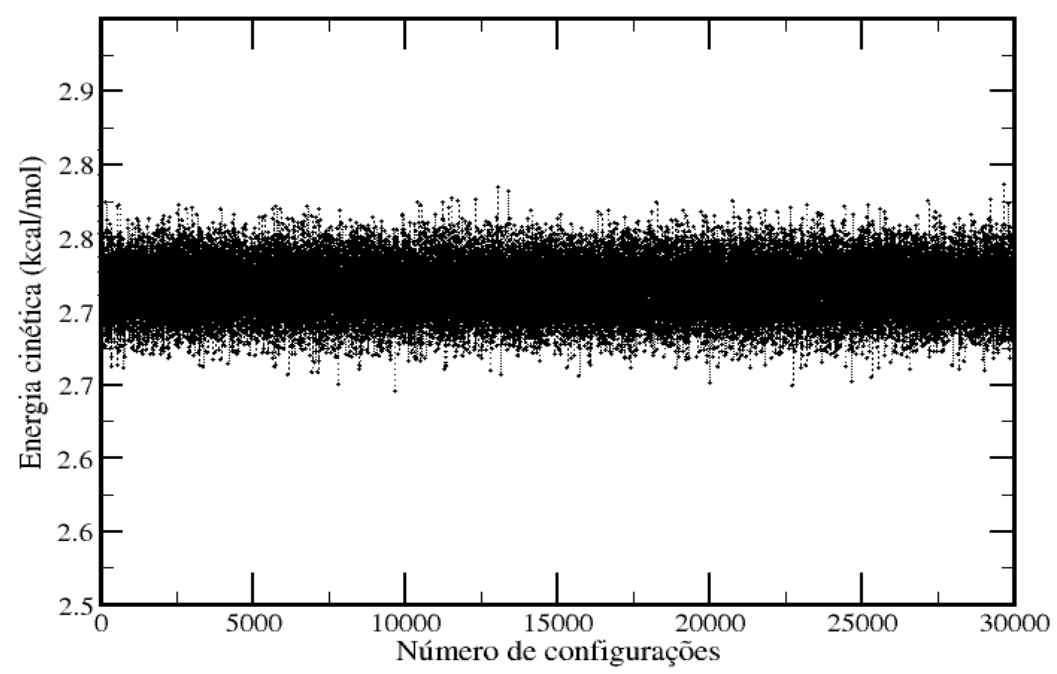

Figura 4.7: Gráfico da energia cinética da Dinâmica Molecular da emodina no equilíbrio para o caso com cargas OPLS. Para os demais conjuntos de cargas, os resultados são semelhantes.

Para identificar as orientações mais prováveis das hidroxilas, analisamos as rotações dos diedros (Dh16, Dh19 e Dh21), no decorrer da dinâmica do sistema. Os resultados obtidos estão mostrados na tabela 4.10 e figuras $4.10,4.11,4.12$ e 4.13 . 


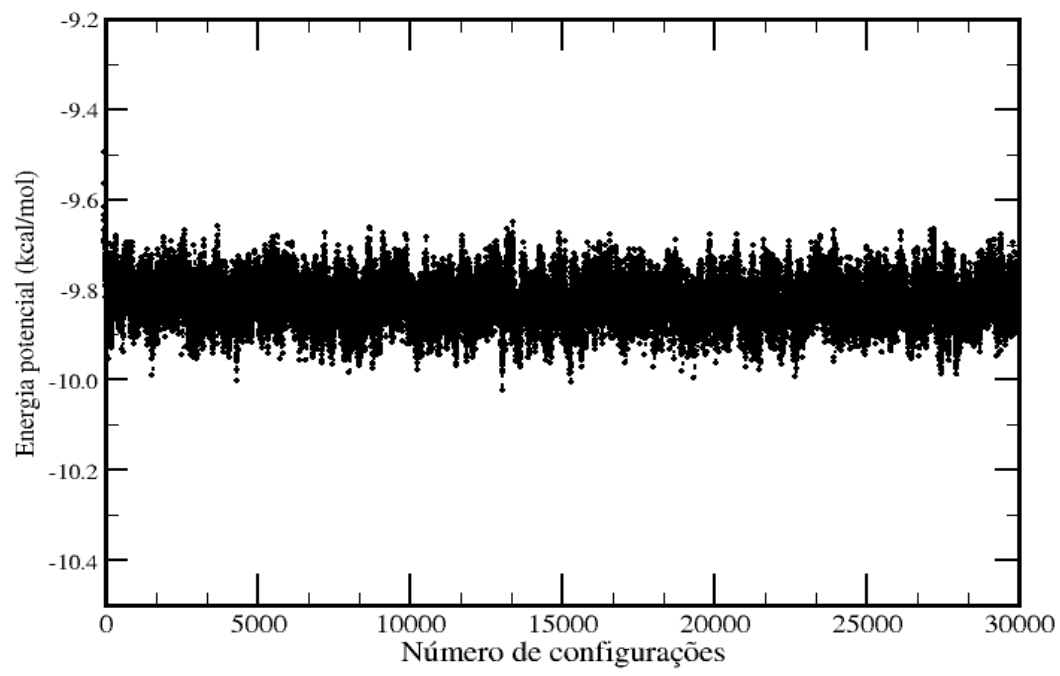

Figura 4.8: Gráfico da energia potencial da $M D$ da emodina no equilíbrio para o caso com cargas OPLS. Para os demais conjuntos de cargas, os resultados são semelhantes.

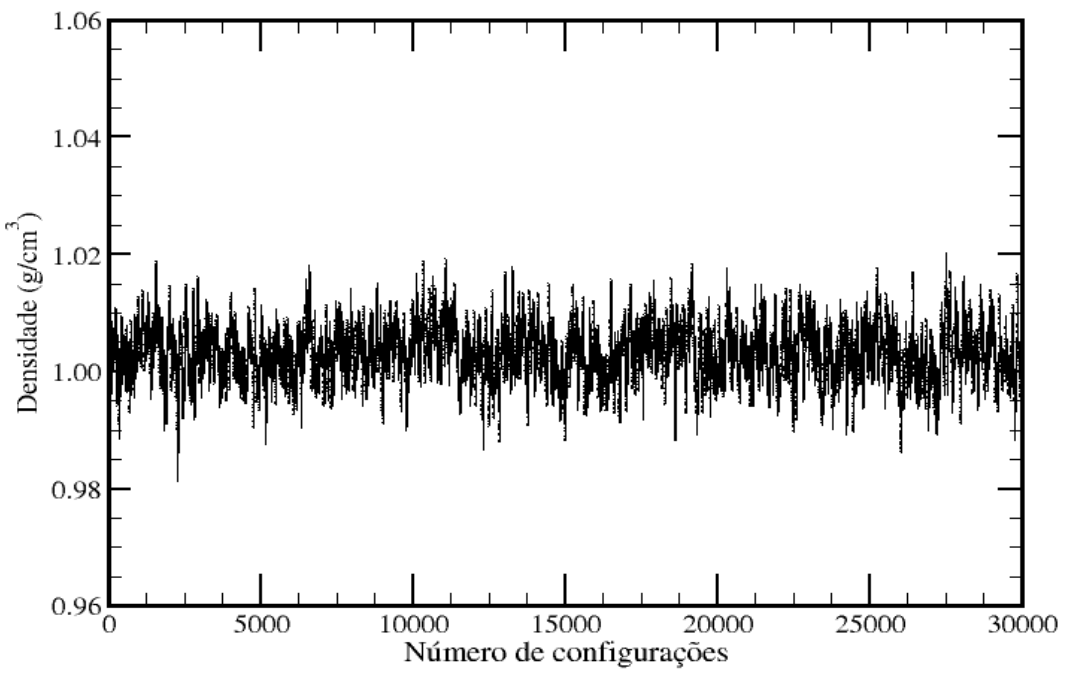

Figura 4.9: Gráfico da densidade da MD da emodina para o caso com cargas OPLS. Para os demais conjuntos de cargas, os resultados são semelhantes. 
Tabela 4.10: Tempo total e percentual em que os ângulos diedros Dh16, Dh19 e Dh21 ficaram na orientação dentro do intervalo de $180^{\circ}$ a $150^{\circ}$, ou seja, H16 e H19 formam ligação de hidrogênio intramolecular com O17 e para a hidroxila O20H21 aponta no sentido do O22.

\begin{tabular}{ccccccc}
\hline & CONF & \multicolumn{3}{c}{ MÉDIA } & \multicolumn{3}{c}{ OPLS } \\
\hline $180^{\circ}$ a $150^{\circ}$ & Tempo(ps) & $\%$ & Tempo(ps) & $\%$ & Tempo(ps) & $\%$ \\
Dh16 & 3000 & 100 & 3000 & 100 & 2625.2 & 87.5 \\
Dh19 & 2899.4 & 96.6 & 2713.4 & 90.5 & 2631.6 & 87.7 \\
Dh21 & 2861.4 & 95.4 & 2534.2 & 84.5 & 1684.7 & 56.2 \\
\hline \hline
\end{tabular}
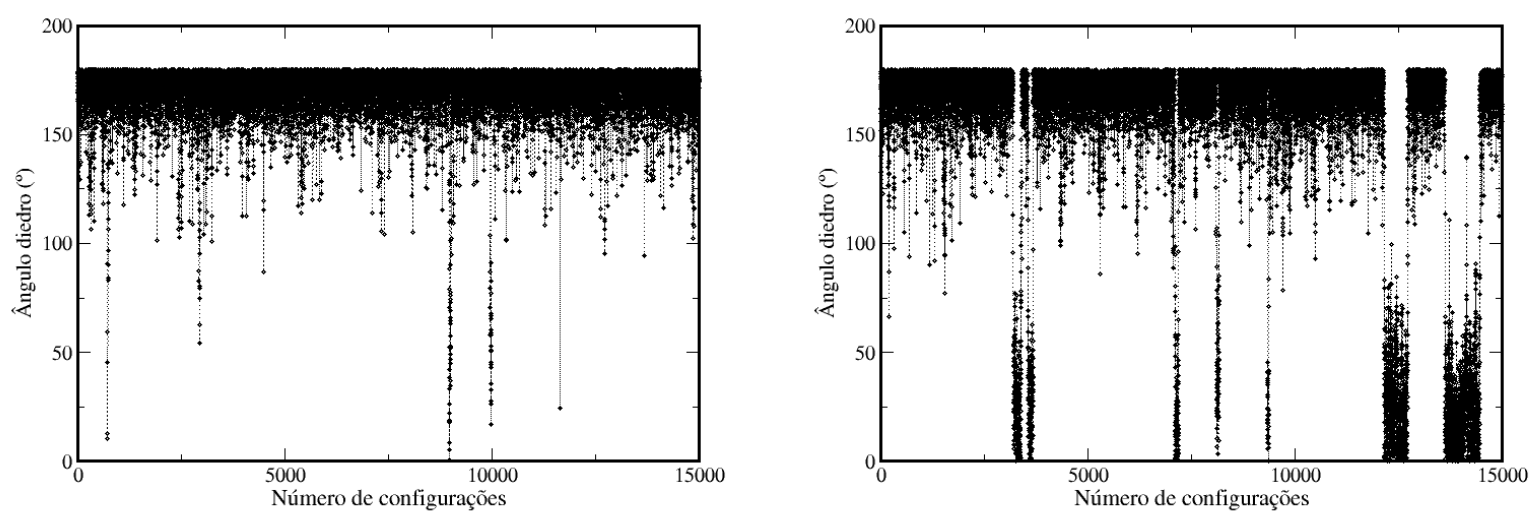

Figura 4.10: Gráfico do ângulo diedro Dh16 versus número de configurações para CONF esquerda e OPLS direita. Para os demais conjuntos de cargas, os resultados são semelhantes.

Observando os resultados mostrados na tabela 4.10, e figuras 4.10, 4.11, 4.12 e 4.13 para os três diedros (Dh16, Dh19 e Dh21), verificamos que eles ficaram a maior parte do tempo de simulação dentro do intervalo $180^{\circ}$ a $150^{\circ}$. Para os modelos de carga CONF e MÉDIA o comportamento dos diedros foram semelhantes. Para esses dois casos, houve uma ocorrência maior que $90 \%$ no intervalo $180^{\circ}-150^{\circ}$, exceto para 

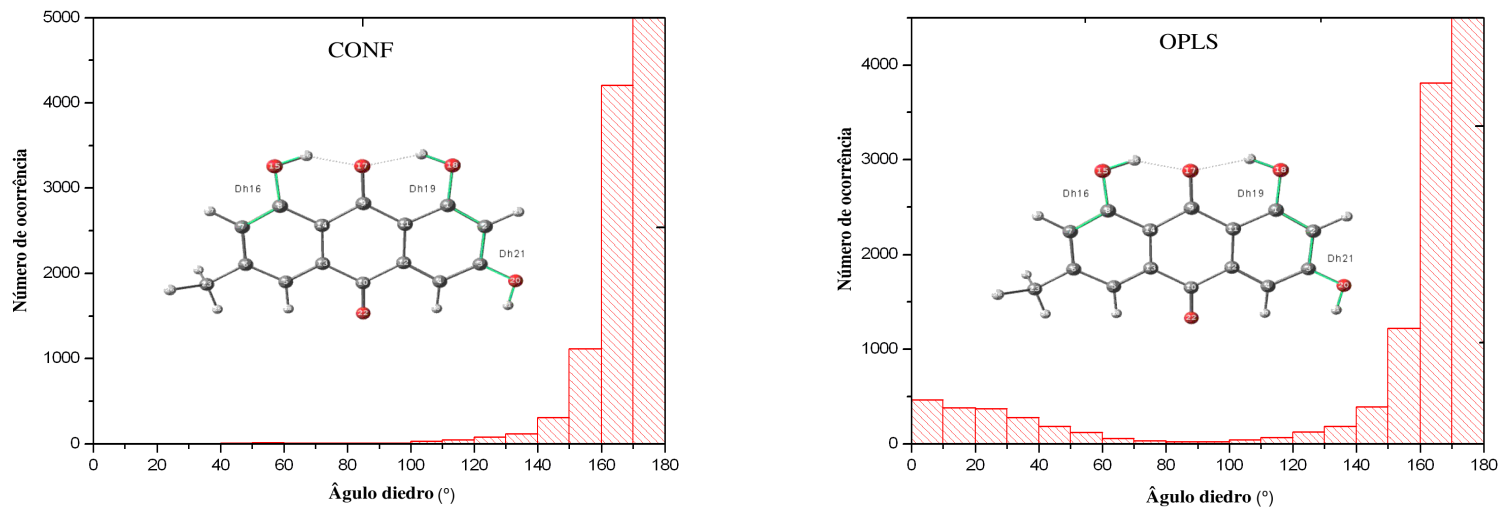

Figura 4.11: Histograma referente ao diedro Dh16 para o conjunto cargas CONF e OPLS. Para os demais conjuntos de cargas, os resultados são semelhantes.
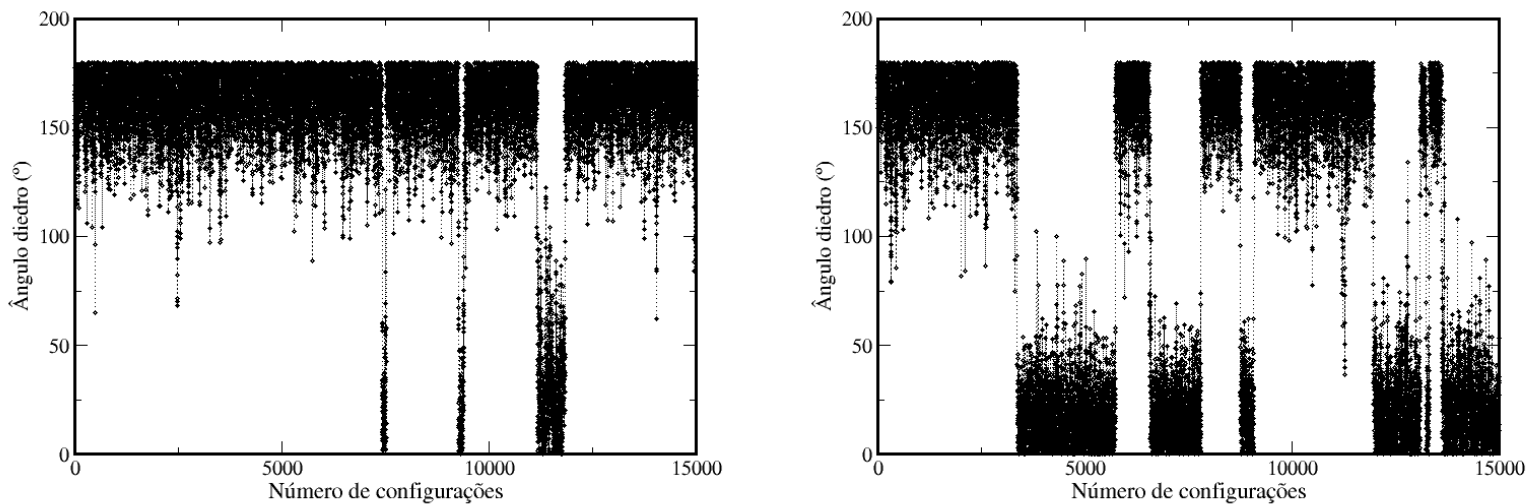

Figura 4.12: Gráfico do ângulo diedro Dh21 versus número de configurações para CONF esquerda e OPLS direita. Para os demais conjuntos de cargas, os resultados são semelhantes.

o Dh21 no caso MÉDIA, que foi de 84\%. Já para o caso do modelo OPLS obtivemos cerca de $87 \%$ para os diedros Dh16 e Dh19 e 56\% para Dh21 no intervalo $180^{\circ}-150^{\circ}$. Nesse modelo, a hidroxila O20H21 apresentou 2 preferências conformacionais, uma com Dh21 entre $0^{\circ}$ e $30^{\circ}$, e outra entre $150^{\circ}$ e $180^{\circ}$. 

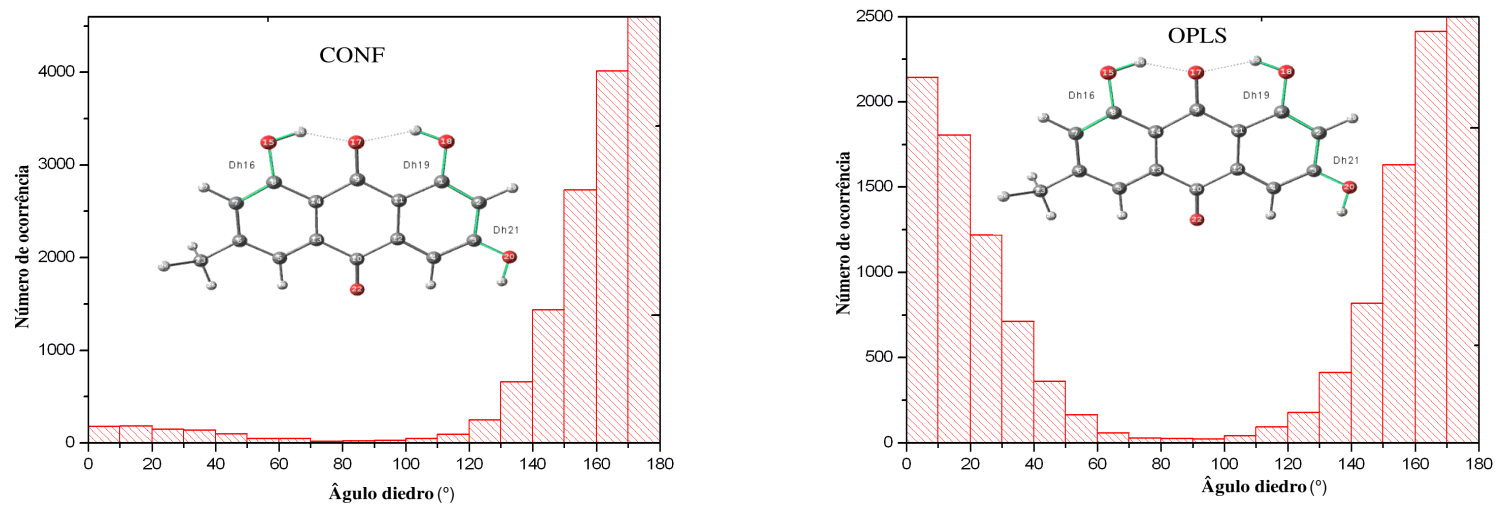

Figura 4.13: Histograma referente ao diedro Dh21 para o conjunto cargas CONF e OPLS. Para os demais conjuntos de cargas, os resultados são semelhantes.

Realizamos uma análise da rotação do grupo metílico pertencente a emodina. Essa análise foi realizada com base na rotação do diedro Dh25, que corresponde ao diedro formado pelos átomos H25-C23-C6-C7, (ver figura 4.14).
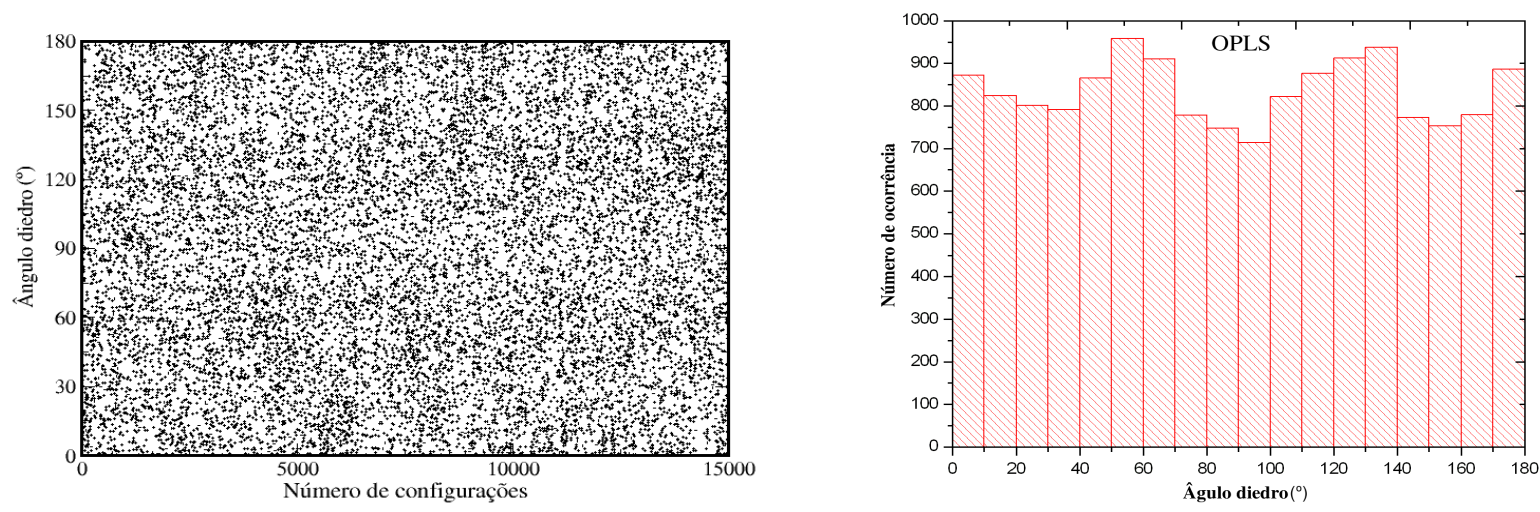

Figura 4.14: Gráfico do ângulo diedro Dh26 versus número de configurações a esquerda e histograma referente a esse diedro a direita. Ambos os gráficos para o conjunto de cargas OPLS. Para os demais conjuntos de cargas, os resultados são semelhantes. 
Na figura 4.14 mostramos a distribuição do ângulo diedro Dh25. Nessa figura pode-se observar que o grupo metílico é bem flexível, ocupando valores entre $0^{\circ}$ a $180^{\circ}$ com uma densidade de pontos quase uniforme. Entretanto analisando o gráfico do histograma do diedro Dh26, nessa mesma figura, verificamos que os hidrogênio do grupo metílico, apresentam uma ligeira preferência a ficar em torno dos ângulos $60^{\circ} \mathrm{e}$ $120^{\circ}$, que são justamente as conformações gauche cis e trans. Isso acontece devido a essas conformações serem as mais favoráveis energeticamente.

Sendo assim, resolvemos realizar uma simulação com a molécula de emodina rígida usando o método Monte Carlo(MC) na conformação com os três diedros em $180^{\circ}$, como mostra a figura 4.15, para verificarmos se o modelo rígido para essa molécula é um bom modelo.

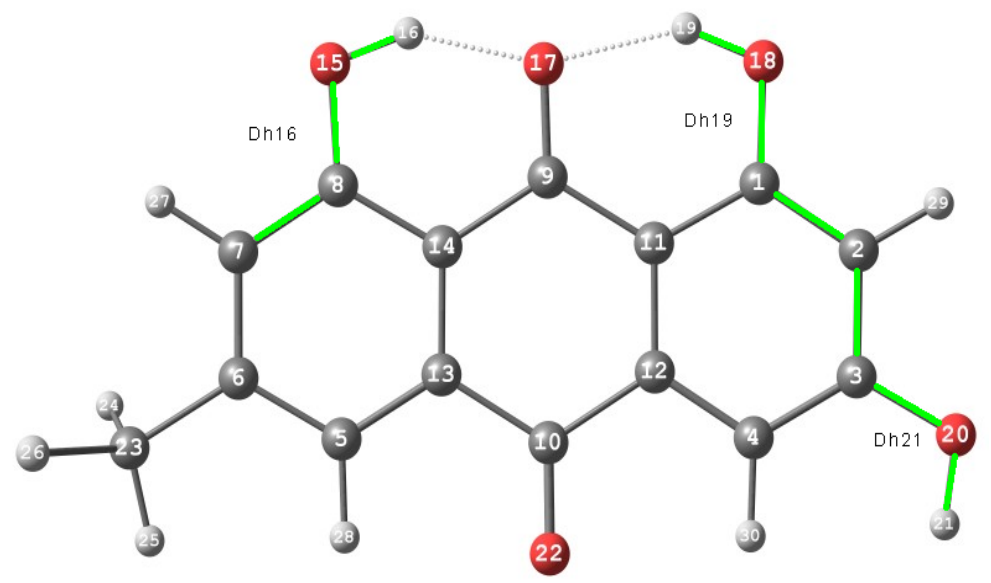

Figura 4.15: Geometria da molécula emodina na conformação com os três diedros, Dh16, Dh19 e Dh21 em $180^{\circ}$.

\subsubsection{Simulação com moléculas rígidas}

Realizamos simulações com a molécula da emodina, usando método de Monte Carlo com amostragem de Metropolis e condições periódicas de contorno numa caixa com 500 moléculas de água no ensemble NPT nas condições normais de temperatura e pressão. O volume inicial da caixa foi calculado a partir da densidade inicial de 1.0 
$\mathrm{g} / \mathrm{cm}^{3}$. Uma configuração inicial do sistema foi gerada, distribuindo aleatoriamente as 501 moléculas na caixa de simulação.

A geometria da emodina foi mantida rígida durante toda simulação na conformação mostrada na figura 4.15, que foi a mais provável obtida da simulação com as moléculas flexíveis. Usamos o mesmo campo de força OPLS, ( ver $\epsilon, \sigma$ tabela 4.11), para o potencial de interação intermolecular com as cargas atômicas geradas de diferentes formas: OPLS, CONF e MÉDIA. O dipolo calculado para a molécula de emodina

Tabela 4.11: Parâmetros Lennard-Jones da molécula emodina do campo de força OPLS [110].

\begin{tabular}{ccc}
\hline \hline átomos & $\epsilon(k c a l / m o l)$ & $\sigma(\AA)$ \\
\hline $\mathrm{C}$ (aromático) & 0.070 & 3.550 \\
$\mathrm{H}$ (aromático) & 0.030 & 2.420 \\
$\mathrm{O}$ (hidroxila) & 0.170 & 3.070 \\
$\mathrm{H}$ (hidroxila) & 0.000 & 0.000 \\
$\mathrm{O}$ (carboxila) & 0.210 & 2.960 \\
$\mathrm{C}$ (metil) & 0.066 & 3.500 \\
$\mathrm{H}$ (metil) & 0.030 & 2.500 \\
\hline \hline
\end{tabular}

nos três conjuntos de cargas é de 2.2, 2.3 e $3.1 D$ respectivamente. Esses valores estão bem próximos dos valores médios do dipolo da emodina obtidos com MD. Assim, como na Dinâmica Molecular, o modelo utilizado para a água foi o SPC [123].

A energia configuracional foi calculada para moléculas com distância menos que o raio de corte $r_{c}=\frac{1}{2} L$, onde $L$ é a aresta da caixa cúbica. Para distâncias além do raio de corte, foi realizado uma correção de longo alcance(CLA) para o potencial de Lennard-Jones. A CLA do potencial de Lennard-Jones é obtida através da função 
distribuição radial de pares. A simulação foi realizada em dois estágios. O primeiro a termalização, partindo de uma configuração totalmente aleatória. Esse estágio foi realizado com 30.000 ciclos de $\mathrm{MC}$, onde em cada ciclo, $\mathrm{N}$ moléculas da caixa são selecionadas para mover. No segundo estágio, a simulação do equilíbrio foi iniciada, partindo da última configuração do processo de termalização. Esse estágio foi realizado com 75.000 ciclos de MC.

As propriedades termodinâmicas calculadas nessas simulações estão mostradas na tabela 4.12 e figuras 4.16 e 4.17. Analisando o gráfico da figura 4.16 da energia potencial por molécula, que corresponde ao estágio do processo de termalização, observamos que o sistema atingiu o equilíbrio nos 30.000 primeiros ciclos.

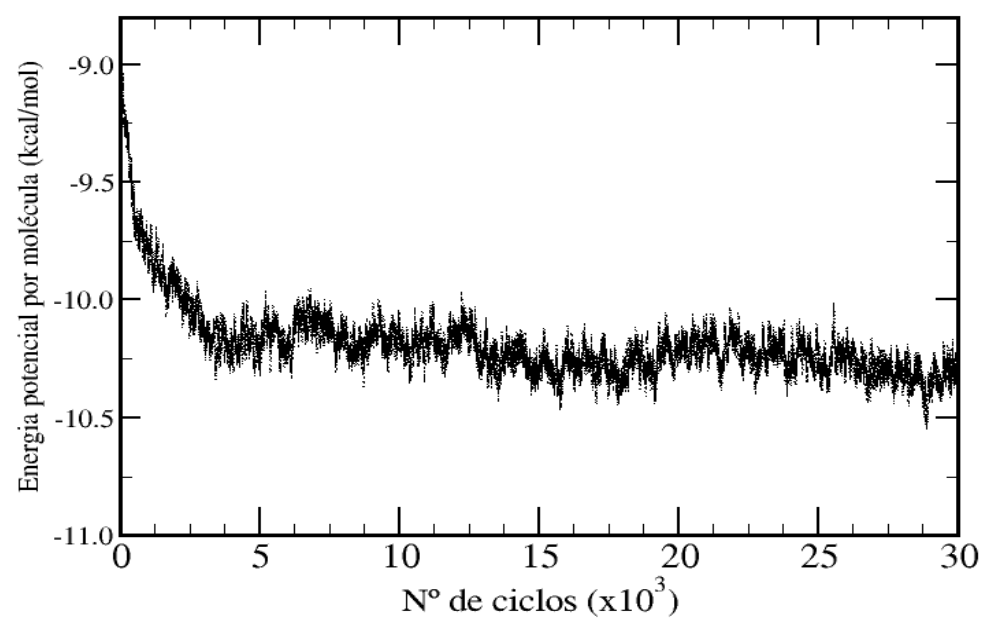

Figura 4.16: Gráfico energia por molécula versus número de ciclos para simulação $M C$ da $\mathbf{E M}$ no ensemble NPT no processo de termalização para o caso OPLS. Para os demais conjuntos de cargas, os resultados são semelhantes.

Na figura 4.17, mostramos que a energia potencial por molécula do sistema no estado de equilíbrio flutua em torno de $-10.2 \pm 0.06$, para o conjunto de carga OPLS. A densidade do sistema não variou muito durante a simulação, onde essa flutuou em torno de $1.00 \pm 0.01$, o que pode ser visto na figura 4.18 . 


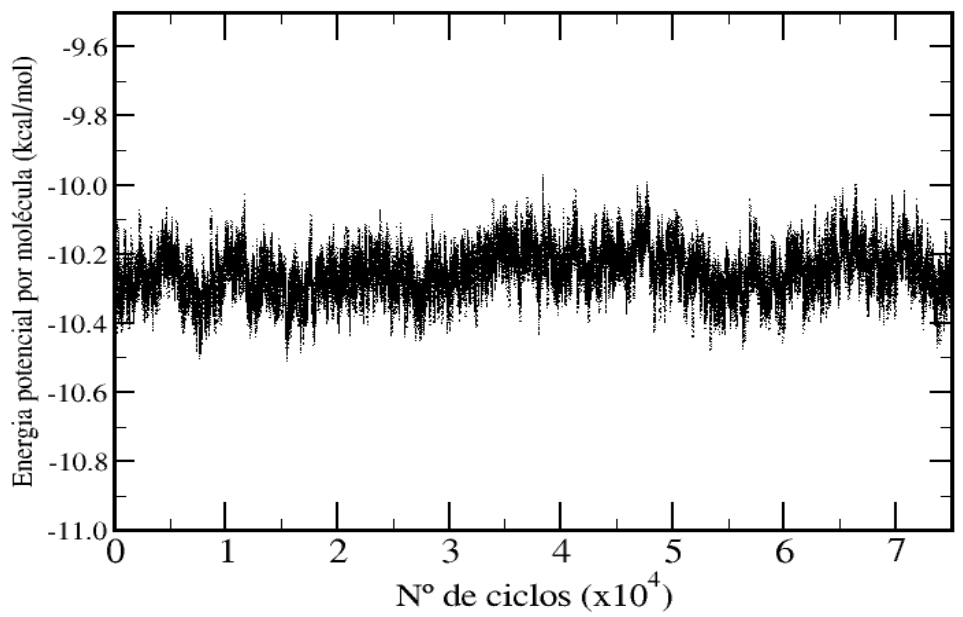

Figura 4.17: Gráfico energia por molécula versus número de ciclos para simulação $M C$ da EM no ensemble NPT no equilíbrio térmico para o caso OPLS. Para os demais conjuntos de cargas, os resultados são semelhantes.

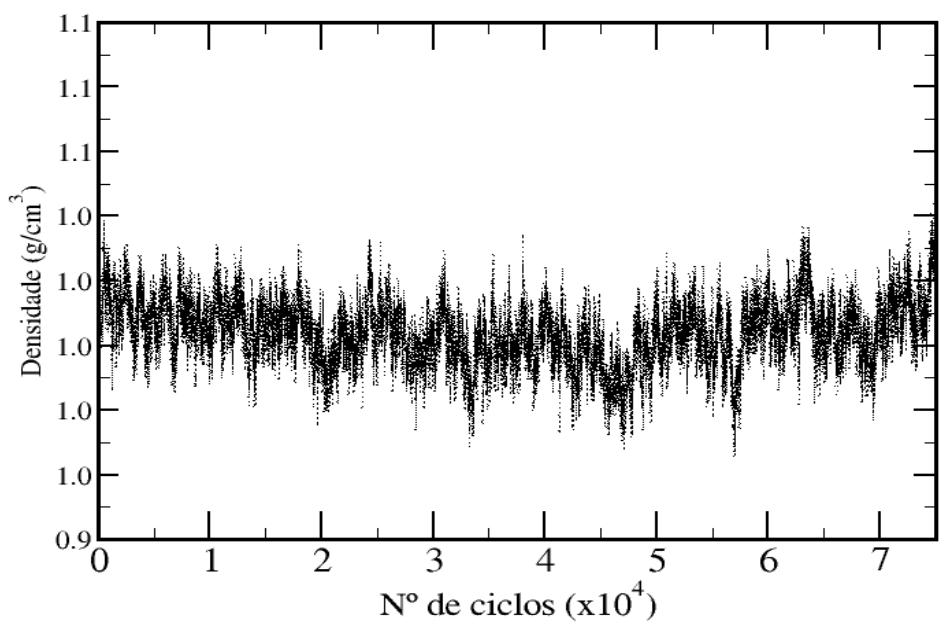

Figura 4.18: Gráfico da densidade da simulação $M C$ da emodina para o caso com cargas OPLS. Para os demais conjuntos de cargas, os resultados são semelhantes. 


\subsubsection{Comparação das simulações}

Nas simulações realizadas utilizando o método de Dinâmica Molecular e Monte Carlo, observamos para ambos os métodos, que o comportamento da energia por molécula durante a simulação é semelhante. Esse comportamento é de tal forma que a energia do sistema sai de uma energia inicial $U_{0}$ e gradualmente atinge um valor médio da energia $\langle U\rangle$, no qual fica flutuando em torno desse valor. As configurações geradas no estágio de não-equilíbrio não são interessantes e nem relevante. Já as configurações geradas no estágio de equilíbrio foram consideradas nos cálculos das propriedades estruturais e termodinâmicas, que discutiremos abaixo.

Tabela 4.12: Dipolo da emodina e suas energias de interação com a água obtidas das simulações MD e MC.

\begin{tabular}{ccccc}
\hline \hline & \multicolumn{2}{c}{$\mathrm{MD}$} & \multicolumn{2}{c}{$\mathrm{MC}$} \\
\hline & $\mathrm{E}(\mathrm{kcal} / \mathrm{mol})$ & $\mu(D)$ & $\mathrm{E}(\mathrm{kcal} / \mathrm{mol})$ & $\mu(D)$ \\
\hline CONF & $-63.0 \pm 7.7$ & $2.7 \pm 0.7$ & $-57.75 \pm 4.3$ & 2.2 \\
MÉDIA & $-64.0 \pm 8.1$ & $2.8 \pm 0.8$ & $-56.79 \pm 5.2$ & 2.3 \\
OPLS & $-66.8 \pm 7.4$ & $2.9 \pm 1.2$ & $-61.85 \pm 4.4$ & 3.1 \\
\hline \hline
\end{tabular}

Na tabela 4.12, mostramos os valores da energia de interação emodina-água $(\mathrm{kcal} / \mathrm{mol})$ e momentos de dipolo $(D)$ para os 3 conjuntos de cargas, obtidos das simulações com os métodos MD e MC. Nessa tabela, verificamos que a interação da emodina com as moléculas de água, nas simulações com os métodos MD e MC, apresenta pouca variação em relação ao modelo usado para as cargas atômicas do soluto, mas o modelo OPLS favorece mais essa interação e isso deve ser decorrência do maior momento de dipolo. Observamos que a energia soluto-solvente obtidas através do método MC com a emodina rígida é sistematicamente menor que as energias obtidas 
através do método MD com a emodina flexível. Entretanto mesmo com essa pequena diferença, essas energias seguem a mesma tendência e estão em boa concordância.

As ligações de hidrogênio e camadas de solvatação da emodina em água foram analisadas para os dois métodos de simulação. A partir das configurações geradas pelos 2 métodos analisamos as ligações de hidrogênio através de critérios geométricos (radial $R_{O O}$ e angular $\left.O \hat{O} H\right)[125,126]$. Neste trabalho usamos os seguintes critérios: $R_{O O} \leq 3.15 \AA$ e $O \hat{O} H \leq 30^{\circ}$. Na tabela 4.13 , listamos o número médio de ligações de hidrogênio e a energia de ligação média para cada simulação realizada com esses métodos de simulação.

Analisando os resultados da tabela 4.13, observamos que existe em média cerca de cinco a seis moléculas de água se ligando a emodina através de ligações de hidrogênio em ambos os métodos nas três distribuições de cargas atômicas. A energia de ligação média é em torno de $5 \mathrm{kcal} / \mathrm{mol}$.

Na tabela 4.13, observamos que o O22 faz mais ligações de hidrogênio que O17, isso deve acontecer devido ao oxigênio O22 está livre sem impedimentos estéricos, facilitando com isso a interação com a água, enquanto o oxigênio O17 está protegido com as duas ligações de hidrogênio intramolecular. Portanto, o O17 prefere interagir intramolecularmente que interagir com o meio externo.

Assim, considerando que a hidroxila pode ter um papel de aceitador de ligações de hidrogênio (na tabela 4.13, esse caso é representado pelos átomos de oxigênio), e um papel de doador de ligações de hidrogênio (na tabela 4.13 , esse caso é representado pelos átomos de hidrogênio), as hidroxilas O15H16, O18H19 e O20H21, têm cerca de 1.0, 1.0 e 2.0 ligações de hidrogênio respectivamente, para os 3 conjuntos de cargas utilizadas em ambos os métodos. Verificamos também, que as energias de interação quando a emodina é doadora de ligações de hidrogênio, é mais forte na MD, mas como ocorre pouca vez, esse efeito não se reflete na interação média. O fato do número de ligações de hidrogênio para o H16 e H19 em MC ser igual a zero, ou seja, $\left\langle N^{\circ}\right\rangle=0.0$, 
Tabela 4.13: Número médio e energia média por ligação de hidrogênio formadas pelas águas com as hidroxilas da emodina obtidas das simulações $\mathrm{MC}$ e MD.

\begin{tabular}{|c|c|c|c|c|c|c|}
\hline $\mathrm{MC}$ & \multicolumn{2}{|c|}{$\mathrm{CONF}$} & \multicolumn{2}{|c|}{ MÉDIA } & \multicolumn{2}{|c|}{ OPLS } \\
\hline átomos & $\left\langle N^{\circ}\right\rangle$ & $\left\langle E_{l i g}\right\rangle$ & $\left\langle N^{\circ}\right\rangle$ & $\left\langle E_{l i g}\right\rangle$ & $\left\langle N^{\mathrm{o}}\right\rangle$ & $\left\langle E_{l i g}\right\rangle$ \\
\hline O15 & 0.9 & -3.40 & 0.8 & -3.15 & 1.0 & -3.50 \\
\hline O17 & 0.1 & -1.21 & 0.1 & -1.11 & 0.1 & -0.61 \\
\hline O18 & 0.8 & -2.86 & 0.6 & -2.90 & 1.0 & -3.77 \\
\hline O20 & 0.7 & -2.33 & 0.7 & -2.75 & 1.2 & -3.34 \\
\hline $\mathrm{O} 22$ & 1.4 & -4.57 & 1.5 & -4.66 & 1.0 & -3.85 \\
\hline H16 & 0.0 & -0.66 & 0.0 & -0.19 & 0.0 & -0.24 \\
\hline H19 & 0.0 & -1.44 & 0.0 & -0.97 & 0.0 & -0.92 \\
\hline $\mathrm{H} 21$ & 1.0 & -10.80 & 1.0 & -9.91 & 1.0 & -7.17 \\
\hline Total & 4.9 & -4.94 & 4.7 & -4.92 & 5.3 & -4.23 \\
\hline MD & \multicolumn{2}{|c|}{ CONF } & \multicolumn{2}{|c|}{ MÉDIA } & \multicolumn{2}{|c|}{ OPLS } \\
\hline átomos & $\left\langle N^{\mathrm{o}}\right\rangle$ & $\left\langle E_{l i g}\right\rangle$ & $\left\langle N^{\mathrm{o}}\right\rangle$ & $\left\langle E_{l i g}\right\rangle$ & $\left\langle N^{0}\right\rangle$ & $\left\langle E_{l i g}\right\rangle$ \\
\hline O15 & 0.9 & -3.96 & 0.9 & -3.96 & 1.0 & -4.17 \\
\hline O17 & 0.3 & -3.11 & 0.3 & -3.42 & 0.2 & -3.19 \\
\hline O18 & 0.7 & -3.14 & 0.7 & -3.43 & 1.0 & -4.00 \\
\hline O20 & 0.8 & -2.67 & 0.8 & -2.86 & 1.2 & -3.73 \\
\hline $\mathrm{O} 22$ & 1.4 & -4.95 & 1.5 & -5.00 & 1.1 & -4.03 \\
\hline H16 & 0.1 & -4.39 & 0.1 & -4.30 & 0.1 & -5.14 \\
\hline H19 & 0.3 & -6.72 & 0.2 & -7.21 & 0.2 & -5.20 \\
\hline H21 & 1.0 & -11.69 & 1.0 & -11.16 & 1.0 & -7.88 \\
\hline Total & 5.4 & -5.46 & 5.6 & -5.40 & 5.9 & -4.42 \\
\hline
\end{tabular}


com precisão de 1 casa decimal, não significa que é zero absoluto, por isso podemos obter a energia média para poucas ligações que têm menos de $1 \%$ de ocorrência, que é o que ocorre nesses casos.

Um outro fato interessante a ressaltar é que a hidroxila O20H21 está livre para interagir com a água, uma vez que essa hidroxila não forma nenhuma ligação de hidrogênio intramolecular. Assim, essa hidroxila interagem mais fortemente com água, que pode ser observado na energia de ligação do H16 com água na tabela 4.13. Essa forte interação com água, torna esse grupo mais vulnerável a desprotonação, em concordância com o trabalho [22]. Enquanto as demais hidroxilas estão interagindo intramolecularmente, com energia de ligação de hidrogênio em módulo menor que da hidroxila O20H21. Os três conjuntos de cargas, CONF, MÉDIA e OPLS, apresentaram resultados análogos com respeito às interações da emodina com água.

A função de distribuição radial (RDF) de pares entre o oxigênio O20 da emodina com o oxigênio da água é mostrado na figura 4.19, para os métodos estudados MD e MC, para o modelo de cargas OPLS. Nessa figura, é identificado um pico na região de 2.4 a $3.15 \AA$, com um máximo em $2.75 \AA$. Integrando esse pico obtêm-se 1.2 moléculas de água nessa primeira vizinhança da emodina para ambos os métodos. Esse valor está em concordância com o valor obtido e mostrado na tabela 4.13 .

Estudamos as camadas de solvatação da emodina através da função de distribuição de mínima distância (MDDF), definida por Coutinho e colaboradores [127, 128]. Essa função pode ser interpretada como a probabilidade de encontrar um par de átomos $\left(a_{i}, b_{j}\right)$ do soluto(a) e solvente(b) numa menor distância $r_{i j}$, dentre todas as distâncias possíveis entre todos os átomos do soluto e solvente. As MDDF obtidas com os métodos MC e MD estão mostradas na 4.20, O número de moléculas em cada camada é definido pela integração de cada pico da MDDF, sendo que o primeiro pico, corresponde a $1^{\mathrm{a}}$ camada de solvatação e assim os demais, ver tabela 4.14 .

Analisando a tabela 4.14 e figuras 4.19 e 4.20 , observamos que a distribuição das 


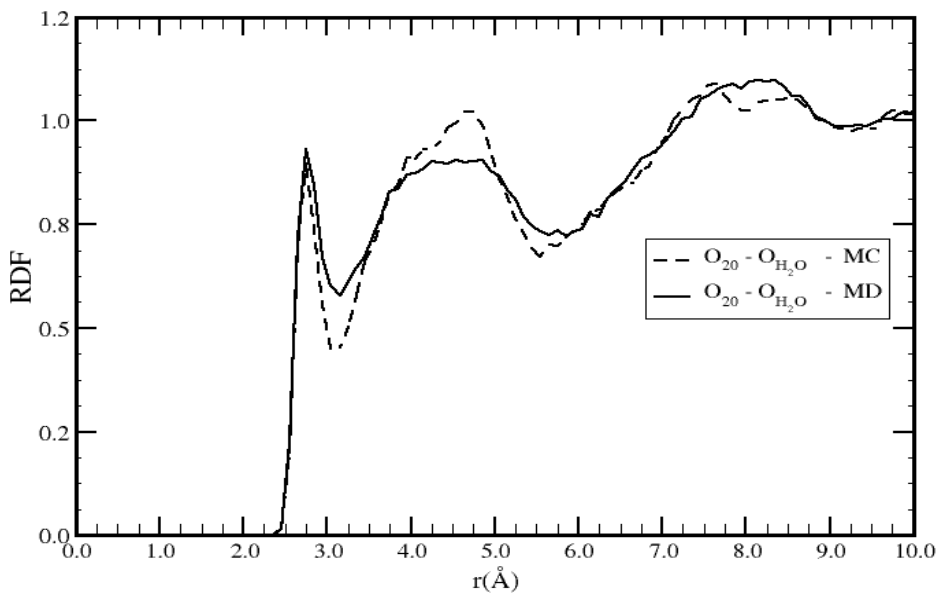

Figura 4.19: Gráfico da função de distribuição radial (RDF) de pares entre o oxigênio O20 da emdina e o oxigênio da água para os métodos $M D$ e $M C$, com o conjunto de cargas OPLS. Para os demais conjuntos de cargas, os resultados são semelhantes.

Tabela 4.14: Estudo da camada de solvatação da emodina em água para os métodos de simulação MC e MD, onde LH refere a camada de água que forma ligações de hidrogênio.

\begin{tabular}{ccccccc}
\hline \hline método & \multicolumn{2}{c}{ CONF } & \multicolumn{2}{c}{ MÉDIA } & \multicolumn{2}{c}{ OPLS } \\
\hline MC & $\mathrm{r}(\AA)$ & $\mathrm{N}^{\circ}$ moléculas & $\mathrm{r}(\AA)$ & $\mathrm{N}^{\circ}$ moléculas & $\mathrm{r}(\AA)$ & $\mathrm{N}^{\circ}$ moléculas \\
\hline $\mathrm{LH}$ & 2.15 & 5.3 & 2.15 & 5.1 & 2.15 & 5.9 \\
$1^{\circ}$ camada & 4.75 & 68.0 & 4.45 & 60.0 & 4.75 & 68.0 \\
$2^{\circ}$ camada & 6.95 & 153.0 & 6.85 & 152.0 & 6.85 & 150.0 \\
\hline MD & $\mathrm{r}(\AA)$ & $\mathrm{N}^{\circ}$ moléculas & $\mathrm{r}(\AA)$ & $\mathrm{N}^{\mathrm{o}}$ moléculas & $\mathrm{r}(\AA)$ & $\mathrm{N}^{\circ}$ moléculas \\
\hline LH & 2.15 & 5.9 & 2.15 & 6.0 & 2.15 & 6.5 \\
$1^{\circ}$ camada & 4.65 & 69.0 & 4.75 & 69.0 & 4.95 & 75.4 \\
$2^{\circ}$ camada & 6.90 & 152.0 & 6.85 & 152.0 & 6.85 & 153.0 \\
\hline \hline
\end{tabular}




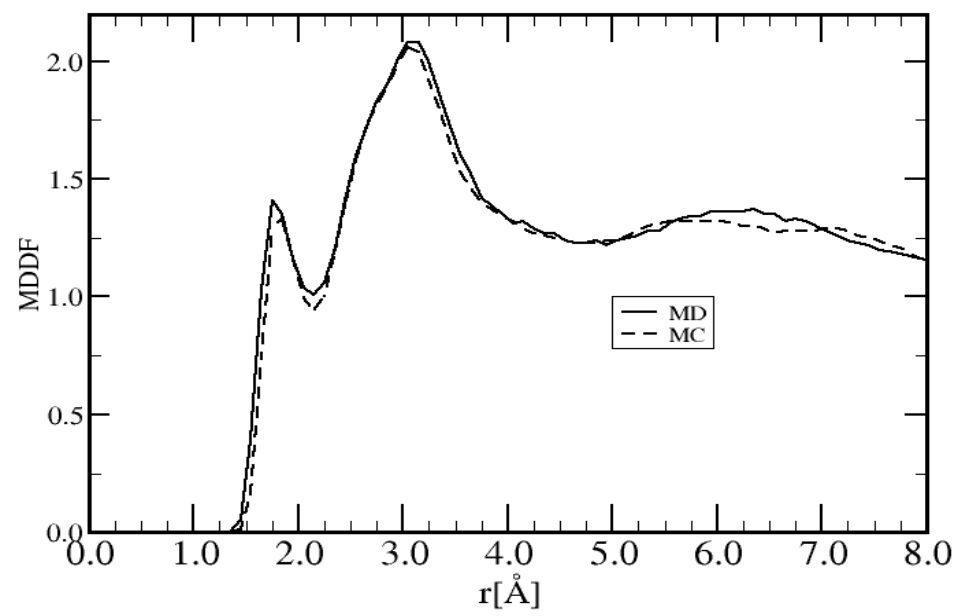

Figura 4.20: : Gráfico da distribuição de minima distância (MDDF), entre a emodina e a água para o modelo de distribuição de cargas atômicas OPLS, obtido da simulação com os métodos MD e MC. Para os demais conjuntos de cargas, os resultados são semelhantes.

moléculas de água em torno da emodina é semelhante em ambos os métodos MC e MD, para as três distribuições de cargas atômicas estudadas CONF, MÉDIA e OPLS. Na primeira camada de solvatação estão cerca de cinco a seis moléculas de água, que são justamente as moléculas de águas que formam as ligações de hidrogênio, vista na tabela 4.13. Na segunda camada estão cerca de 65 águas, e na terceira camada estão cerca de 150 águas. Portanto o modelo rígido descreve bem as interações da emodina com água, para os três conjuntos de cargas estudados. Assim, escolhemos esse modelo e o conjunto de cargas OPLS para estudar a solvatação diferencial e o espectro eletrônico de absorção da emodina em diferentes solventes.

\subsection{Solvatação diferencial}

Para tentar compreender o carácter hidro/lipofílico da molécula de emodina, estudamos a sua solvatação diferencial em 3 solventes com diferentes polaridades: água, clorofórmio e metanol. O processo de solvatação da emodina em diferentes 
solventes foi realizado baseados nas técnicas de Ben-Naim [129], onde a idéia é inserir uma molécula do soluto em fase gasosa para o interior do líquido à temperatura $T$ e à pressão $p$ constante.

A energia livre de Gibbs de solvatação foi calculada usando a teoria de perturbação termodinâmica, descrito no capítulo de métodos, utilizando as técnicas de Monte Carlo com amostragem de Metropolis, implementado no programa DICE. Esse cálculo foi realizado para três tipos de solventes: (i) 1000 moléculas água. (ii) 500 moléculas de metanol. (iii) 500 moléculas de clorofórmio. Todas as simulações foram realizadas no ensemble NPT nas condições normais de pressão e temperatura.

O cálculo da energia livre é considerado um dos mais sensíveis dentro da termodinâmica, uma vez que a energia livre de Gibbs está associada com o potencial químico do sistema. Portanto calcular a energia livre do processo de transferir uma molécula do soluto para o interior do líquido é bastante problemático. A fim de contornar esse problema, adotamos a técnica de calcular a diferença de energia livre de aniquilar a molécula do soluto na solução, ou seja, $\Delta G_{E M \rightarrow 0}$ [130], ver ciclo termodinâmico ilustrado na figura 4.21. Vários trabalhos tem sido publicado na literatura utilizando essa técnica de aniquilação do soluto em cálculo da energia livre de solvatação [131,132].

Numa simulação computacional, a molécula EM, é caracterizada por um conjunto de parâmetros do potencial de interação como, $q, \epsilon$ e $\sigma$. Assim a molécula $\mathbf{E M}$, pode ser representada por, $\mathbf{E M}^{(q, \epsilon, \sigma)}$, que representa a molécula com todos os seus parâmetros de interação. O procedimento adotado neste trabalho para o cálculo da diferença de energia livre de aniquilação, $\Delta G_{E M \rightarrow 0}$ foi dividido em três etapas de perturbação:

(i) $\mathbf{E M}^{(q, \epsilon, \sigma)} \rightarrow \mathbf{E M}^{(0, \epsilon, \sigma)}$ - Nessa etapa, as cargas atômicas da molécula emodina são aniquiladas, mantendo-se os parâmetros de Lennard-Jones fixos. Esse processo de aniquilação das cargas atômicas é dividido em vários cálculos da energia 


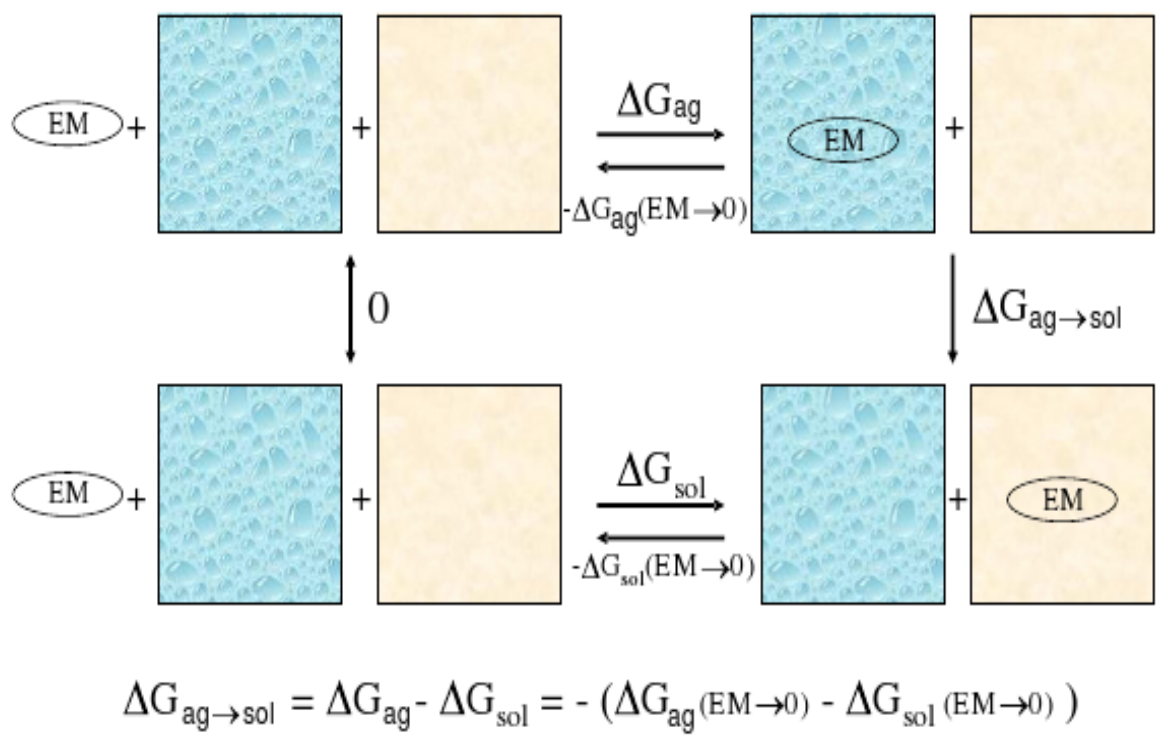

Figura 4.21: Ciclo Termodinâmico descrevendo o cálculo da diferença de energia livre em água e outro solvente para a molécula de emodina.

livre, onde o conjunto de cargas $\left\{q_{i}\right\}$ é reduzido gradativamente, de forma perturbativo, segundo as porcentagens: $100 \% \rightarrow \mathbf{9 5} \% \rightarrow 90 \% \rightarrow \mathbf{8 0} \% \rightarrow 70 \% \rightarrow$ $\mathbf{5 5} \% \rightarrow 40 \% \rightarrow \mathbf{2 0} \% \rightarrow 0 \%$. Usando o procedimento de simulação para os dois lados ("double-wide") [133], são necessariamente 4 simulações para realizar essa etapa: uma com a simulação realizada com o percentual de $95 \%$ das cargas, e perturbando o sistema simultaneamente para $100 \%$ e $90 \%$; outra com a simulação com $80 \%$ e perturbando o sistema simultaneamente para $90 \%$ e $70 \%$; outra com $55 \%$ perturbando para $70 \%$ e $40 \%$; e a última simulação com $20 \%$ perturbando para $40 \%$ e $0 \%$. O conjunto de cargas inicial está listada na tabela 4.7 onde utilizamos as cargas atômicas obtidas do campo de força (OPLS).

(ii) $\mathbf{E M}^{(0, \epsilon, \sigma)} \rightarrow \mathbf{E M}^{(0,0.01, \sigma)}$ - Nessa etapa, o poço atrativo do potencial de LennardJones é aniquilado. Isso é realizado quando o conjunto de parâmetros $\left\{\epsilon_{i}\right\}$, é reduzido até um valor muito pequeno, a fim de não zerar todo o potencial, ver figura 4.22 . 


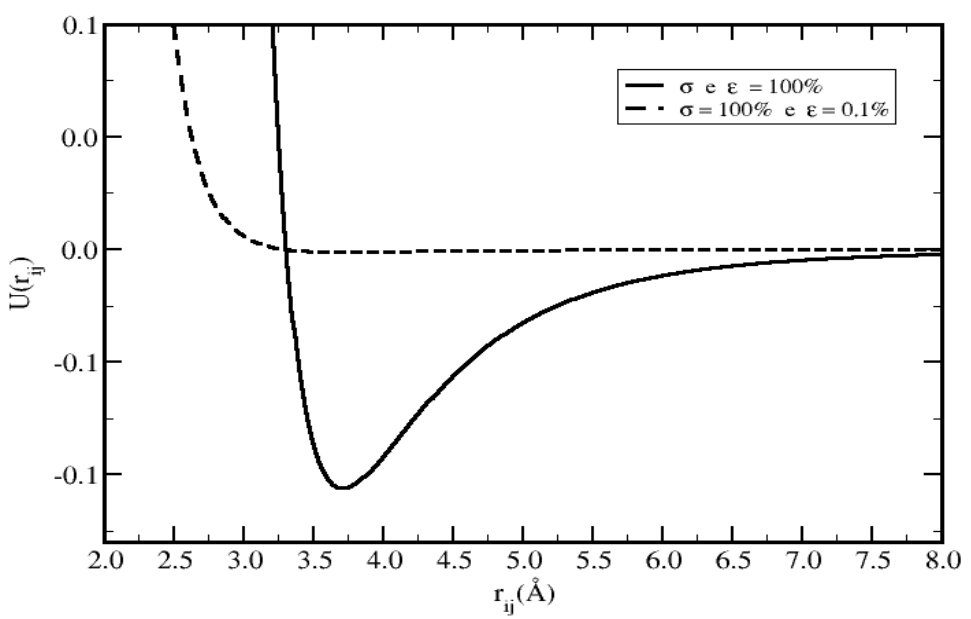

Figura 4.22: Representação do potencial dispersivo de Lennard-Jones, para o conjunto de parâmetros $\{\epsilon=100 \%, \sigma=100 \%\}$ e $\{\epsilon=0.1 \%, \sigma=100 \%\}$, para o par de átomos $C$-O.

Esse conjunto $\left\{\epsilon_{i}\right\}$ é perturbado segundo as porcentagens: $100 \% \rightarrow \mathbf{8 7 . 5} \% \rightarrow$ $75 \% \rightarrow \mathbf{6 2 . 5} \% \rightarrow 50 \% \rightarrow \mathbf{3 7 . 5} \% \rightarrow 25 \% \rightarrow \mathbf{1 2 . 5} \% \rightarrow 0.1 \%$. Também utilizando o procedimento de simulação para dois lados. Portanto são realizadas 4 simulações em $87.5 \%, 62.5 \%, 37.5 \%$ e $12.5 \%$.

(iii) $\mathbf{E M}^{(0,0.01, \sigma)} \rightarrow \mathbf{E M}^{(0,0,0)}$ - Nessa etapa completa-se o processo do cálculo do $\Delta G_{E M \rightarrow 0}$, com a aniquilação do conjunto $\left\{\sigma_{i}\right\}$. Os valores de $\left\{\sigma_{i}\right\}$ são perturbados segundo as porcentagens: $\mathbf{1 0 0} \% \rightarrow \mathbf{7 5} \% \rightarrow \mathbf{5 0} \% \rightarrow \mathbf{2 5} \% \rightarrow 0 \%$. Nesse caso não é utilizado o procedimento de dois lados, pois aparecem variações de energias bastante grandes, quando se aumenta o tamanho dos parâmetros $\left\{\sigma_{i}\right\}$. Desta forma, foram realizadas 4 simulações: uma em 100\% perturbando para $75 \%$; outra de $75 \%$ perturbando para $50 \%$; outra de $50 \%$ para $25 \%$; e por último de $25 \%$ para $0 \%$.

Nas tabelas 4.15 e 4.16, observamos que os intervalos de perturbação estão adequados, uma vez que nenhum $\left|\Delta G\left(\lambda_{i j}\right)\right|$ é superior ao limite recomendado de 8 
Tabela 4.15: Energia livre de aniquilação em $(\mathrm{kcal} / \mathrm{mol})$ para o conjunto de cargas $\left\{q_{i}\right\}$, e o conjunto de parâmetros do potencial atrativo de LennardJones, $\left\{\epsilon_{i}\right\}$, para a molécula de emodina em água, clorofórmio e metanol.

\begin{tabular}{|c|c|c|c|c|}
\hline$\left\{q_{i}\right\}$ & & & $\Delta G\left(\lambda_{i j}\right)$ & \\
\hline$\lambda_{i}$ & $\lambda_{j}$ & água & clorofórmio & metanol \\
\hline 1.00 & 0.95 & $2.02 \pm 0.02$ & $0.31 \pm 0.05$ & $1.40 \pm 0.01$ \\
\hline 0.95 & 0.90 & $1.86 \pm 0.02$ & $0.30 \pm 0.04$ & $1.26 \pm 0.01$ \\
\hline 0.90 & 0.80 & $3.20 \pm 0.02$ & $0.51 \pm 0.04$ & $2.33 \pm 0.01$ \\
\hline 0.80 & 0.70 & $2.58 \pm 0.02$ & $0.45 \pm 0.05$ & $1.93 \pm 0.01$ \\
\hline 0.70 & 0.55 & $2.72 \pm 0.05$ & $0.55 \pm 0.04$ & $2.13 \pm 0.02$ \\
\hline 0.55 & 0.40 & $1.83 \pm 0.03$ & $0.43 \pm 0.04$ & $1.44 \pm 0.02$ \\
\hline 0.40 & 0.20 & $1.50 \pm 0.03$ & $0.37 \pm 0.06$ & $1.09 \pm 0.04$ \\
\hline 0.20 & 0.00 & $0.50 \pm 0.03$ & $0.09 \pm 0.05$ & $0.34 \pm 0.05$ \\
\hline total & & $16.21 \pm 0.22$ & $3.01 \pm 0.37$ & $11.92 \pm 0.17$ \\
\hline \multicolumn{5}{|l|}{$\epsilon_{i}$} \\
\hline 1.000 & 0.875 & $1.71 \pm 0.01$ & $2.38 \pm 0.01$ & $1.81 \pm 0.00$ \\
\hline 0.875 & 0.750 & $1.82 \pm 0.01$ & $2.53 \pm 0.01$ & $1.92 \pm 0.00$ \\
\hline 0.750 & 0.625 & $1.94 \pm 0.01$ & $2.70 \pm 0.01$ & $2.03 \pm 0.01$ \\
\hline 0.625 & 0.500 & $2.09 \pm 0.01$ & $2.90 \pm 0.00$ & $2.17 \pm 0.01$ \\
\hline 0.500 & 0.375 & $2.30 \pm 0.01$ & $3.22 \pm 0.01$ & $2.40 \pm 0.01$ \\
\hline 0.375 & 0.250 & $2.64 \pm 0.01$ & $3.69 \pm 0.01$ & $2.73 \pm 0.02$ \\
\hline 0.250 & 0.125 & $3.22 \pm 0.01$ & $4.49 \pm 0.01$ & $3.24 \pm 0.01$ \\
\hline 0.125 & 0.001 & $4.49 \pm 0.04$ & $7.60 \pm 0.03$ & $5.43 \pm 0.03$ \\
\hline total & & $20.21 \pm 0.11$ & $29.51 \pm 0.09$ & $21.75 \pm 0.09$ \\
\hline
\end{tabular}


Tabela 4.16: Energia livre de aniquilação em $(\mathrm{kcal} / \mathrm{mol})$ para o conjunto de parâmetros $\left\{\sigma_{i}\right\}$ do potencial de Lennard-Jones, para a molécula de emodina em água, clorofórmio e metanol.

\begin{tabular}{ccccc}
\hline \hline$\left\{\sigma_{i}\right\}$ & \multicolumn{3}{c}{$\Delta G\left(\lambda_{i j}\right)$} \\
\hline$\lambda_{i}$ & $\lambda_{j}$ & água & clorofórmio & metanol \\
\hline 1.00 & 0.75 & $-3.78 \pm 0.18$ & $-1.86 \pm 0.10$ & $-1.15 \pm 0.02$ \\
0.75 & 0.50 & $-3.30 \pm 0.11$ & $-1.87 \pm 0.04$ & $-2.13 \pm 0.04$ \\
0.50 & 0.25 & $-4.83 \pm 0.10$ & $-2.59 \pm 0.05$ & $-1.87 \pm 0.05$ \\
0.25 & 0.00 & $-2.06 \pm 0.12$ & $-1.16 \pm 0.02$ & $-1.18 \pm 0.10$ \\
\hline total & & $\mathbf{- 1 3 . 9 6} \pm \mathbf{0 . 5 1}$ & $\mathbf{- 7 . 4 8} \pm \mathbf{0 . 2 1}$ & $\mathbf{- 6 . 3 2} \pm \mathbf{0 . 2 1}$ \\
\hline \hline
\end{tabular}

$\mathrm{kcal} / \mathrm{mol}$. Valores acima desse valor recomendado tornam a convergência muito lenta das variações de energia livre, por isso devem ser evitadas.

Na tabela 4.17, mostramos um sumário da diferença de energia livre de solvatação, que é o negativo da diferença de energia livre de aniquilação, ver figura 4.21 . Portanto, cada etapa da aniquilação, $\mathbf{E M}^{(q, \epsilon, \sigma)} \rightarrow \mathbf{E M}^{(0, \epsilon, \sigma)}, \mathbf{E M}^{(0, \epsilon, \sigma)} \rightarrow \mathbf{E M}^{(0,0.01, \sigma)}$ e $\mathbf{E M}^{(0,0.01, \sigma)} \rightarrow \mathbf{E M}^{(0,0,0)}$, está associado a um termo da diferença de energia livre de solvatação, que são os termos eletrostático, van der Waals e cavitação, respectivamente. A diferença de energia livre de solvatação total é obtida somando a diferença de energia livre de todas as contribuições resultantes em cada etapa, ou seja, $\Delta G_{\text {total }}=\Delta G_{\text {elet }}+\Delta G_{v d W}+\Delta G_{\text {cav }}$.

Observamos que a energia livre de solvatação associada ao termo eletrostático é maior em água, em torno de $-16.2 \mathrm{kcal} / \mathrm{mol}$, e menor em clorofórmio, em torno de $-3.0 \mathrm{kcal} / \mathrm{mol}$. Esses valores mostram que, em termos eletrostáticos é mais favorável solvatar a emodina em água que em clorofórmio. Já em metanol esse termo 
Tabela 4.17: Sumário da energia livre de solvatação de uma molécula de emodina em água, metanol e clorofórmio nas condições normais de pressão e temperatura

\begin{tabular}{cccc}
\hline \hline$\Delta G(\mathrm{kcal} / \mathrm{mol})$ & água & metanol & clorofórmio \\
\hline$\Delta G_{\text {elet }}$ & $-16.21 \pm 0.22$ & $-11.92 \pm 0.17$ & $-3.01 \pm 0.37$ \\
$\Delta G_{v d W}$ & $-20.21 \pm 0.11$ & $-21.75 \pm 0.09$ & $-29.51 \pm 0.09$ \\
$\Delta G_{\text {cav }}$ & $13.96 \pm 0.51$ & $6.32 \pm 0.21$ & $7.48 \pm 0.21$ \\
\hline$\Delta G_{\text {total }}$ & $-22.46 \pm 0.84$ & $-27.35 \pm 0.47$ & $-25.04 \pm 0.67$ \\
\hline \hline
\end{tabular}

eletrostático é intermediário entre clorofórmio e água.

A energia livre solvatação associada ao termo atrativo de van der Waals, para os três solventes estudados, apresentam maior contribuição para a energia livre de solvatação total. Observamos que em clorofórmio, a atração de van der Waals é maior, em torno de $-29.5 \mathrm{kcal} / \mathrm{mol}$, e em metanol, em torno de $-21.7 \mathrm{kcal} / \mathrm{mol}$, e é menor em água, em torno de $-20.2 \mathrm{kcal} / \mathrm{mol}$. Já a energia livre de solvatação associada ao termo de cavitação é maior em modulo para água, em torno de $13.96 \mathrm{kcal} / \mathrm{mol}$ e com valores bem próximos em metanol, $6.32 \mathrm{kcal} / \mathrm{mol}$ e clorofórmio, $7.48 \mathrm{kcal} / \mathrm{mol}$. Mostrando que é mais difícil abrir uma cavidade na água que nos outros solventes. Esse resultado está de acordo com o esperado, devido as fortes ligações de hidrogênio existente na água.

Os valores obtidos do cálculo da energia livre de solvatação da emodina em água, metanol e clorofórmio nos asseguram que a emodina apresenta uma maior afinidade em metanol, depois em clorofórmio e por último, em água. Esses resultados vem corroborar com os resultados encontrados na literatura em que asseguram que a emodina dissolve melhor em solventes orgânicos [22,25].

Nesta parte do trabalho, aproveitamos para comparar esses resultados obtidos 
com perturbação termodinâmica com os resultados obtidos com modelo contínuo de solventes discutidos na seção 4.2.2. Na tabela 4.18, mostramos os valores da diferença de energia livre de solvatação da molécula emodina em água, clorofórmio e metanol, com o solvente descrito com o modelo contínuo polarizável (PCM).

Tabela 4.18: Valores da energia livre de solvatação de uma molécula de emodina em água, metanol e clorofórmio, com o solvente descrito com o modelo contínuo polarizável (PCM).

\begin{tabular}{cccc}
\hline \hline$\Delta G(\mathrm{kcal} / \mathrm{mol})$ & água & metanol & clorofórmio \\
\hline$\Delta G_{\text {elet }}$ & -14.41 & -13.74 & -9.52 \\
$\Delta G_{v d W}$ & -22.39 & -19.34 & -17.16 \\
$\Delta G_{\text {cav }}$ & 33.76 & 24.18 & 23.88 \\
\hline$\Delta G_{\text {total }}$ & -3.04 & -8.90 & -2.80 \\
\hline \hline
\end{tabular}

Comparando os valores obtidos com perturbação termodinâmica com os resultados obtidos com PCM, observamos que a energia livre de solvatação para os três termos, eletrostático, van der Waals e cavitação, concordam em sinais, mas com valores bem diferentes. Os resultados da energia livre de solvatação da emodina em água, metanol e clorofórmio com o modelo PCM, mostram que a emodina apresenta uma maior afinidade em metanol, o que concorda com os resultados com perturbação termodinâmica. Entretanto, mostra que essa molécula apresenta uma maior afinidade em água que em clorofórmio, em discordância com os resultados com perturbação termodinâmica.

Usando os resultados da perturbação termodinâmica para energia livre de solvatação , calculamos a energia livre de partição da emodina água/metanol, $\Delta G_{(a g \rightarrow m e t)}=$ $-4.9 \pm 1.3 \mathrm{kcal} / \mathrm{mol}$ e água $/$ clorofórmio, $\Delta G_{(a g \rightarrow c l o r o)}=-2.6 \pm 1.5 \mathrm{kcal} / \mathrm{mol}$. Esse cálculo da energia livre de partição, para um sistema água/solvente, $\Delta G_{(a g \rightarrow s o l)}$ é dado 
por:

$$
\Delta G_{(a g \rightarrow s o l)}=\Delta G_{s o l}-\Delta G_{a g}
$$

Na literatura, encontramos uma medida do coeficiente de partição $\left(K_{p}\right)$ da emodina em água/octanol no valor de $(13.93 \pm 2.24) \times 10^{3}$ [20]. Com esse coeficiente calculamos a energia livre de partição água/octanol, através da relação dada por:

$$
\Delta G_{(a g \rightarrow o c t)}=-R T \ln \left(K_{p}\right)
$$

Como a medida foi realizada a temperatura de $30{ }^{\circ} \mathrm{C}$, ou seja, $303 \mathrm{~K}$, obtive$\operatorname{mos} \Delta G_{(a g \rightarrow o c t)}=-5.6 \pm 0.1 \mathrm{kcal} / \mathrm{mol}$. Comparando esse valor experimental com os valores teóricos, podemos observar que o valor teórico da energia livre de partição da emodina em água/metanol, é o que mais se aproxima do valor experimental. Apesar da medida ter sido realizada em octanol e o cálculo em metanol, o valor da energia livre nesses dois álcoois é bem próximo. Essa concordância podem ser compreendida, comparando alguns parâmetros conhecidos na literatura para esses solventes. Na ta-

Tabela 4.19: Parâmetros dos solventes metanol, octanol, clorofórmio e água. Onde $E_{T}(30)$, corresponde um parâmetro de polaridade do solvente, segundo a molécula, 2,6-diphenyl-4-(2,4,6-triphenylpyridium-1-yl), $\epsilon$, corresponde a constante dielétrica, $n$, o índice de refração e $\rho$ a densidade em g. $\mathrm{cm}^{-3}$.

\begin{tabular}{ccccc}
\hline \hline solventes & $E_{T}(30)$ & $\epsilon$ & $n$ & $\rho$ \\
\hline metanol & 55.4 & 33 & 1.33 & 0.791 \\
octanol & 48.1 & 10.3 & 1.43 & 0.824 \\
clorofórmio & 39.1 & 4.8 & 1.45 & 1.498 \\
água & 63.1 & 80 & 1.33 & 1.00 \\
\hline \hline
\end{tabular}

bela 4.19, os valores dos parâmetros $E_{T}(30)$ e $\rho$ para os álcoois metanol e octanol estão 
mais próximos do que, para os solventes octanol e metanol. Já os valores da constante dielétrica $\epsilon$ e índices de refração estão mais próximos para os solventes clorofórmio e octanol. Como a energia livre é calculada através da soma das contribuições, eletrostáticas, van der Waals e cavitação, existem uma competitividade entre esses termos para energia livre total. Assim esperamos acontecer para o conjunto de parâmetros dos solventes. Portanto justificar o porquê, através de parâmetros dos solventes, a energia livre de partição água/metanol e água/octanol, apresentam valores semelhantes não é conclusivo.

\subsection{Espectro de absorção}

\subsubsection{Molécula isolada}

O cálculo do espectro eletrônico de absorção foi realizado na geometria da emodina na conformação mais estável, obtida a partir de cálculo ab initio no nível B3LYP/631G*. A geometria dessa molécula está ilustrada na figura 4.23 , com os parâmetros

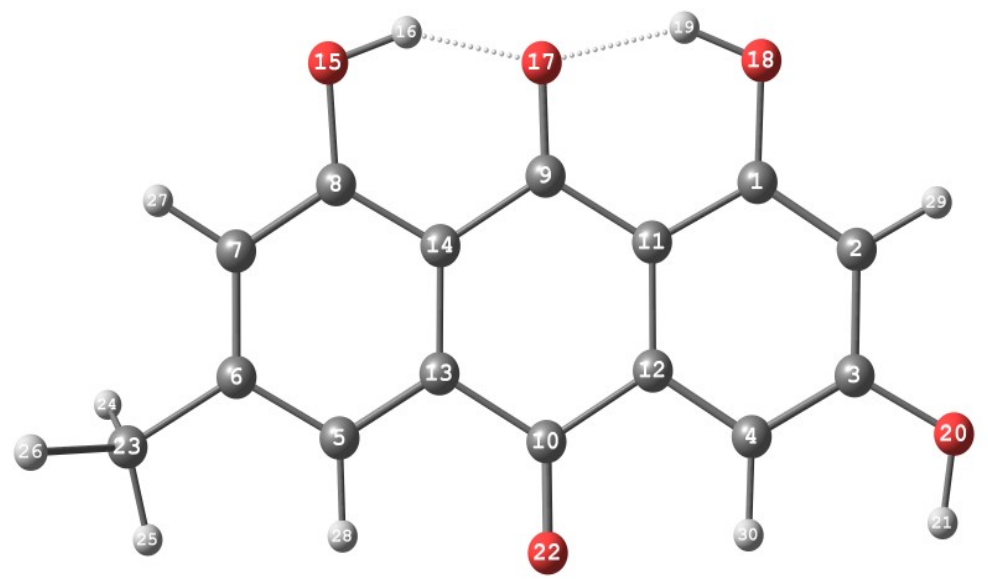

Figura 4.23: Geometria da molécula emodina otimizada com B3LYP/6-31G*.

geométricos apresentados na tabela 4.1. Essa geometria está em boa concordância com a geometria obtida por Nguyen et al. [25], com o nível de cálculo B3LYP/6-31G(d,p). 
Na conformação da emodina otimizada realizamos cálculos do espectro eletrônico de absorção através do método INDO/CIS com parametrização espectroscópica implementado no programa ZINDO. Os resultados obtidos estão ilustrado na tabela 4.20 e figuras 4.24 e 4.25 .

Tabela 4.20: Valores calculados para os máximos das bandas no espectro eletrônico de absorção da emodina isolada, em $10^{3} \mathrm{~cm}^{-1}$, calculado com INDO/CIS. Os orbitais podem ser visualizados nas figuras 4.24 e 4.25. Em parêntese estão mostrados os valores em $\mathrm{nm}$. E a abreviação "f. osc" representa a força do oscilador. Na referência [25], o cálculo do espectro foi calculado com o método B3LYP /6-31g (d,p)//PCM-TD-B3LYP /6-31+G(d,p).

\begin{tabular}{cccccc}
\hline \hline tipo & orbitais & transição & f. osc. & ref [25] & f.osc. [25] \\
\hline$n-\pi^{*}$ & HOMO-3 $\rightarrow$ LUMO +1 & $22.7(440)$ & $<10^{-4}$ & 22.2 & 0.18 \\
$\pi-\pi^{*}$ & HOMO $\rightarrow$ LUMO & $28.5(351)$ & 0.380 & $25.3 ; 26.0$ & $0.03 ; 0.01$ \\
$\pi-\pi^{*}$ & HOMO-1 $\rightarrow$ LUMO & $31.1(322)$ & 0.005 & 31.4 & 0.11 \\
$\pi-\pi^{*}$ & HOMO-2 $\rightarrow$ LUMO & $34.4(291)$ & 0.007 & 35.2 & 0.15 \\
$\pi-\pi^{*}$ & HOMO-1 $\rightarrow$ LUMO +1 & $38.8(258)$ & 0.087 & $37.2 ; 38.9$ & $0.03 ; 0.28$ \\
\hline \hline
\end{tabular}

Analisando os orbitais moleculares das cinco transições, mostradas na tabela 4.20 identificamos que a $1^{\mathrm{a}}$ transição envolve os orbitais moleculares HOMO-3 e LUMO +1 , onde HOMO é o orbital mais alto ocupado e o LUMO é o orbital mais baixo desocupado. Como pode ser observado na figura 4.24, o orbital molecular HOMO-3 envolve algumas ligações de carbono do anel central e majoritariamente orbitais não ligantes dos oxigênios. Tendo uma maior contribuição no O22. Sendo assim, classificamos esse orbital do tipo $n$. Já o orbital $\mathrm{LUMO}+1$, (ver figura 4.24), é perpendicular ao plano da molécula e está delocalizado sobre toda ela. Portanto dado essas características classificamos esse orbital molecular do tipo $\pi^{*}$. Assim, identificamos essa $1^{\mathrm{a}}$ transição como $n-\pi^{*}$. 


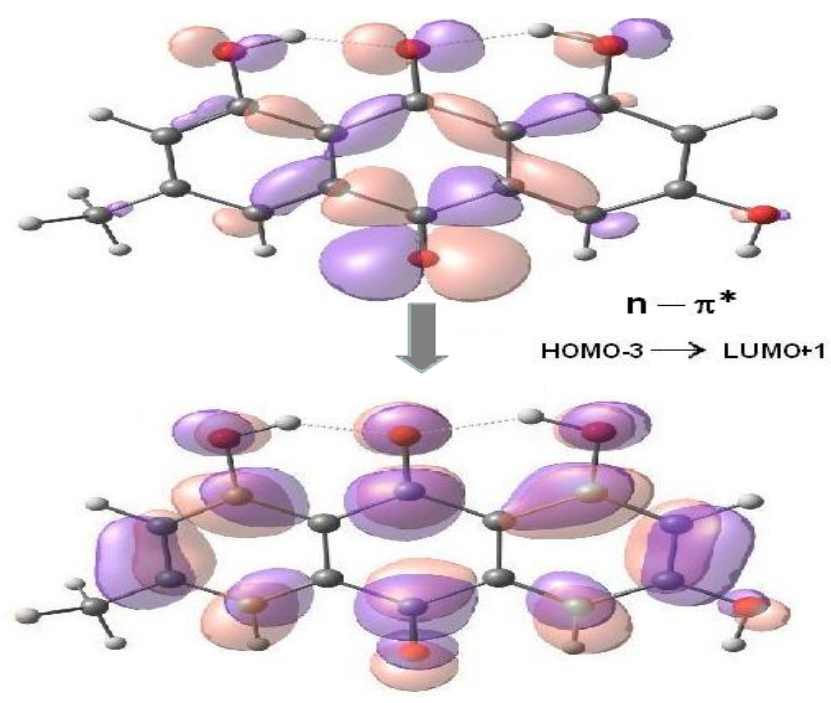

Figura 4.24: Orbitais moleculares envolvidos na transição $n-\pi^{*}$ da emodina.

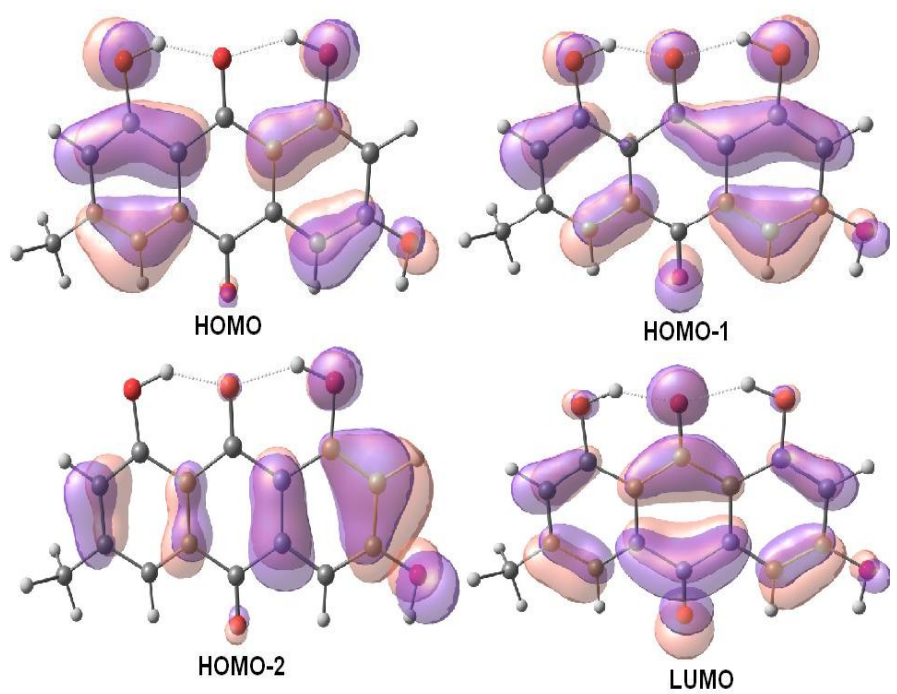

Figura 4.25: Orbitais moleculares envolvidos nas transições $\pi-\pi^{*}$ intensas da emodina.

As demais transições mostradas na tabela 4.20, envolvem os orbitais moleculares ocupados HOMO, HOMO-1 e HOMO-2 e virtuais LUMO e LUMO+1, mostrados nas figuras 4.24 e 4.25 . Todos esses orbitais são perpendiculares ao plano da molécula e apresentam uma grande delocalização. Portanto são orbitais $\pi$ (ocupados) e $\pi^{*}$ (desocupados). Assim, as 4 últimas transições são todas $\pi-\pi^{*}$. 
Comparando os valores dos máximos das bandas com o método INDO/CIS, para emodina isolada, com os do trabalho de Nguyen et al. [25], obtidos com o método B3LYP/6-31g(d,p)//PCM-TD-B3LYP/6-31+G(d,p), para molécula de emodina em etanol, observamos que o máximo da $1^{\mathrm{a}}$ banda, se encontra em $22.7 \times 10^{3} \mathrm{~cm}^{-1}$, com a força de oscilador da ordem de $10^{-5}$ para o método INDO/CIS, enquanto no trabalho de Nguyen, encontram essa banda em $22.2 \times 10^{3} \mathrm{~cm}^{-1}$, portanto com o valor bem próximo do obtido com método semi-empírico. Já a força do oscilador, obtido por Nguyen é bem maior (da ordem de $10^{-1}$ ), e eles classificam essa $1^{a}$ transição do tipo $\pi-\pi^{*}$. Experimentalmente os valores dessa $1^{\text {a }}$ transição são 22.6, 22.7 [25], 22.9 e $23.0 \times 10^{3} \mathrm{~cm}^{-1}$, para os solventes clorofórmio, etanol, metanol e água respectivamente. Esses valores mostram um deslocamento da banda para maiores energias (deslocamento para o azul) com o aumento da polaridade do solvente e esse comportamento é típico de transição $n-\pi^{*}$. Essa discrepância na classificação da $1^{\mathrm{a}}$ transição precisa ser mais cuidadosamente investigada com a utilização de outros funcionais de densidade. Já as demais transições estão todas com o mesmo tipo $\pi-\pi^{*}$, com os valores dos máximos das bandas em boa concordância com nossos resultados. As forças de oscilador não correspondem as intensidades de absorção, mas são proporcionais.

Comparamos também os valores dos máximos das bandas calculados com o método INDO/CIS, com nossas medidas experimentais para emodina em solvente de baixa polaridade (clorofórmio), ver tabela 3.1. Observamos que os valores teóricos estão em boa concordância com os experimentais, onde obtemos teoricamente a $1^{\mathrm{a}}$ banda em $22.7 \times 10^{3} \mathrm{~cm}^{-1}$, e medimos ela em $22.6 \times 10^{3} \mathrm{~cm}^{-1}$. Já para $4^{\mathrm{a}}$ e $5^{\mathrm{a}}$ bandas, obtemos elas na regigão de $34.4 \times 10^{3} \mathrm{~cm}^{-1}$ e $38.8 \times 10^{3} \mathrm{~cm}^{-1}$, enquando medinos essas na região de $34.5 \times 10^{3} \mathrm{~cm}^{-1}$ e $37.3 \times 10^{3} \mathrm{~cm}^{-1}$ respectivamente.

Na figura 4.26, mostramos o gráfico da medida do espectro eletrônico de absorção da molécula emodina em clorofórmio na concentração de $0.1 \mathrm{mM}$, e os valores do espectro calculados com método INDO/CIS para essa molécula isolada. Nesse gráfico 


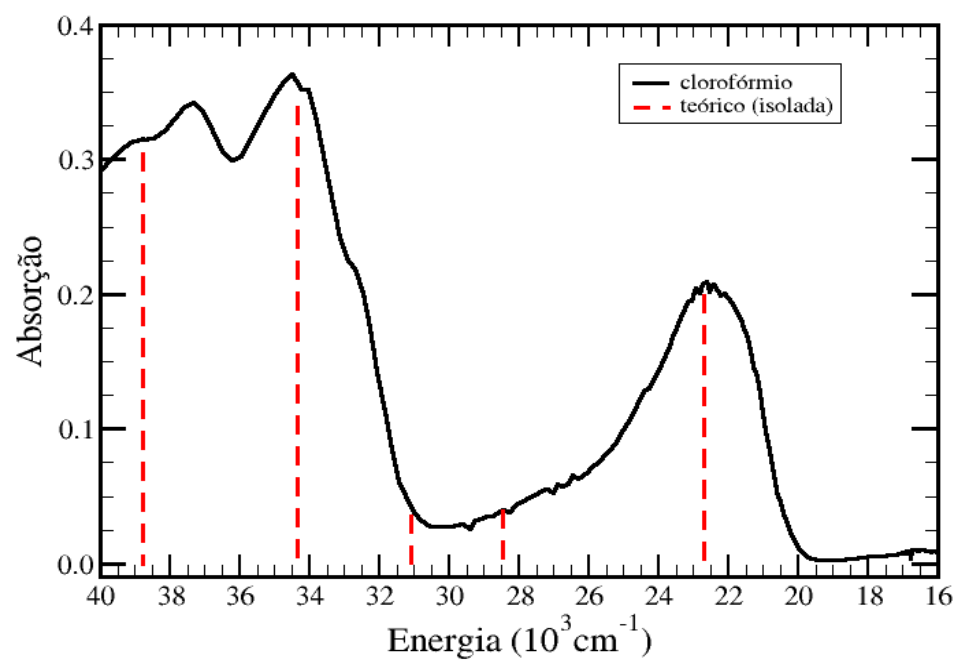

Figura 4.26: Gráfico do espectro eletrônico de absorção da molécula emodina em clorofórmio na concentraçâo de $0.1 \mathrm{mM}$ (linha sólida), com os valores dos máximos das bandas calculados com método INDO/CIS para essa molécula isolada (linha verticais tracejadas). As alturas das linhas verticais não representam a intensidade da transição calculada.

a altura das linhas verticais não representa a intensidade da transição calculada. Elas foram traçadas até a altura do espectro em clorofórmio, apenas para ilustrar a boa concordância das energias de transição calculadas.

Experimentalmente existe evidência que quando há substituição química no O22 [134], a $1^{\mathrm{a}}$ banda em $22.7 \times 10^{3} \mathrm{~cm}^{-1}$, desaparece. Isso mostra que os orbitais que calculamos estão localizados corretamente.

\subsubsection{Molécula em solução}

Usando a geometria da emodina na conformação mostrada na figura 4.23, realizamos cálculos do espectro eletrônico de absorção, usando o método INDO/CIS implementado no programa ZINDO, em meios solventes a fim de analisar o efeito do solvente nos deslocamentos das bandas. Esses cálculos foram realizados com a molécula emodina em meio aquoso, em clorofórmio e em metanol, com a descrição do 
solvente através do modelo contínuo(SCRF).

Nas tabelas 4.21, 4.22 e 4.23, estão os resultados dos cálculos do espectro eletrônico de absorção da emodina em água, clorofórmio e metanol. Analisando esses resultados, observamos que o efeito do solvente no espectro eletrônico de absorção não foi capaz de mudar o caráter da transição, mantendo a $1^{\mathrm{a}}$ transição como $n-\pi^{*}$ e $2^{\mathrm{a}}$ - $5^{\mathrm{a}}$ transições como $\pi-\pi^{*}$.

Tabela 4.21: Valores calculados para os máximos das bandas no espectro eletrônico de absorção da emodina em água em $\left(10^{3} \mathrm{~cm}^{-1}\right)$, calculado com INDO/CIS(SCRF). Em parêntese estão mostrados os valores em $\mathrm{nm}$.

\begin{tabular}{cccc}
\hline \hline \multicolumn{1}{c}{ tipo } & transição & água & experimental \\
\hline$n-\pi^{*}$ & HOMO-3 $\rightarrow$ LUMO +1 & $22.5(444)$ & $23.0(434)$ \\
$\pi-\pi^{*}$ & HOMO $\rightarrow$ LUMO & $28.6(350)$ & $-\ldots$ \\
$\pi-\pi^{*}$ & HOMO-1 $\rightarrow$ LUMO & $31.2(321)$ & $-\ldots$ \\
$\pi-\pi^{*}$ & HOMO-2 $\rightarrow$ LUMO & $34.3(291)$ & $-\cdots$ \\
$\pi-\pi^{*}$ & HOMO-1 $\rightarrow$ LUMO +1 & $38.7(259)$ & $37.6(266)$ \\
\hline \hline
\end{tabular}

Embora existam muitos trabalhos teóricos na literatura abordando o estudo do espectro eletrônico de absorção da emodina [25] [27] [29] [28] [120] [135], eles classificam a $1^{\mathrm{a}}$ transição como $\pi-\pi^{*}$. Entretanto, Kristine et al. [136], classificou essa transição como $n-\pi^{*}$ para a molécula antralin! na região de $23.8 \times 10^{3} \mathrm{~cm}^{-1}(420 \mathrm{~nm})$. Analisando as tabelas $4.20 \mathrm{e} 4.23$, podemos ver que a transição $n-\pi^{*}$, calculada em nosso trabalho se encontra na região de 22.7, 22.5, 22.6 e $22.5 \times 10^{3} \mathrm{~cm}^{-1}(440,444,443$ e $444 \mathrm{~nm})$ para emodina isolada, em água, clorofórmio e metanol respectivamente. Portanto verificamos um efeito muito pequeno para o solvente tanto experimental como teórico.

\footnotetext{
${ }^{1}$ Anthralin (1,8-dihidroxi-9(10H-antracenone) é um fármaco de estrutura química semelhante da emodina, sem o $\mathrm{O} 22$.
} 
Tabela 4.22: Valores calculados para os máximos das bandas no espectro eletrônico de absorção da emodina em clorofórmio em $\left(10^{3} \mathrm{~cm}^{-1}\right)$, calculado com INDO/CIS(SCRF). Em parêntese estão mostrados os valores em $\mathrm{nm}$.

\begin{tabular}{cccc}
\hline \hline \multicolumn{1}{c}{ tipo } & transição & clorofórmio & experimental \\
\hline$n-\pi^{*}$ & HOMO-3 $\rightarrow$ LUMO +1 & $22.6(443)$ & $22.6(442)$ \\
$\pi-\pi^{*}$ & HOMO $\rightarrow$ LUMO & $28.5(351)$ & --- \\
$\pi-\pi^{*}$ & HOMO-1 $\rightarrow$ LUMO & $31.1(321)$ & $-\cdots$ \\
$\pi-\pi^{*}$ & HOMO-2 $\rightarrow$ LUMO & $34.3(291)$ & $34.5(290)$ \\
$\pi-\pi^{*}$ & HOMO-1 $\rightarrow$ LUMO +1 & $38.7(258)$ & $37.3(268)$ \\
\hline \hline
\end{tabular}

Tabela 4.23: Valores calculados para os máximos das bandas no espectro eletrônico de absorção da emodina em metanol em $\left(10^{3} \mathrm{~cm}^{-1}\right)$, calculado com INDO/CIS(SCRF). Em parêntese estão mostrados os valores em $n m$.

\begin{tabular}{cccc}
\hline \hline tipo & transição & metanol & experimental \\
\hline$n-\pi^{*}$ & HOMO-3 $\rightarrow$ LUMO +1 & $22.5(444)$ & $22.9(436)$ \\
$\pi-\pi^{*}$ & HOMO $\rightarrow$ LUMO & $28.6(350)$ & $-\cdots$ \\
$\pi-\pi^{*}$ & HOMO-1 $\rightarrow$ LUMO & $31.2(321)$ & $-\cdots$ \\
$\pi-\pi^{*}$ & HOMO-2 $\rightarrow$ LUMO & $34.3(291)$ & $34.5(290)$ \\
$\pi-\pi^{*}$ & HOMO-1 $\rightarrow$ LUMO +1 & $38.7(259)$ & $37.4(267)$ \\
\hline \hline
\end{tabular}


As quatros transições $\pi-\pi^{*}$, são observada no trabalho de Nguyen et al. [25], na região de $26.0,31.4,35.2$ e $37.24 \times 10^{3} \mathrm{~cm}^{-1}(385,318,284$ e $269 \mathrm{~nm})$ para a $2^{\mathrm{a}}, 3^{\mathrm{a}}, 4^{\mathrm{a}}$ e $5^{\mathrm{a}}$ transição. Observando as tabelas 4.21, $4.22 \mathrm{e} 4.23$, podemos ver que nossos resultados obtidos para essas transições em diferentes meios estão em boa concordância com os resultados encontrado na literatura e com os resultados obtidos experimentalmente, ver tabela 3.1 e figura 3.3 . O efeito solvente, observado nos deslocamento das bandas no espectro eletrônico de absorção da emodina é bem pequeno também para essas bandas. Portanto o efeito de polarização do meio a emodina é desprezível.

Adicionalmente, na tentativa de melhorar o modelo de solvente, selecionamos 75 configurações estatisticamente descorrelacionadas de nossa simulação MC e separamos a molécula de emodina rodeada pelas moléculas de solvente até a terceira camada de solvatação, ou seja, 150 moléculas de água, 200 de clorofórmio e 170 de metanol para realizarmos cálculos quânticos do espectro eletrônico com o método INDO/CIS. Consideramos nesses cálculos o solvente de forma explícita e com cargas pontuais. Porém com o solvente representado com cargas pontuais não conseguirmos obter mudanças significativas das anteriormente obtidas com o modelo contínuo de solvente SCRF. Já com a inclusão das moléculas explícitas obtivemos um deslocamento na $1^{\mathrm{a}}$ banda para $23.7 \times 10^{3} \mathrm{~cm}^{-1}(440 \mathrm{~nm})$ para a solvatação aquosa. Enquanto que para as outras bandas e solventes não obtivemos mudanças significativas.

Desta forma, evidenciamos que experimentalmente a sensibilidade ao solvente do espectro eletrônico de absorção da emodina é devida muito mais ao processo de desprotonação da mesma do que propriamente dito um efeito do solvente em sua estrutura eletrônica. Pois separando os resultados em $p H$ ácido (garantindo que temos apenas a forma neutra da emodina), obtivemos $23.0 \times 10^{3} \mathrm{~cm}^{-1}(434 \mathrm{~nm})$ em água, $22.6 \times 10^{3} \mathrm{~cm}^{-1}(442 \mathrm{~nm})$ em clorofórmio e $22.9 \times 10^{3} \mathrm{~cm}^{-1}(436 \mathrm{~nm})$ em metanol para a $1^{\mathrm{a}}$ banda, $34.5 \times 10^{3} \mathrm{~cm}^{-1}(290 \mathrm{~nm})$ em clorofórmio e metanol para a $2^{\mathrm{a}}$ banda e $37.6,37.4$ e $37.3 \times 10^{3} \mathrm{~cm}^{-1}(266,267$ e $268 \mathrm{~nm})$ para $3^{\text {a }}$ banda em água, clorofórmio e 
metanol respectivamente.

Do ponto de vista teórico os resultados obtidos para a molécula isolada já apresentam concordância com os valores experimentais, 22.7 e $34.438 .8 \times 10^{3} \mathrm{~cm}^{-1}(440$, 291 e $258 \mathrm{~nm}$ ). Colocando os efeitos do solvente nos cálculos teóricos não identificamos mudanças significativas desses valores tanto com modelos contínuo como modelo discreto (explícito e apenas eletrostático com cargas pontuais.)

Sendo assim, evidenciamos que o espectro eletrônico de absorção da molécula de emodina pode ser um bom sensor de $p H$ do ambiente, porém não deve ser utilizado para identificar mudanças do ambiente molecular dessa molécula. 


\section{Capítulo 5}

\section{Conclusões e Perspectivas}

Neste trabalho estudamos as propriedades estruturais e eletrônicas da molécula emodina isoladamente e em diferentes meios, água, clorofórmio e metanol, do ponto de vista experimental (espectro UV-Vis) e teórico, através de cálculos quânticos com funcional de densidade $(B 3 L Y P)$, conjunto de função base de Pople (6-31G*), modelo contínuo polarizável (PCM) e simulações computacionais em meio líquido. Estudos da molécula isolada mostraram que a mudança orientacional nas três hidroxilas provoca a formação de 2 ligações de hidrogênio intramoleculares fortes e uma diminuição no dipolo de 5.5 a $1.7 \mathrm{D}$.

Antes de iniciar o estudo das propriedades da emodina em meio líquido, testamos o conjunto de cargas atômicas (parte mais sensível do potencial de interação) do campo de força OPLS comparativamente as cargas obtidas para a conformação mais estável e média sobres vários confôrmeros. Usando simulações computacionais com os métodos de Dinâmica Molecular(MD) e Monte Carlo(MC), concluímos que os conjuntos de cargas são equivalentes e optamos em usar o OPLS porque pretendemos dar continuidade a esse estudo em membranas, e OPLS já está bem estabelecido na literatura.

O estudo da emodina com Dinâmica Molecular mostrou que as 2 ligações de hidrogênio intramoleculares são raramente quebradas devido as interações com a água, 
o que estabiliza sua geometria com um momento de dipolo aproximadamente $3 \mathrm{D}$. Portanto a pouca capacidade de formar ligações de hidrogênio com a água e seu baixo dipolo lhe atribuem um caráter hidrofóbico. As simulações com a emodina rígida (MC) apresentaram resultados análogos aos obtidos com ela flexível (MD). Portanto o modelo rígido é um bom modelo para estudar as interações da emodina com solventes. Em ambos os métodos, a interação da hidroxila O20H21 com a água foi mais forte comparativamente com as outras hidroxilas. Portanto a hidroxila O20H21 é mais vulnerável a uma desprotonação, o que está em concordância com a proposta experimental da $1^{\text {a }}$ desprotonação na posição 3 [22].

Usando o modelo rígido com o conjunto de cargas OPLS, calculamos a diferença de energia livre de solvatação da emodina em água, clorofórmio e metanol. Como esperado encontramos que a emodina apresentou:

(i) uma maior interação eletrostática com a água,

(ii) uma maior cavitação também na água,

(iii) uma melhor solvatação em metanol,

Comparando a solvatação em metanol e clorofórmio, a emodina apresentou menor cavitação $\left(\Delta G_{\text {cav }}=-1.16 \mathrm{kcal} / \mathrm{mol}\right)$, maior interação eletrostática $\left(\Delta G_{\text {elet }}=-8.91\right.$ $\mathrm{kcal} / \mathrm{mol})$, e menor atração de van der Waals $\left(\Delta G_{v d W}=7.76 \mathrm{kcal} / \mathrm{mol}\right)$ em metanol. Sendo devido a interação eletrostática que a emodina solvata melhor em metanol.

Calculamos a energia livre de partição da emodina água $/$ metanol, $\Delta G_{(a g \rightarrow m e t)}=$

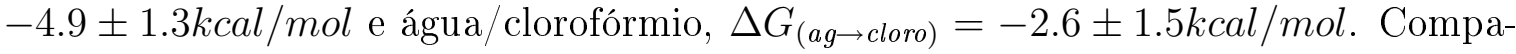
rando o valor da energia livre de partição água/metanol, com o valor experimental encontrado na literatura, água/octanol $\left(\Delta G_{(a g \rightarrow o c t)}=-5.6 \pm 0.1 \mathrm{kcal} / \mathrm{mol}\right)$, obtivemos um valor teórico próximo do valor experimental. 
Realizamos medidas do espectro eletrônico de absorção da emodina em água, clorofórmio e metanol, obtivemos que essa molécula é caracterizada por 3 bandas em $23.0 \times 10^{3} \mathrm{~cm}^{-1}(434 \mathrm{~nm})$ em água, $22.6 \times 10^{3} \mathrm{~cm}^{-1}(442 \mathrm{~nm})$ em clorofórmio e $22.9 \times 10^{3} \mathrm{~cm}^{-1}$ $(436 \mathrm{~nm})$ em metanol para a $1^{\mathrm{a}}$ banda, $34.5 \times 10^{3} \mathrm{~cm}^{-1}(290 \mathrm{~nm})$ em clorofórmio e metanol para a $2^{\text {a }}$ banda e $37.6,37.4$ e $37.3 \times 10^{3} \mathrm{~cm}^{-1}(266,267$ e $268 \mathrm{~nm})$ para $3^{\text {a }}$ banda em água, clorofórmio e metanol respectivamente. Para comparar com essas medidas, calculamos os deslocamentos das bandas do espectro eletrônico de absorção da emodina na conformação mais estável (formando 2 ligações de hidrogênio intramoleculares) com o método INDO/CIS para a molécula isolada e em água, clorofórmio e metanol. Como principais resultados, obtivemos que tanto o espectro UV-Vis experimental como o teórico mostrou ser pouco sensível ao solvente. Porém deve-se tomar cuidado com o $p H$ da solução, uma vez que em $p H$ neutro a forma desprotonada coexiste com a forma neutra.

Os valores obtidos para os máximos das 3 bandas do espectro UV-Vis da emodina isolada, foram 22.7, 34.4 e $38.8 \times 10^{3} \mathrm{~cm}^{-1}(440,291$ e $258 \mathrm{~nm})$, para $1^{\mathrm{a}}, 2^{\mathrm{a}}$ e $3^{\mathrm{a}}$ banda respectivamente. Portanto os valores teóricos para a molécula isolada já da uma boa concordância com o experimental. Com o modelo contínuo SCRF não se identifica mudanças significativas nem com modelo explícito de solvente. Assim, concluímos que a estrutura eletrônica da emodina não é muito sensível ao efeito do solvente e, portanto o espectro eletrônico de absorção não é uma boa propriedade para identificar mudanças do ambiente molecular dessa molécula, mais sim mudanças no $p H$. 


\section{Referências Bibliográficas}

[1] W. C. Evans. Treas and Evans Pharmacognosy. W.B. Saunders, London, (1996).

[2] J. Bruneton. Pharmacognosy, phytochemistry, medical plants. Intercept Ltd and Lavoisier Publishing, Paris, (1999).

[3] B. A. P. Van den Gorkom, E. G. E. de Vries, A. Karrenbeld and J. H. Kleibeuker. Anthranoid laxatives and their potential carcinogenic effects. Alimentary Pharmacology and Therapeutics. 13, 443 (1999).

[4] H. Anke, I. Kolthoum and H. Laatsch. Metabolic products of microorganisms. 192. The anthraquinones of the Aspergillus glaucus group. II. Biological activity. Archives of Microbiology. 126, 231 (1980).

[5] T. Le Van. Emodin a fungal metabolite and the effects of emodin on the growth of some soil microorganisms. Acta Agraria et Silvestria Seriea Agraria. 23, 235 (1984).

[6] W. H. Wang and J. G. Chung. Emodin-induced inhibition of growth and DNA damage in the Helicobacter pylori. Current Microbiology. 35, 262 (1997).

[7] U. P. Singh, K. P. Singh, S. P. Singh and V. B. Ram. Effect of emodin isolated from Rhamnus triquetra on spore germination of some fungi. Fitop. Brasileira. 17, 420 (1992). 
[8] H. H. Wang. Antitrichomonal action of emodin in mice. J. of Ethnopharmac. 40, 111 (1993).

[9] D. L. Barnard, J. H. Huffman, J. L. Morris, S. G. Wood, B G. Hughes and R. W. Sidwell. Evaluation of the antiviral activity of anthraquinones, anthrones and anthraquinone derivatives against human cytomegalovirus. Antiviral Research. 17, 63 (1992).

[10] K. Kawai, T. Kato, H. Mori, J. Kitamura, Y. Nozawa. A comparative study on cytotoxicity and biochemical properties of anthraquinone mycotoxins modin and skyrin from Penicillium islandium. Toxicol. Lett. 20, 155 (1984).

[11] A. Kumar, S. Dhawan and B.B. Aggarwal. Emodin (3-methyl-1,6,8trihydroxyanthraquinone) inhibits TNF-induced NF-kappaB activation, IkappaB degradation, and expression of cell surface adhesion proteins in human vascular endothelial cells. Oncogene. 17, 913 (1998).

[12] Y.C. Kuo, H.C. Meng and W.J. Tsai. Regulation of cell proliferation, inflammatory cytokine production and calcium mobilization in primary human $T$ lymphocytes by emodin from Polygonum hypoleucum Ohwi. Inflamm. Res. 50, $73(2001)$.

[13] Y.C. Chen, S.C. Shen, W.R. Lee, E.L. Hsu, H.Y. Lin, C.H. Ko and S.W. Tseng. Emodin induces apoptosis in human promyeloleukemic HL-60 cells accompanied by activation of caspase 3 cascade but independent of reactive oxygen species production. Biochem. Pharmacol. 64, 1713 (2002).

[14] G. Srinivas, R.J. Anto, P. Srinivas, S. Vidhyalakshmi, V.P. Senan and D. Karunagaran. Emodin induces apoptosis of human cervical cancer cells through poly (ADP-ribose) polymerase cleavage and activation of caspase-9. Eur. J. of Pharmacol. 473, 117 (2003). 
[15] T.C. Chan, C.J. Chang, N.M. Koonchanok and R.L. Geahlen. Selective inhibition of the growth of ras-transformed human bronchial epithelial cells by emodin a protein-tyrosine kinase. Biochem. Biophys. Res. Commun. 193, 1152 (1993).

[16] S. P. D. Dwivedi, V. B. Pandey, A. H. Shah and Y. B. Rao. Chemical constituents of Rhammuns procumbens and pharmacological actions ofemodin. Phytotherapy Research. 2, 51, (1988).

[17] R. K. Goel, G. Das Gupta, S. N. Ram and V. B. Pandey. Antiulcerogenic and anti-inflammatory effects of emodin, isolated from Rhammus triquerta wall. Indian J. of Exp. Biolog. 29, 230 (1991).

[18] X. M. Zhou and Q. H. Chen. Biochemical study of chinese rhubarb XXII. Inhibitory effect of anthraquinone derivatives on sodium-potassium-ATPase of a rabbit renal medulla and their diuretic actin. Acta Phamacologica Sinica. 23, 17 (1988).

[19] E. L. Duarte, T. R. Oliveira, D. S. Alves, V. Micol and M. T. Lamy. On the interaction of the anthraquinone barbaloin with negatively charged DMPG bilayers. Langmuir. 24, 4041, (2008).

[20] D.S. Alves, L. Pérez-Fons, A. Estepa and V. Micol. Membrane-related effects underlying the biological activity of the anthraquinones emodin and barbaloin. Biochem. Pharm. 68, 549 (2004).

[21] R. H. Thomson, Naturally Occurring Quinones, 2nd ed. Academic Press, London, (1971).

[22] T. Pal and N. R. Jana. Emodin (1,3,8-trihydroxy-6-methylanthraquinone): A spectrophotometric reagent for the determination of beryllium(II), magnesium(II) and calcium(II). Analyst. 118, 1337 (1993). 
[23] L. H. Keith and D. B. Walters. National Toxicology Program's Chemical Solubility Compendium. Lew. Publish. United States, (1992).

[24] D. Wang, G. Yang and X. Song. Determination of $p$ Ka values of anthraquinone compounds by capillary electrophoresis. Electroph. 22, 464 (2001).

[25] S. C. Nguyen, B. K. V. Hansen, S. V. Hoffmann and J. Spanget-Larsen. Eletronic states of emodin and its conjugate base. Synchrotron linear dichroism spectroscopy and quantum chemical calculations. Chem. Phys. 352, 167 (2008).

[26] V. Y. Fain, B. E. Zaitserv and M.A. Ryabov. Tautomerism of the natural anthraquinones physcion and emodin and analogs. Chem. Natural Comp. 41, 411 (2005).

[27] V. Y. Fain, B. E. Zaittsev and M. A. Ryabov. Anthraquinones tautomerism. Hydroxy-substituted anthraquinones. Russ. J. Org. Chem. 43, 1460 (2007).

[28] D. Jacquemin, X. Assfeld, J. Preat and E. A. Perpete. Comparison of theoretical approaches for predicting the UV/Vis spectra of anthraquinones. Mol. Phys. 105, 325 (2007).

[29] V. Y. Fain, B. E. Zaittsev and M. A. Ryabov. Tautomerism an rotation isomerism of 1,4-diamino-9,10-antraquinone. Russ. J. General Chem. 78, 2167 (2008).

[30] C. Reichardt. Solvatochromic dyes as solvent polarity indicators. Chem. Rev. 94, 2319 (1994).

[31] L. Onsager. Electric moments of molecules in liquids. J. Chem. Soc. 58, 1486 (1936).

[32] J. G. Kirkwood. The interaction of ions in an ionic medium. Chem. Phys. 2, 351 (1934). 
[33] D. Rinaldi and J. L. Rivail. Polarisabilites moléculaires et effet diélectrique de milieu à l'état liquide. Étude théorique de la molécule d'eau et de ses diméres. Theor. Chim. Acta. 32, 57 (1973).

[34] D. Rinaldi and J. L. Rivail. A quantum chemical approach to dielectric solvent effects in molecular liquids. Chem. Phys.. 18, 233 (1976).

[35] O. Tapia and O. Goscinski. Self-consistent reaction field theory of solvent effects. Mol. Phys. 29, 1653 (1975).

[36] J. Tomasi and M. Persico. Molecular Interactions in Solution: An Overview of Methods Based on Continuous Distributions of the Solvent. Chem. Rev. 94, 2027, (1994).

[37] S. Chalmet, D. Rinaldi and M.F. Ruiz-López. A QM/MM/continuum model for computations in solution: Comparison with $Q M / M M$ molecular dynamics simulations. Inter. J. Quantum Chem. 84, 559 (2001).

[38] P. Bandyopadhyay, M. S. Gordon, B. Mennucci and J. Tomasi. An integrated effective fragment-polarizable continuum approach to solvation: Theory and application to glycine. J. Chem. Phys. 116 , 5023 (2002).

[39] S. Miertus, E. Scrocco and J. Tomasi.Electrostatic Interaction of a Solute with a Continuum. A Direct Utilization of ab initio Molecular Potentials for the Prevision of Solvent Effects. Chem. Phys. 55, 117 (1981).

[40] N. Metropolis, A. W. Rosenbluth, M. N. Rosenbluth, A. H. Teller and E. Teller. Equation of state calculations by fast computing machines. J. Chem. Phys. 21, 1087 (1953).

[41] B. J. Alder and T. E. Wainwright. Phase transition for a hard sphere system. J. Chem. Phys. 27, 1208 (1957). 
[42] B. J. Alder and T. E. Wainwright. Studies in Molecular Dynamics. I. general method. J. Chem. Phys. 31, 459 (1959).

[43] J. Gao. Methods and applications of combined quantum mechanical and molecular mechanical potentials. Rev. Comp. Chem. 7, 119 (1996).

[44] T. N. Truong and E. V. Stefanovich. Development of a perturbative approach for Monte Carlo simulations using a hybrid ab initio QM/MM method. Chem. Phys. Lett. 256, 348 (1996).

[45] S. Canuto and K. Coutinho. Solvent effects from a sequential Monte Carlo quantum mechanical approach. Adv. Quantum Chem. 28, 89 (1997).

[46] K. Coutinho, M. J. de Oliveira and S. Canuto Sampling configurations in Monte Carlo simulations for quantum mechanical studies of solvent effects. Int. J. Quantum Chem. 66, 249 (1998).

[47] M. C. P. Lima, K. Coutinho, W. R. Rocha and S. Canuto. Reaction mechanism and tautomeric equilibrium of 2-Mercaptopyridine in gas phase and in aqueous solution: A combined monte carlo and quantum mechanics study. J. Phys. Chem. A 110, 7253 (2006).

[48] K. J. de Almeida, K. Coutinho, W. B. de Almeida, W. R. Rocha and S. Canuto. A Monte Carlo - Quantum Mechanical study of the solvatochromism of pyrimidine in water and in carbon tetrachloride. Phys. Chem. Chem. Phys. 3, 1583 (2001).

[49] M. P. Allena and D. J. Tildesley. Computer Simulation of Liquids. Claredon Press, London, (1987).

[50] H. Müller-Krumbhaar and K. Binder. Dynamic properties of the Monte Carlo method in statistical mechanics. J. Stat. Phys. 8, 1 (1973). 
[51] C. Cohen-Tannoudji, B. Diu and F. Laloë. Quantum Mechanics,volume one. J. Wiley\&Sons , Paris (1973)

[52] D. Rayner and D.R. Hartree. The calculation of atomic structure. J. Wiley, New York (1957).

[53] W. Kohn and P. Hohenberg. Inhomogeneous electron gas. Phys. Rev.. 136, B864 (1964)

[54] M. Born and J. R. Oppenheimer. Zur Quantentheorie der Molekeln. Ann. Phys. Leipzig. 84, 457 (1927).

[55] J. D. M. Vianna, A. Fazzio and S. Canuto. Teoria Quântica de Moléculas e Sólidos, Simulação Computacional. Livraria da Física, São Paulo, (2004).

[56] N. H. Morgon e K. Coutinho. (Eds). Métodos de Química Teórica e Modelagem Molecular. Livraria da Física, São Paulo, (2007).

[57] F. L. Pilar. Elementary Quantum Chemistry. Dover Publications, INC, Mineola, New York, (1990).

[58] P. Atkins and R. Friedman. Molecular Quantum Mechanics. Oxford University Press, New York (2005).

[59] S. T. Thornton and J. B. Marion. Classical Dynamics of Particles and Systems. Thomson Brooks/Cole, Belmont (2004).

[60] J. C. Slater. The theory of complex spectra. Phys. Rev. 34, 1293 (1929).

[61] C. C. J. Roothaan. New Developments in Molecular Orbital Theory. Rev. Mod. Phys. 26, 69 (1951).

[62] H. C. Georg. Efeitos do Meio em Propriedades Conformacionais e Eletrônicas de Moléculas. Tese de doutoramento, Universidade de São Paulo, São Paulo (2006). 
[63] R. Pariser and R. G. Parr. A semi-empirical theory of the electronic spectra and electronic structure of complex unsaturated molecules. I. J. Chem. Phys. 21, 466 (1953).

[64] R. Hoffmann. An extended Hückel theory. I. Hydrocarbons. J. Chem. Phys. 39, $1397(1963)$.

[65] J. A. Pople, D. P. Santry and G. A. Segral. Approximate self-consistent molecular orbital theory. I. Invariant procedures. J. Chem. Phys. 43, S129 (1965).

[66] J. A. Pople and G. A. Segral. Approximate self-consistent molecular orbital theory. II. Calculations with complete neglect of differential overlap. J. Chem. Phys. 43, S136 (1965).

[67] J. A. Pople and G. A. Segral. Approximate self-consistent molecular orbital theory. III. CNDO results for $A B_{2}$ and $A B_{3}$ systems. J. Chem. Phys. 44, 3289 (1966).

[68] J. A. Pople, D. L. Beveridge and P. A. Dobosh. Approximate self-consistent molecular orbital theory. V. Intermediate neglect of differential overlap. J. Chem. Phys. 47, 2026 (1967).

[69] W. Thiel. The MNDOC method, a correlated version of the MNDO model. J. Am. Chem. Soc. 103, 1413 (1981).

[70] J. E. Ridley and M. C. Zerner. An intermediate neglect of differential overlap technique for spectroscopy: pyrrole and the azines. Theor. Chim. Acta. 32, 111 (1973).

[71] J. E. Ridley and M. C. Zerner. Triplet states via intermediate neglect of differential overlap: benzene, pyridine and the diazines. Theor. Chim. Acta. 42, 223 (1976). 
[72] M. Malagoli and W. Thiel. A semiempirical approach to nonlinear optical properties of large molecules at the MNDO and MNDO/d level. Chem. Phys. 203, 73 (1996).

[73] J. Del Bene and H. H. Jaffé. Use of the CNDO method in spectroscopy. I. benzene, pyridine, and the diazines. J. Chem. Phys. 48, 1807 (1968).

[74] M. C. Zerner. ZINDO: A semi-empirical program package. University of Florida, Gainesville, FL 32611.

[75] S. S. de Albuquerque. Violação da Teoria de Escala em Sistemas Unidimensionais com Desordem Diluída e Distemas com Acoplamentos de Longo-Alcance. Tese de doutoramento. Universidade Federal de Alagoas, Maceió (2006).

[76] C. Kittel. Introduction to Solid State Physics. John Wiley and Sons, New York (1968).

[77] H. A. Duarte. Índice de reatividade química a partir da teoria do funcional de densidade: formalismo e perspectivas. Quimimca Nova. 24, 501, (2001).

[78] W. Kohn and L. J. Sham. Self-consistent equations including exchange and correlation effects. 140, A1133 (1965).

[79] A. D. Becke. Density-functional exchange-energy approximation with correct asymptotico behavior. Phys. Rev. A 38, 3098 (1988).

[80] A. D. Becke. Density-functional thermochemistry. I. The effect of the exchangeonly gradient correction. J. Chem. Phys 96, 2155 (1992).

[81] A. D. Becke. Density-functional thermochemistry. III. The role of exact exchange. J. Chem. Phys. 98, 5648 (1993).

[82] J. P. Perdew, K. Burke and M. Ernzenhof. Generalized Gradient Approximation Made Simple. Phys. Rev. lett. 77, 3865 (1996). 
[83] A. D. Becke. Density-functional thermochemistry. II. The effect of the PerdewWang generalized-gradient correlation correction. J. Chem. Phys 97, 9173 (1992).

[84] J. P. Perdew. Density-functional approximation for the correlation energy of the inhomogeneous electron gas. Phys. Rev. B 33, 8822 (1986).

[85] J. P. Perdew and W. Yue Accurate and simple density functional for the electronic exchange energy: Generalized gradient approximation. Phys. Rev. B 33, $8800(1986)$.

[86] J. P. Perdew, S. Kurth, A. Zupan and P. Blaha. Accurate Density Functional with Correct Formal Properties: A Step Beyond the Generalized Gradient Approximation. Phys. Rev. Lett. 82, 2544 (1999).

[87] S. Dressler and W. Thiel. Anharmonic force fields from density functional theory. Chem. Phys. Lett. 273, 71 (1997).

[88] C. Lee, W. Yang and R. G. Parr. Development of the Colle-Salvetti correlationenergy formula into a functional of the electron density. Phys. Rev. B 37, 785 (1988)

[89] A. D. Becke. A new inhomogeneity parameter in density-functional theory. $J$. Chem. Phys. 109, 2092 (1998).

[90] K. Kim and K. D. Jordan. Comparison of density functional and MP2 calculations on the water monomer and dimer. J. Phys. Chem. 98, 10098 (1994).

[91] P. J. Stephens, F. J. Devlin, C. F. Chabalowski and M. J. Frisch. Ab initio calculation of vibrational absorption and circular dichroism spectra using density functional force fields. J. Phys. Chem. 98, 11623 (1994). 
[92] J. A. Chevary, S. H. Vosko, K. A. Jackson, M. R. Pederson and D. J. Singh. Atoms, molecules, solids, and surfaces: Applications of the generalized gradient approximation for exchange and correlation. Phys. Rev. B 46, 6671 (1992).

[93] A. Szabo and N. S. Ostlund. Modern Quantum Chemistry. Dover, Mineola (1996).

[94] L. E. Chirlian and M. M. Francl. Atomic charges derived from electrostatic potentials: A detailed study. J. Comp. Chem. 8, 894 (1987).

[95] C. I. Bayly, P. Cieplak, W. Cornell and P. A. Kollman. A well-behaved electrostatic potential based method using charge restraints for deriving atomic charges: the RESP model. J. Phys. Chem. 40, 10269 (1993).

[96] A. K. Rappe and W. A. Goddard III. Charge equilibration for molecular dynamics simulations. J. Phys. Chem. 8, 3358 (1991).

[97] C. M. Breneman and K. B. Wiberg. Determining atom-centered monopoles from molecular electrostatic potentials. The need for high sampling density in formamide conformational analysis. J. Comp. Chem. 11, 361 (1990).

[98] H. A. Carlson, T. B. Nguyen, M. Orozco and W. L. Jorgensen. Accuracy of free energies of hydration for organic molecules from 6-31g*-derived partial charges. J. Com. Chem. 14, 1240 (1993).

[99] V. Ludwig, K. Coutinho and S. Canuto. A Monte Carlo - quantum mechanics study of the lowest $n-p *$ and $p-p *$ states of uracil in water. Phys. Chem. Chem. Phys. 9, 4907 (2007).

[100] H. C. Georg, K. Coutinho and S. Canuto. Solvent effects on the UV-visible absorption spectrum of benzophenone in water: A combined Monte Carlo quantum mechanics study including solute polarization. J. Chem. Phys. 126, 34507 (2007). 
[101] T. L. Fonseca, K. Coutinho and S. Canuto. Probing supercritical water with the $n-p *$ transition of acetone: A Monte Carlo/quantum mechanics study. J. Chem. Phys. 126, 34508 (2007).

[102] H. C. Georg, K. Coutinho and S. Canuto. Converged electronic polarization of acetone in liquid water and the role in the $n-p *$ transition. Chem. Phys. Lett. 429, 119 (2006).

[103] A. C. Borin, L. Serrano-Andrés, V. Ludwig, K. Coutinho and S. Canuto. Theoretical Electronic Spectra of 2-Aminopurine in Vapor and in Water. Int. J. Quantum Chem. 106, 2564 (2006).

[104] D. Frenkel and B. Smit. Understanding Molecular Simulation. Academic Press, New York, (1996).

[105] K. Coutinho. Modelo Discreto de Solvente Solvatocromismo no Espectro de Absorção Molecular. Tese de doutoramento, Universidade de São Paulo, São Paulo (1997).

[106] S. A. Adcock and J. A. McCammom. Molecular dynamics: survey of methods simulating the activity of proteins. Chem. rev. 106, 1589 (2006).

[107] S. R. A. Salinas. Introdução à Física Estatística. EDUSP, São Paulo, (2005).

[108] K. Coutinho and S. Canuto. DICE: A Monte Carlo program for liquid simulation. University of São Paulo, São Paulo (2003).

[109] W. L. Jorgensen, J. D. Madura and Carol J. Swenson. Optimized intermolecular potential functions for liquid hydrocarbons. J. Am. Chem. Soc. 106, 6638 (1984).

[110] W. L. Jorgensen, D. S. Maxwell and J. Tirado-Reves. Development and testing of the OPLS all-atom force field on conformational energetics and properties of organic liquids. J. Am. Chem. Soc. 118, 11225 (1996). 
[111] W. F. V. Gunsteren and P. K. W. Weiner. Computer Simulation of Biomolecular Systems: Theoretical and Experimental Aplications. Escom, Leiden, (1989).

[112] D. L. Beveridge and F. M. DiCapua. Free energy via molecular simulation: applications to chemical and biomolecular systems. Annu. rev. Biophys. 18, 431 (1989).

[113] P. Kollman. Free energy calculations: Applications to chemical and biochemical phenomena. Chem. Rev. 93, 2395 (1993).

[114] P. A. Bash, U. C. Singh, R. Langridge and P. Kollman. Free energy calculations by computer simulation. Science. 236, 564 (1987).

[115] M. Mezei and D. L. Beveridge. Free Energy Simulations. Ann. N. Y. Acad. Sci. 482, 1 (1986).

[116] C. H. Bennett Efficient estimation of free energy differences from Monte Carlo data. J. Comp. Phys. 22, 245 (1976).

[117] R. W. Zwanzig. High-temperature equation of state by a perturbation method. I. nonpolar gases. J. Chem. Phys. 22, 1420 (1954).

[118] M. J. Frisch, et al. GAUSSIAN 03: Connected system of programs for performing semiempirical, ab initio, and density functional molecular orbital (MO) calculations, Gaussian, Inc. Wallingford CT, (2004).

[119] J. W. Ponder, et. al. TINKER 4.2: Molecular modeling software is a complete and general package for molecular mechanics and dynamics, with soma special features for biopolymers, Washington University (2004).

[120] S. Møller, K. B. Andersen, J. Spanget-Larsen and J. Waluk. Excited-state intramolecular proton transfer in anthralin quantum chemical calculations and fluorescence spectra. Chem. Phys. Lett.. 291, 51 (1998). 
[121] H. J. C. Berendsen, J. P. M. Postma, W. F. van Gunsteren, A. DiNola and J. R. Haak. Molecular dynamics with coupling to an external bath J. Chem. Phys. 81, 3684 (1984).

[122] L. Verlet. Computer 'experiments' on classical fluids. I. Thermodynamical properties of Lenard-Jones molecules. Phys. Rev. 159, 98 (1967).

[123] H. J. C. Berendsen, J. P. M. Postma, W. F. van Gunsteren, and J. Hermans. Interaction models for water in relation to protein hydration. In Intermolecular Forces. B. Pullman, ed. Reidel, Dordrecht. (1981).

[124] T. Darden, D. York and L. Pedersen. Particle mesh Ewald: An N.log(N) method for Ewald sums in large systems. J. Chem. Phys. 98, 10089 (1993).

[125] S. Canuto and K. Coutinho. From hydrogen bond to bulk: Solvation analysis of the $n-\pi *$ transition of formaldehyde in water. J. Quantum Chem. 77, 192 (2000).

[126] W. L. Jorgensen, J. Chandrasekhar, J. D. Madura, R. W. Impey and M. L. Klein. Comparison of simple potential functions for simulating liquid water. J. Chem. Phys. 79, 926 (1983).

[127] S. Canuto, K. Coutinho and D. Trzesniank. New developments in Monte Carlo/quantum mechanics methodology. The solvatochromism of $\beta$-carotene in different solvents. Adv. Quantum Chem. 41, 161 (2002).

[128] H. C. Georg, K. Coutinho and S. Canuto Solvent effects on the UV-visible absorption spectrum of benzophenone in water: A combined Monte Carlo quantum mechanics study including solute polarization. J. Chem. Phys. 126, 34507 (2007).

[129] A. Ben-Naim. Solvation Thermodynamics. Plenum Press, New York, (1987). 
[130] W.L. Jorgensen, J.K. Buckner, S. Boudon and J. Tirado-Rives. Efficient computation of absolute free energies of binding by computer simulations. Application to the methane dimer in water. J. Chem. Phys. 89, 3742 (1988).

[131] H. C. Georg, K. Coutinho, S. Canuto. A look inside the cavity of hydrated acyclodextrin: A computer simulation study. Chem. Phys. Lett. 413, 16 (2005).

[132] D. L. Beveridge and F. M. DiCapua. Free energy via molecular simulation: applications to chemical and biomolecular systems. Ann. Rev. Biophys. Biophys. Chem. 18, 431 (1989).

[133] W. L. Jorgensen, J. M. Briggs and M. L. Contreras. Relative partition coefficients for organic solutes from fluid simulations. J. Phys. Chem. 94, 1683 (1990).

[134] A. R. Cunha and C. C. Vequi-Suplicy. Medidas do espectro eletrônico de absorção da molécula barbaloina em água. Medidas realizadas no laboratório de Biofísica do IFUSP. São Paulo (2008).

[135] B. O. Myrvold, J. Spanget-Larsen and E. W. Thulstrup. Transition moment directions in 9,10-anthraquinones symmetrical cases. Chemical Physics. 104, 305 (1986).

[136] K. B. Andersen and J. Spanget-Larsen. Electronic transitions and intramolecular hydrogen bonding in anthralin. UV-VIS linear dichroism spectroscopy and quantum chemical calculations. Spectrochim. Acta Part A. 53, 2615 (1997). 


\section{Apêndice A}

\section{Aproximação de Born-Oppenheimer(BO)}

Na equação 2.1, o hamiltoniano $\hat{\mathbf{H}}$ que descreve um sistema composto por $M$ núcleos e $N$ elétrons é mostrado na equação A.1 em unidades atômicas dado por:

$$
\begin{array}{r}
\hat{\mathbf{H}}(\mathbf{r}, \mathbf{R})=-\sum_{i=1}^{N} \frac{1}{2} \nabla_{i}^{2}-\sum_{A=1}^{M} \frac{1}{2 M_{A}} \nabla_{A}^{2}-\sum_{i=1}^{N} \sum_{A=1}^{M} \frac{Z_{A}}{r_{i A}}+\sum_{i<j}^{N} \frac{1}{r_{i j}}+\sum_{A<B}^{M} \frac{Z_{A} Z_{B}}{r_{A B}} \\
=\hat{\mathbf{T}}_{\text {elet }}+\hat{\mathbf{T}}_{\text {núcl }}+\hat{\mathbf{V}}_{\text {elet-núcl }}+\hat{\mathbf{V}}_{\text {elet }}+\hat{\mathbf{V}}_{\text {núcl }}
\end{array}
$$

onde $\mathbf{r} \equiv\left\{r_{i}\right\}$ corresponde ao vetor de posição do elétron $i, \mathbf{R} \equiv\left\{\mathbf{R}_{A}\right\}$ corresponde a posição do núcleo $A$ e $r_{i A} \equiv\left|\mathbf{r}_{i}-\mathbf{R}_{A}\right|$ corresponde a distancia entre o elétron $i$ e o núcleo $A$. As constantes $Z_{A}$ e $M_{A}$ correspondem o número atômico e massa atômica do núcleo $A$. Os operadores $\hat{\mathbf{T}}_{\text {elet }}, \hat{\mathbf{T}}_{\text {núcl }}, \hat{\mathbf{V}}_{\text {elet }}$ e $\hat{\mathbf{V}}_{\text {núcl }}$ correspondem a energia cinética e potencial dos elétrons e núcleos respectivamente. O operador $\hat{\mathbf{V}}_{\text {elet-núcl }}$ corresponde a atração elétron-núcleo.

Considerando o fato do termo da energia cinética nuclear em A.1 ser muito menor que os outros termos, uma vez que a massa atômica nuclear é muito maior que a massa do elétron, temos que $\hat{\mathbf{H}}(\mathbf{r}, \mathbf{R}) \rightarrow \hat{H}_{T}(\mathbf{r}, \mathbf{R})$, onde $\hat{H}_{T}(\mathbf{r}, \mathbf{R})$ corresponde o hamiltoniano total para os núcleos fixos numa posição $\mathbf{R}$ dado por:

$$
\hat{H}_{T}(\mathbf{r}, \mathbf{R})=\left(\hat{\mathbf{T}}_{\text {elet }}+\hat{\mathbf{V}}_{\text {elet-núcl }}+\hat{\mathbf{V}}_{\text {elet }}\right)+\hat{\mathbf{V}}_{\text {núcl }}
$$


dentro da aproximação de Born-Oppenheimer esse hamiltoniano é separado em duas partes, uma correspondente a energia eletrônica e a outra a nuclear,

$$
\hat{H}_{T}(\mathbf{r}, \mathbf{R})=\hat{H}_{\text {elet }}(\mathbf{r} ; \mathbf{R})+\hat{H}_{\text {núcl }}(\mathbf{R})
$$

onde o hamiltoniano elétronico é dado pela equação A.4.

$$
\hat{H}_{\text {elet }}(\mathbf{r} ; \mathbf{R})=-\sum_{i=1}^{N} \frac{1}{2} \nabla_{i}^{2}-\sum_{i=1}^{N} \sum_{A=1}^{M} \frac{Z_{A}}{r_{i A}}+\sum_{i<j}^{N} \frac{1}{r_{i j}}
$$

com a equação que descreve esse sistema elétronico dado por,

$$
\hat{H}_{\text {elet }}(\mathbf{r} ; \mathbf{R}) \chi_{k}(\mathbf{r} ; \mathbf{R})=\varepsilon_{k} \chi_{k}(\mathbf{r} ; \mathbf{R})
$$

onde $\chi_{k}(\mathbf{r} ; \mathbf{R})$ é a função de estado eletrônica e $\varepsilon_{k}$ a respectiva energia eletrôcica. Portanto o auto valor do operador $\hat{H}_{T}(\mathbf{r}, \mathbf{R})$ para a molécula com os núcleos fixos é dado por:

$$
E_{T}(\mathbf{R})=\varepsilon_{\text {elet }}+\sum_{A<B}^{M} \frac{Z_{A} Z_{B}}{r_{A B}}
$$

O estado $\Psi_{\text {total }}(\mathbf{r}, \mathbf{R})$ dado pela equação 2.2 , pode ser expandido no conjunto completo das autofunções eletrônicas do operador $\hat{H}_{k}(\mathbf{r} ; \mathbf{R})$,

$$
\Psi_{\text {total }}(\mathbf{r}, \mathbf{R})=\sum_{k} \phi_{k}(\mathbf{R}) \chi_{k}(\mathbf{r} ; \mathbf{R})
$$

onde $\phi_{k}(\mathbf{R})$, corresponde aos coeficientes da expansão.

Usando a equação de Schrödinger 2.1 e as equações A.5 e A.7, obtem-se:

$$
\begin{gathered}
\left(-\sum_{A=1}^{M} \frac{1}{2 M_{A}} \nabla_{A}^{2}+\hat{H}_{\text {elet }}(\mathbf{r} ; \mathbf{R})+\sum_{A<B}^{M} \frac{Z_{A} Z_{B}}{r_{A B}}\right) \sum_{k} \phi_{k}(\mathbf{R}) \chi_{k}(\mathbf{r} ; \mathbf{R})=E \sum_{k} \phi_{k}(\mathbf{R}) \chi_{k}(\mathbf{r} ; \mathbf{R}) \\
=\left(-\sum_{A=1}^{M} \frac{1}{2 M_{A}} \nabla_{A}^{2}+\varepsilon_{\text {elet }}+\sum_{A<B}^{M} \frac{Z_{A} Z_{B}}{r_{A B}}\right) \sum_{k} \phi_{k}(\mathbf{R}) \chi_{k}(\mathbf{r} ; \mathbf{R})=E \sum_{k} \phi_{k}(\mathbf{R}) \chi_{k}(\mathbf{r} ; \mathbf{R})
\end{gathered}
$$


usando as equações A.5 e A.6, obtem-se:

$$
\sum_{k}\left(-\sum_{A=1}^{M} \frac{1}{2 M_{A}} \nabla_{A}^{2}+\left(E_{T}(\mathbf{R})-E\right)\right) \phi_{k}(\mathbf{R}) \chi_{k}(\mathbf{r} ; \mathbf{R})=0
$$

temos que,

$$
\begin{array}{r}
\nabla_{A}^{2}\left[\phi_{k}(\mathbf{R}) \chi_{k}(\mathbf{r} ; \mathbf{R})\right]=\nabla_{A}\left[\left(\nabla_{A} \phi_{k}(\mathbf{R})\right) \chi_{k}(\mathbf{r} ; \mathbf{R})\right]+\left[\phi_{k}(\mathbf{R})\left(\nabla_{A} \chi_{k}(\mathbf{r} ; \mathbf{R})\right)\right] \\
=\left(\nabla_{A}^{2} \phi_{k}(\mathbf{R})\right) \chi_{k}(\mathbf{r} ; \mathbf{R})+2\left(\nabla_{A} \phi_{k}(\mathbf{R})\right)\left(\nabla_{A} \chi_{k}(\mathbf{r} ; \mathbf{R})\right)+\phi_{k}(\mathbf{R})\left(\nabla_{A}^{2} \chi_{k}(\mathbf{r} ; \mathbf{R})\right)
\end{array}
$$

multiplicando a equação A.10 por $\chi_{n}^{*}(\mathbf{r} ; \mathbf{R})$ e integrando, obtem-se:

$$
\begin{array}{r}
-\sum_{k} \sum_{A=1}^{M} \frac{1}{2 M_{A}} \int \nabla_{A}^{2}\left[\phi_{k}(\mathbf{R}) \chi_{k}(\mathbf{r} ; \mathbf{R})\right] \chi_{n}^{*}(\mathbf{r} ; \mathbf{R}) d^{3} r \\
+\sum_{k}\left(E_{T}(\mathbf{R})-E\right) \int \phi_{k}(\mathbf{R}) \chi_{k}(\mathbf{r} ; \mathbf{R}) \chi_{n}^{*}(\mathbf{r} ; \mathbf{R}) d^{3} r=0
\end{array}
$$

usando a equação A.11, obtem-se:

$$
\begin{array}{r}
-\sum_{k} \sum_{A=1}^{M} \frac{1}{2 M_{A}} \int\left(\nabla_{A}^{2} \phi_{k}(\mathbf{R})\right) \chi_{k}(\mathbf{r} ; \mathbf{R}) \chi_{n}^{*}(\mathbf{r} ; \mathbf{R}) d^{3} r \\
-\sum_{k} \sum_{A=1}^{M} \frac{1}{2 M_{A}} 2 \int\left(\nabla_{A} \phi_{k}(\mathbf{R})\right)\left(\nabla_{A} \chi_{k}(\mathbf{r} ; \mathbf{R})\right) \chi_{n}^{*}(\mathbf{r} ; \mathbf{R}) d^{3} r \\
-\sum_{k} \sum_{A=1}^{M} \frac{1}{2 M_{A}} \int \phi_{k}(\mathbf{R})\left(\nabla_{A}^{2} \chi_{k}(\mathbf{r} ; \mathbf{R})\right) \chi_{n}^{*}(\mathbf{r} ; \mathbf{R}) d^{3} r+\left(E_{T}(\mathbf{R})-E\right) \phi_{n}(\mathbf{R})=0(
\end{array}
$$

integrando o primeiro termo da equação A.13, obtem-se:

$$
\begin{aligned}
& \quad-\left\{\sum_{A=1}^{M} \frac{1}{2 M_{A}} \nabla_{A}^{2}-\left(E_{T}(\mathbf{R})-E\right)\right\} \phi_{n}(\mathbf{R})= \\
& -\sum_{k} \sum_{A=1}^{M} \frac{1}{2 M_{A}}\left\{2 \int\left(\nabla_{A} \chi_{k}(\mathbf{r} ; \mathbf{R})\right) \chi_{n}^{*}(\mathbf{r} ; \mathbf{R}) d^{3} r . \nabla_{A}+\int\left(\nabla_{A}^{2} \chi_{k}(\mathbf{r} ; \mathbf{R})\right) \chi_{n}^{*}(\mathbf{r} ; \mathbf{R}) d^{3} r\right\} \phi_{k}(\mathbf{R})
\end{aligned}
$$

definindo

$$
\phi_{n k}(R, \nabla)=\sum_{A=1}^{M} \frac{1}{M_{A}}\left(Y_{n k}^{(A)} \nabla_{A}+Z_{n k}^{(A)}\right)
$$


onde,

$$
\begin{gathered}
Y_{n k}^{(A)}=\int\left(\nabla_{A} \chi_{k}(\mathbf{r} ; \mathbf{R})\right) \chi_{n}^{*}(\mathbf{r} ; \mathbf{R}) d^{3} r \\
Z_{n k}^{(A)}=\frac{1}{2} \int\left(\nabla_{A}^{2} \chi_{k}(\mathbf{r} ; \mathbf{R})\right) \chi_{n}^{*}(\mathbf{r} ; \mathbf{R}) d^{3} r
\end{gathered}
$$

assim a equação A.14 torna-se,

$$
-\left\{\sum_{A=1}^{M} \frac{1}{2 M_{A}} \nabla_{A}^{2}-E_{T}(\mathbf{R})\right\} \phi_{n}(\mathbf{R})=E \phi_{n}(\mathbf{R})+\sum_{k} \phi_{n k}(R, \nabla) \phi_{k}(\mathbf{R})
$$

para todos os $\phi_{n k}$ nulos, obtem-se a equação de Schrödinger independente do tempo para o movimetno dos núcleos na molécula, dado pela equação,

$$
\hat{H}_{n u ́ c l}(\mathbf{R}) \phi_{n}(\mathbf{R})=E \phi_{n}(\mathbf{R})
$$

com o hamiltoniano correspondente a parte cuclear dado por:

$$
\hat{H}_{\text {núcl }}(\mathbf{R})=-\sum_{A=1}^{M} \frac{1}{2 M_{A}} \nabla_{A}^{2}+E_{T}(\mathbf{R})
$$

onde $E_{T}(\mathbf{R})$ é o potencial efetivo correspondente ao movimento nuclear que é definido para cada $\mathbf{R}$, formando uma hipersuperfície de energia potencial. O valor de $E_{T}(\mathbf{R})$ é obtido a partir da solução das equações A.5 A.6. para o hamiltoniano correspondente a parte eletrônica. 


\section{Apêndice B}

\section{Arquivos de Entrada da Dinâmica Molecular da Emodina}

Neste apêndice mostramos os arquivos de entrada, no qual, realizamos a Dinâmica Molecular(MD) com a molécula de emodina no programa Tinker. O Tinker é um programa para realização de Dinâmica Molecular(MD), com alguns recursos especiais para biomoléculas. Esse programa utiliza vários campos de forças conhecidos na literatura molecular, como o Amber ff94, ff96, ff98 and ff99, CHARMM19, CHARMM27, DANG, MM2, MM3, OPLS-UA, OPLS-AA, OPLS-AA/L e AMOEBA. Neste trabalho, usamos o campo de força OPLS-AA para realização da MD. Os principais arquivos de entrada do programa Tinker são: o arquivo de parâmetros do campo de força ".prm", o arquivo de coordenadas ".xyz" e o arquivo de controle ".key". Segue abaixo a descrição de cada um desses arquivos:

O arquivo de parâmetros ".prm". Nesse arquivo encontram-se todos os parâmetros necessário para a função do pontencial de interação molecular como por exemplo: o tipo do átomo, os parâmetros ( van der Waals $\left(\epsilon_{i j}\right.$ e $\left.\sigma_{i j}\right)$, os de estiramento da ligação $\left(k_{i j}^{r}\right.$ e $\left.r_{e q}\right)$, os de oscilação no ângulo $\left(k_{i j k}^{\theta}\right.$ e $\left.\theta_{e q}\right)$, os três parâmetros da torção $\operatorname{simples}\left(\mathcal{U}_{1}, \mathcal{U}_{2}\right.$ e $\left.\mathcal{U}_{3}\right)$ e as cargas para cada tipo de átomo.

Esse arquivo ".prm" não é necessariamente obrigatório para realização da MD, 
uma vez que é possível declarar todos esses parâmetros no arquivo de entrada ".key". É recomendável, que realize a MD, declarando os parâmetros do campo de força no arquivo ".key", pois essa prática permite escolher adquadamente os parâmetros do campo de força para o sistema de interesse, gerando com isso, resultados mais confiáveis. Um outro fator importante nessa prática é a liberdade em realizar uma MD com parâmetros adicionais ao campo de força, como por exemplo, usar um conjunto de cargas obtidas do cálculo quântico ab-initio.

O arquivo de coordenadas ".xyz". Nesse arquivo se encontra as coordenadas x, y e z em $A$ de cada átomo do sistema, no nosso caso, 30 e 1500 átomos pertencente 1 molécula de emodina e 500 moléculas de água, respectivamente. No arquivo B.0.1, está listado o arquivo, ".xyz" para esse sistema. A descrição desse arquivo é dada da seguinte forma: na primeira coluna desse arquivo, está o índice de cada átomo do sistema, e na segunda coluna está o tipo de cada átomo descrito no campo de força OPLS-AA, Na $3^{\mathrm{a}}, 4^{\mathrm{a}}$ e $5^{\mathrm{a}}$ colunas, estão as coordenadas x, y e z, respectivamente de cada átomo. $\mathrm{Na} 6^{\mathrm{a}}$ coluna, encontra-se o índice do tipo do átomo descrito no campo de força OPLS-AA, e na $7^{\mathrm{a}}, 8^{\mathrm{a}}$ e $9^{\mathrm{a}}$ colunas, estão as conectividades, ou seja, as ligações entre os átomos de uma mesma molécula.

O arquivo de Keyword: ".key". Esse é um arquivo bastante importante na realização da Dinâmica Molecular. Nesse arquivo é declarado os parâmetros do campo de força e os parâmetros de controle da MD como por exemplo, a forma do potencial de interação, o método usado para resolver as equações diferenciais para a movimentação dos átomos, no nosso caso, é o algoritimo de Verlet, o tipo de termotático, a semente do gerador de números aleatórios, a descrição das moléculas do sistemas, o tamanho da caixa da MD, etc. No arquivo B.0.2, está listado o arquivo, ".key" para o sistema emodina/água.

A seguir mostramos os arquivos B. 0.1 e B. 0.2 , que são os arquivos de coordenadas ".xyz" e de Keyword: “.key", respectivamente. 


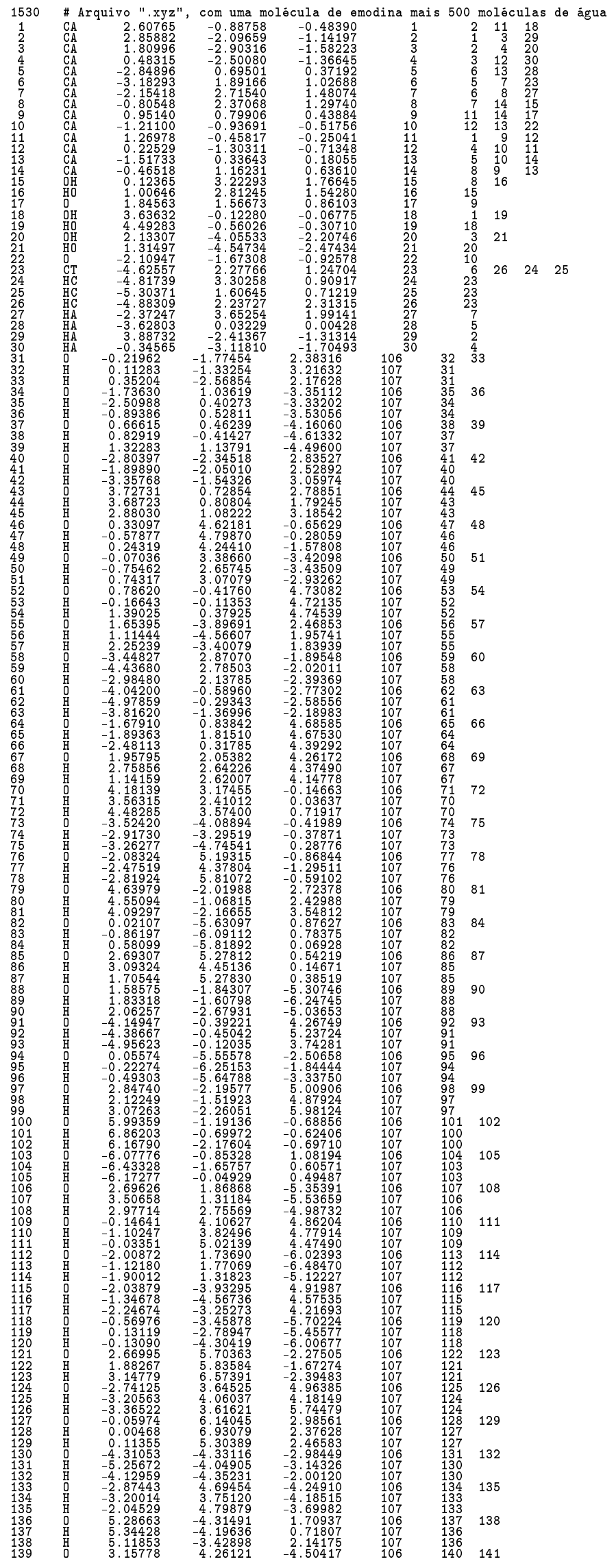




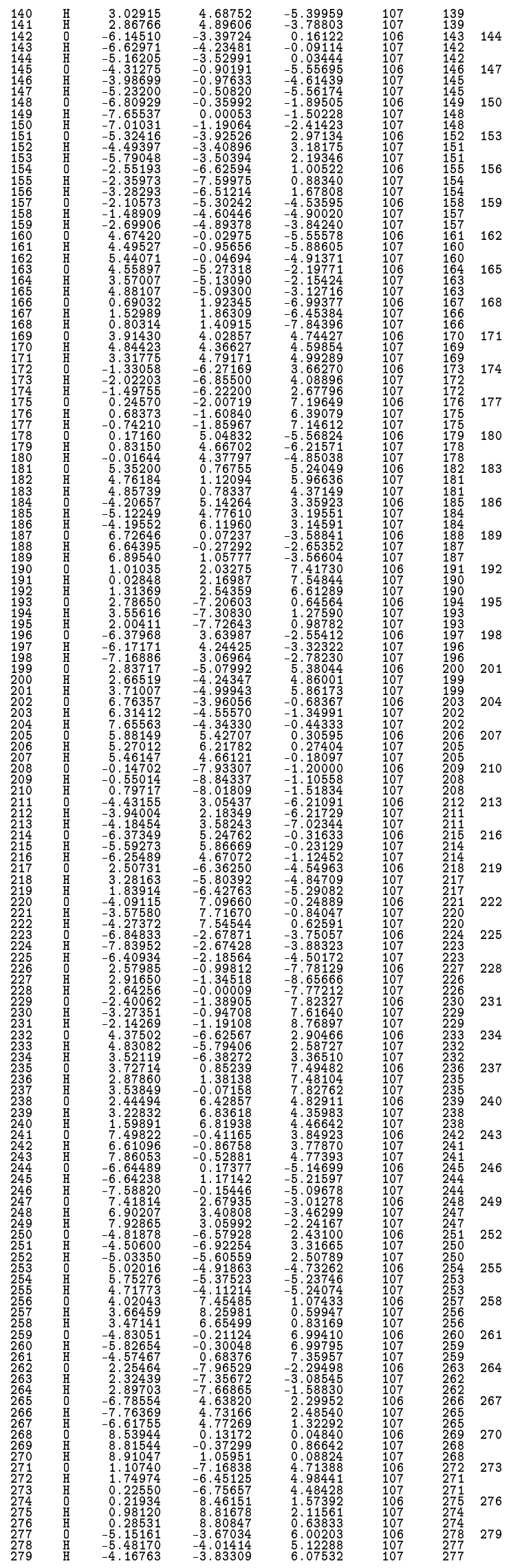




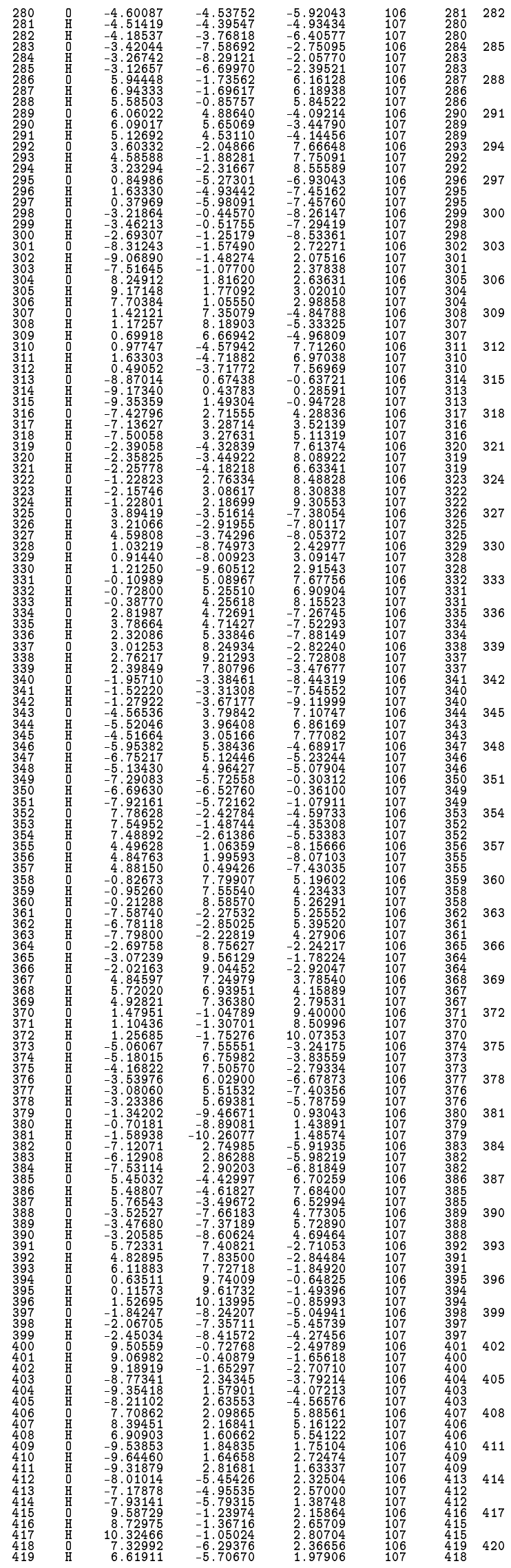




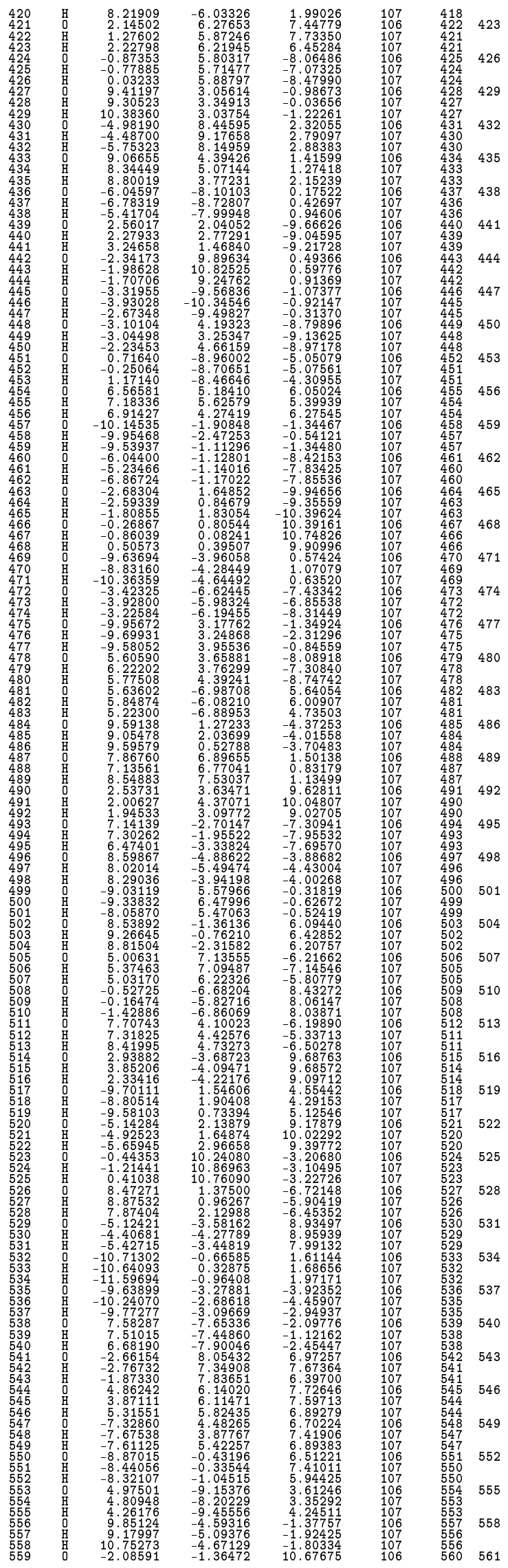




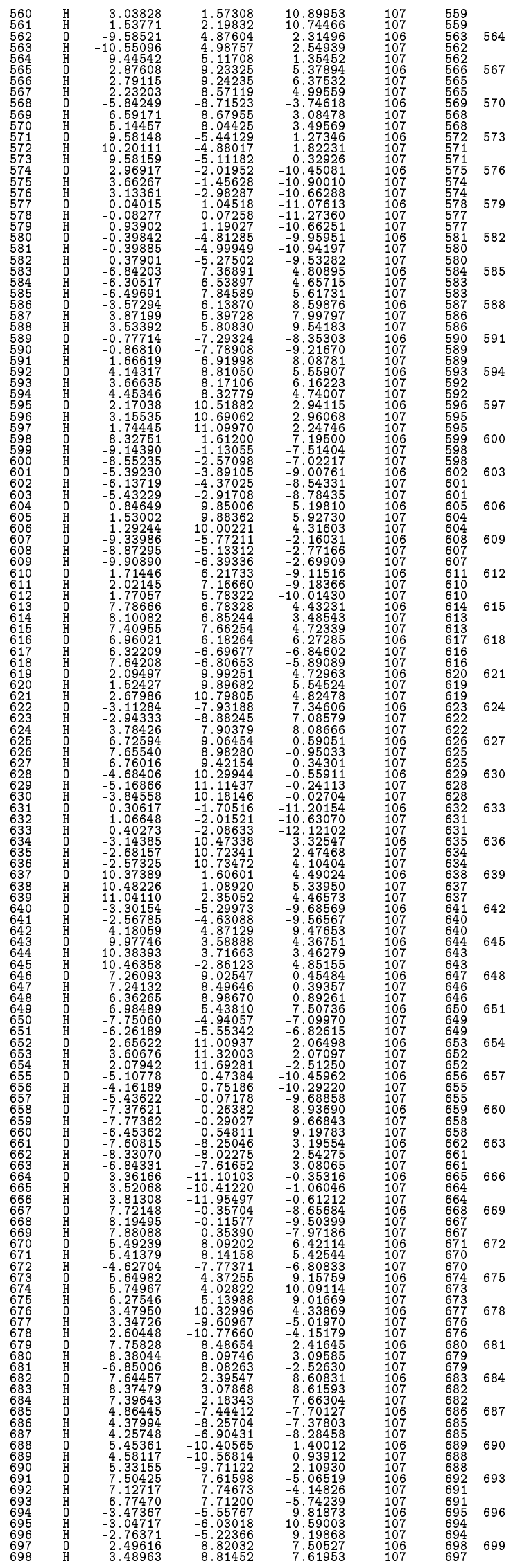




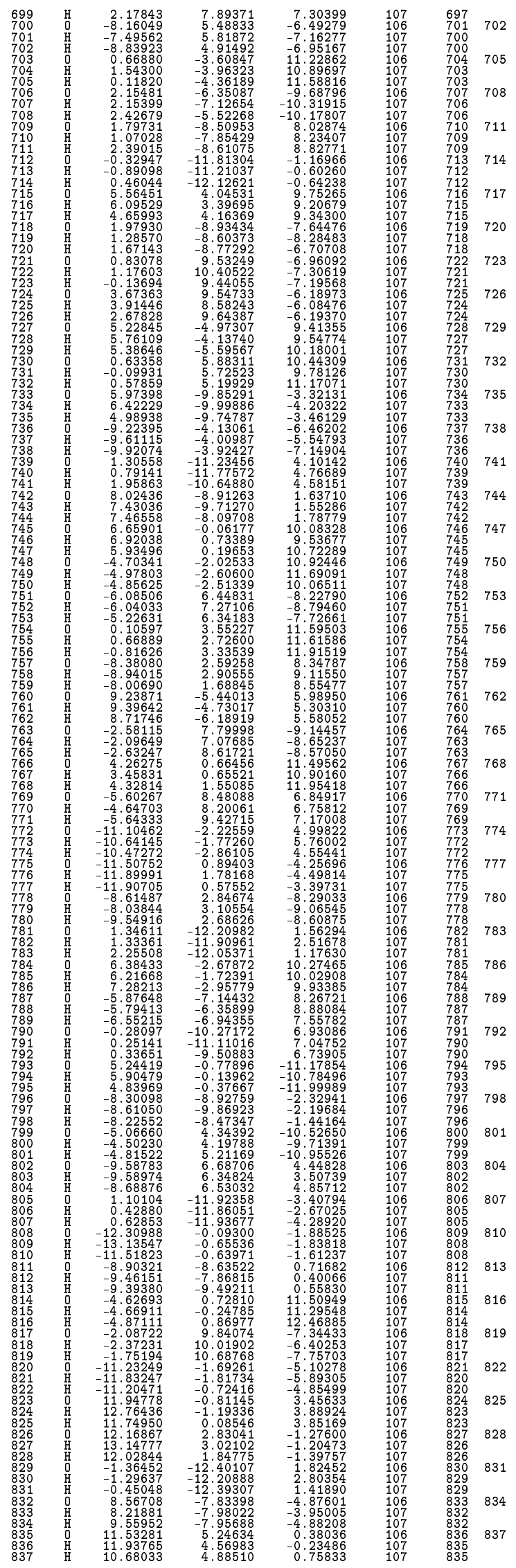




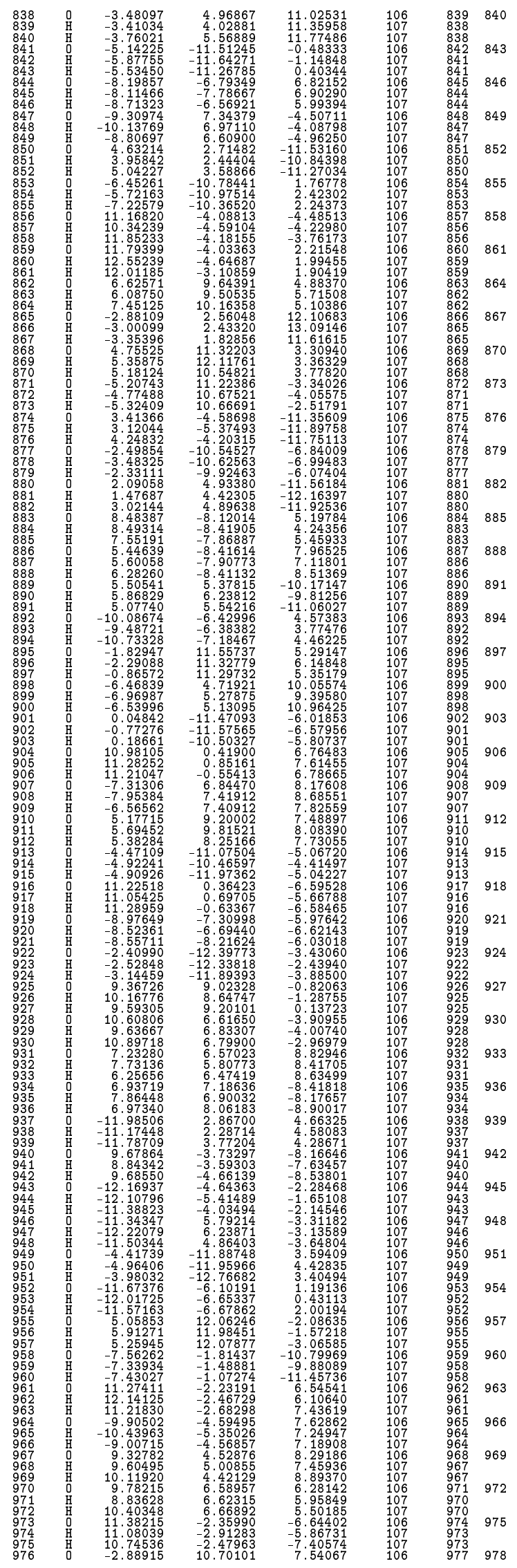




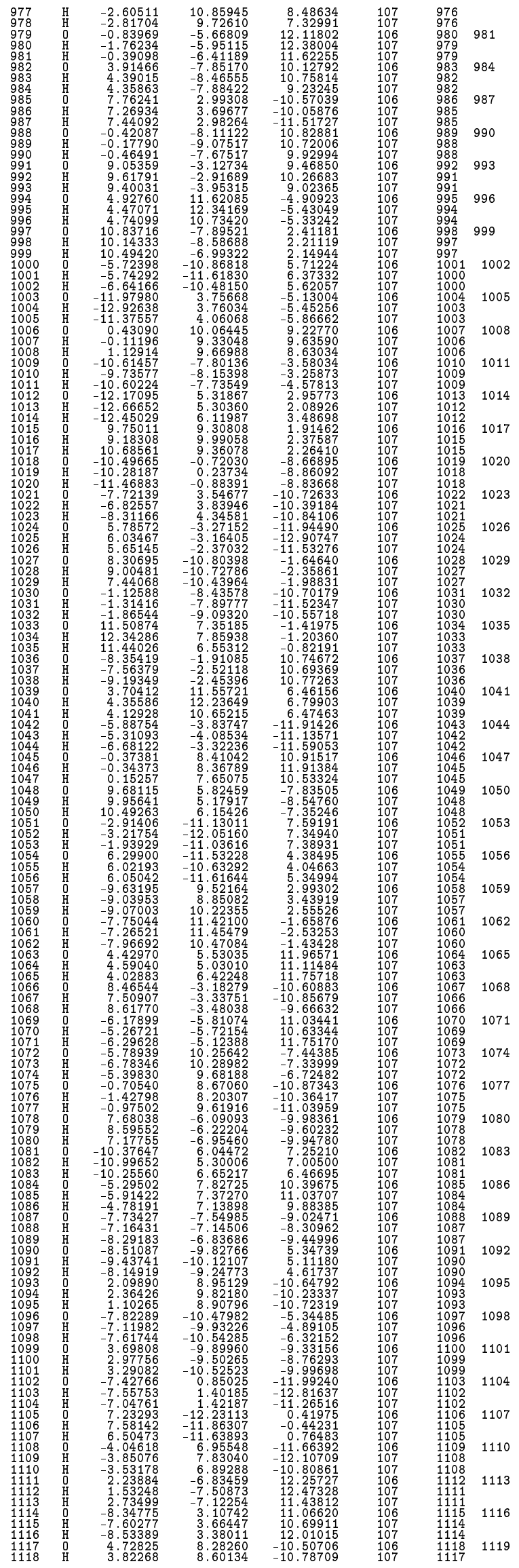




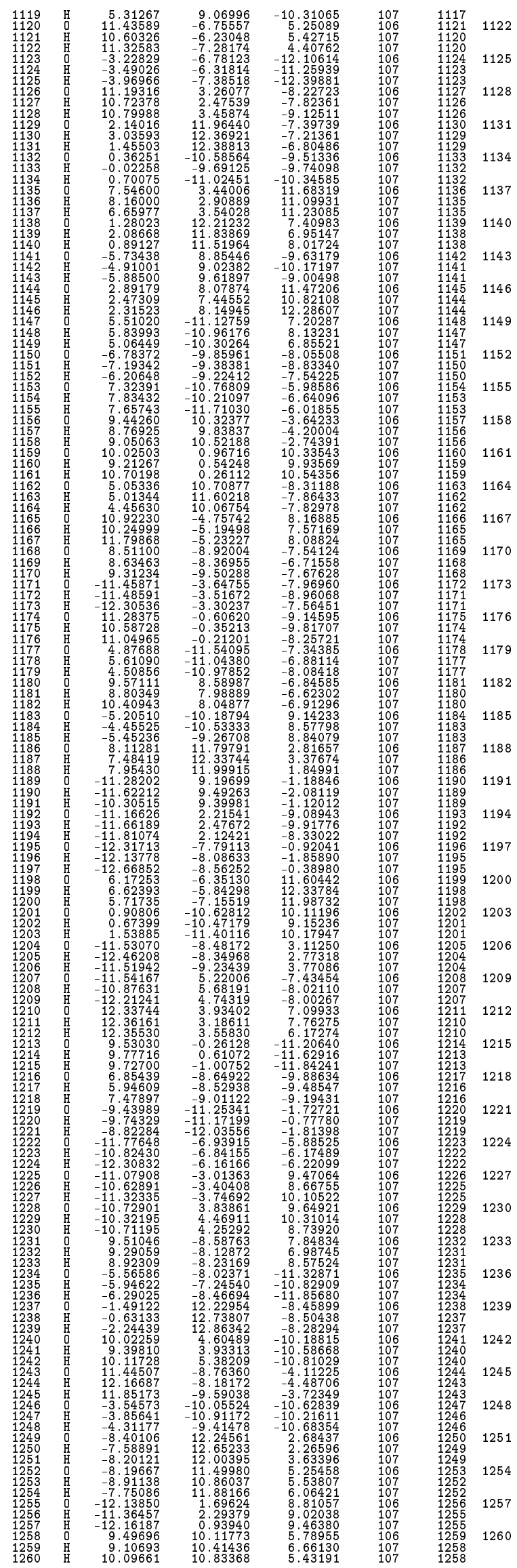




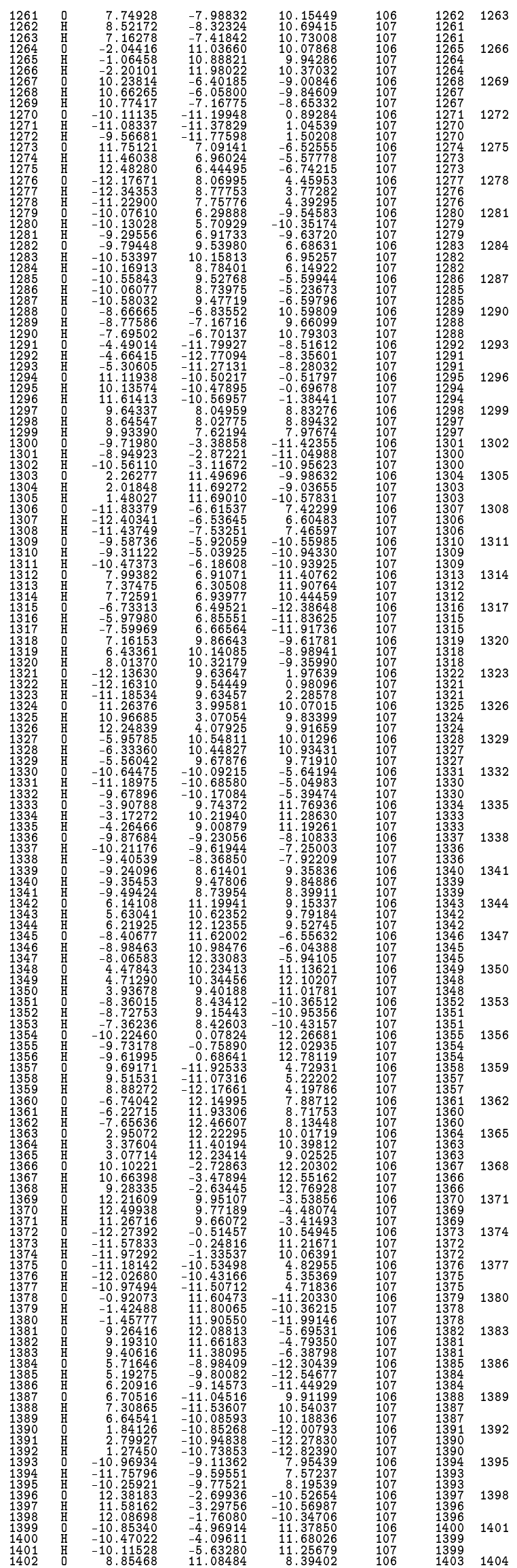




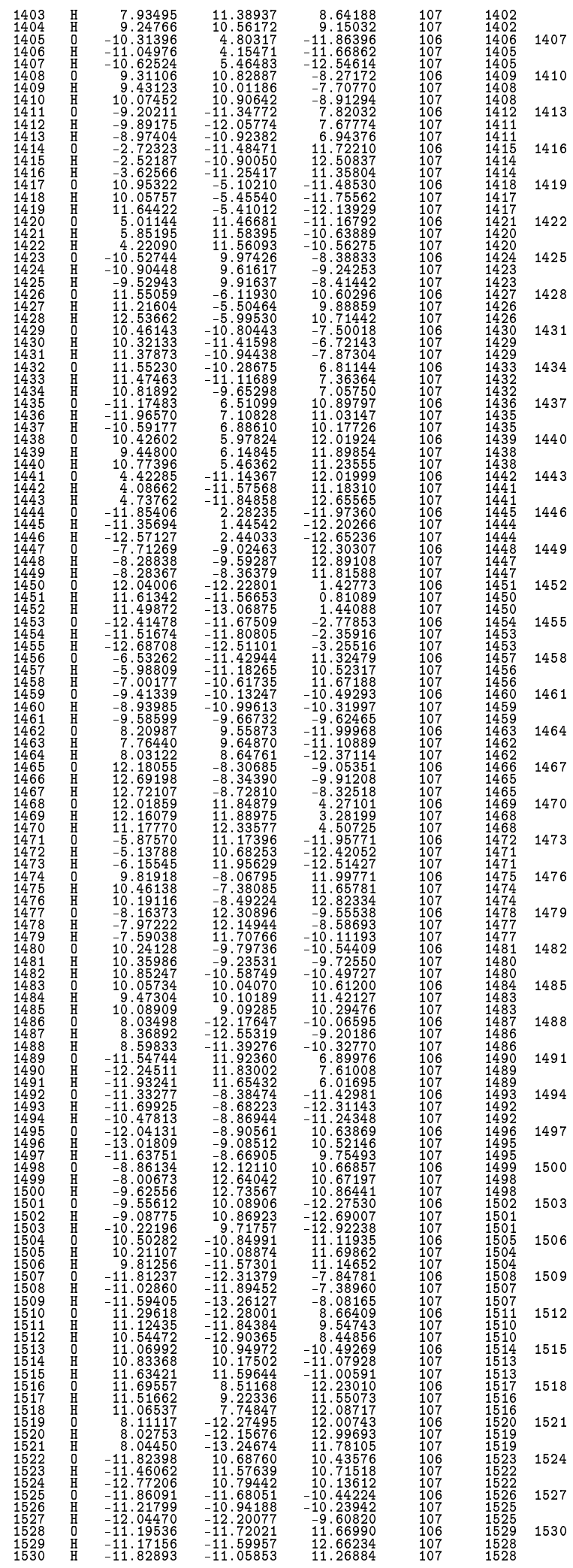

Arquivo B.0.1: Descrição do arquivo de coordenadas ".xyz", do sistema, 1 molécula de emodina mais 500 moléculas de água, totalizando um sistema com 1530 átomos. 


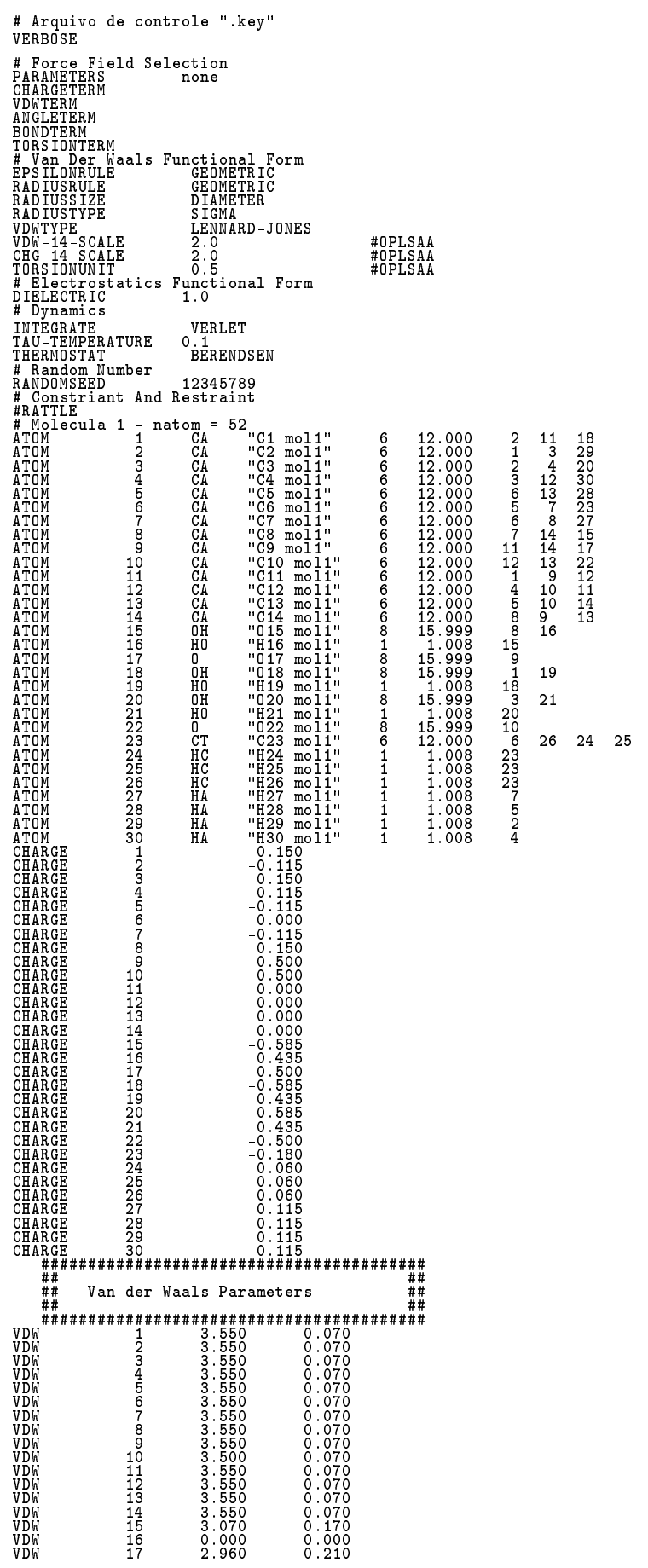




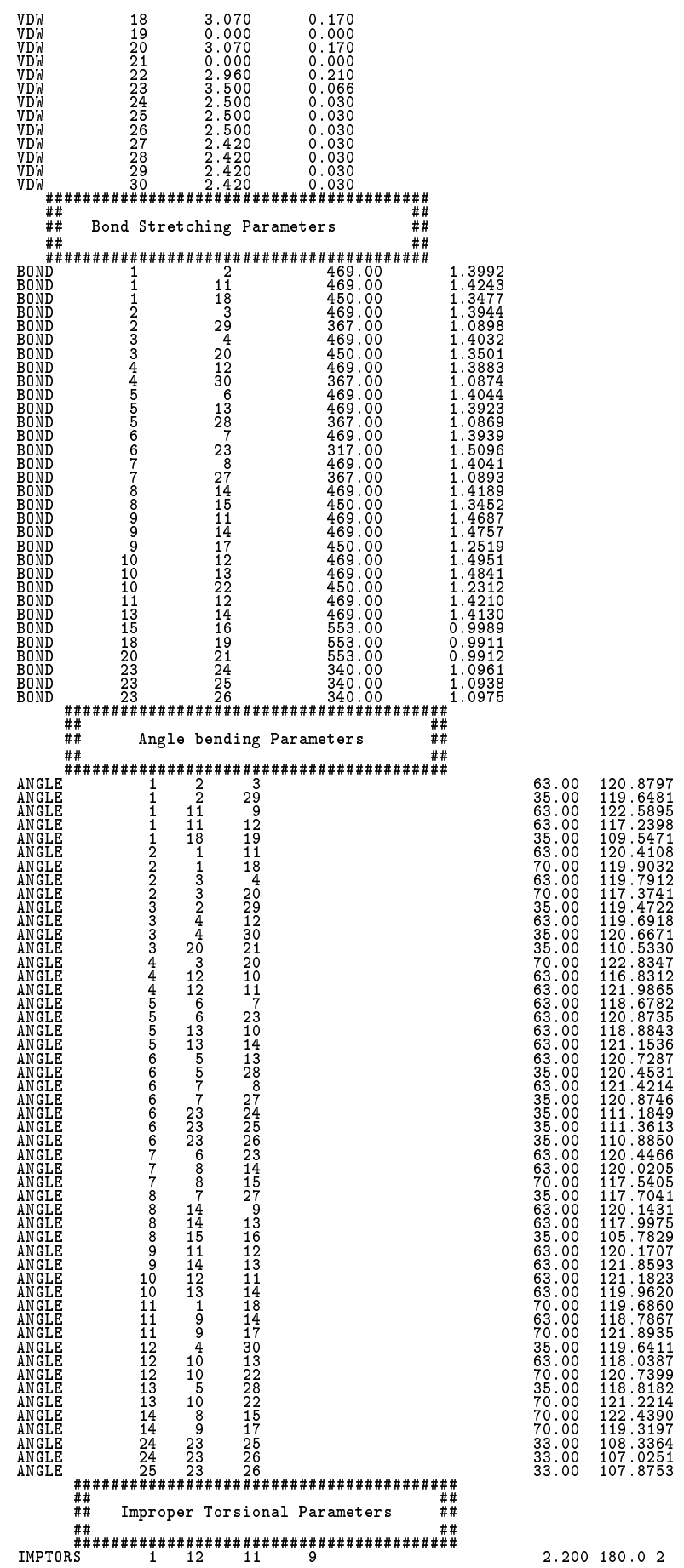




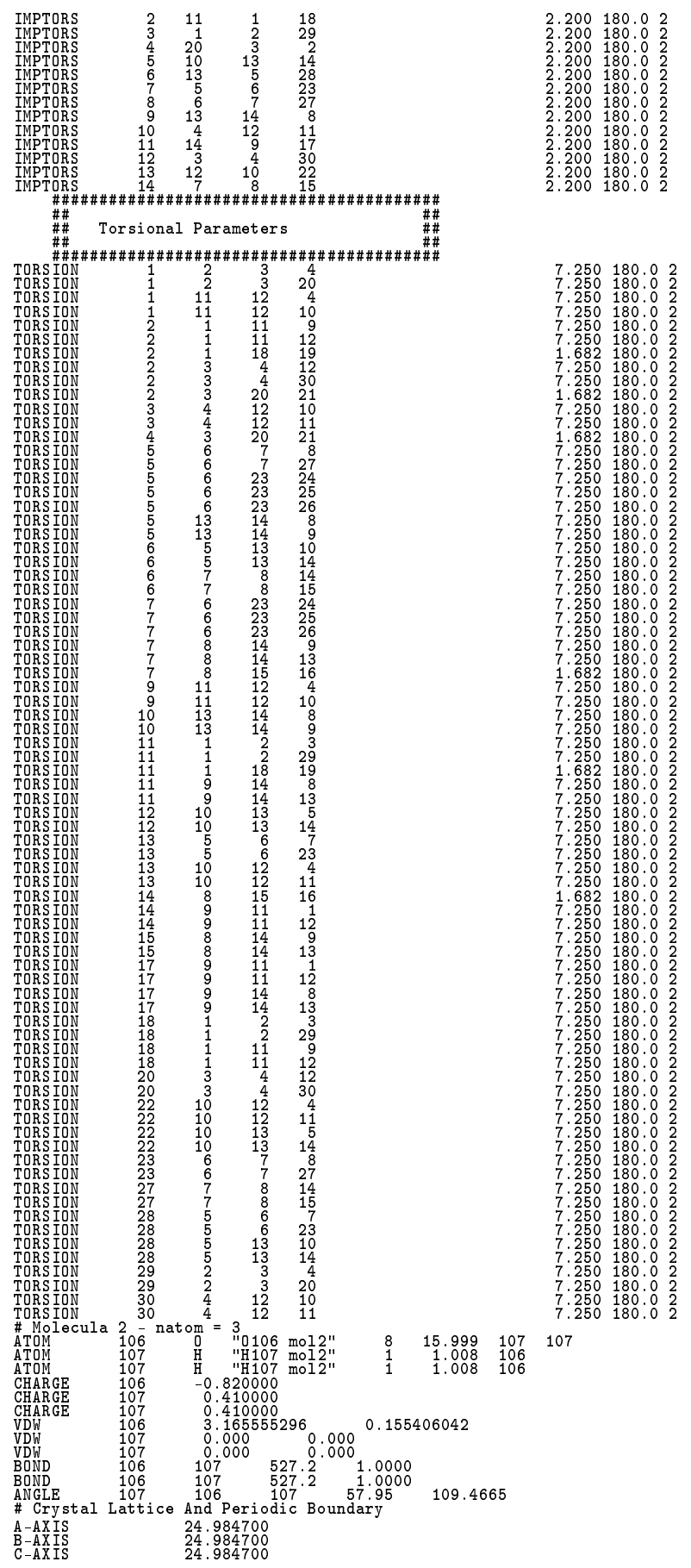

Arquivo B.0.2: Descrição do arquivo de controle ".key", do sistema emodina/água. Os parâmetros do campo de força, listados nesse arquivo foram obtidos do arquivo "oplsaa.prm", postado na homepage do programa Tinker, http://dasher.wustl.edu/tinker/distribution/params/oplsaa.prm. 